\title{
COMPREHENSIVE REVIEW ON THE FLOW CHARACTERISTICS OF TWO-PHASE FLOWS IN INCLINED TUBES
}

\author{
Hakan Karademir ${ }^{*}$, Güven Özçelik ${ }^{2}$, Özgen Açıkgöz ${ }^{1}$, Ahmet Selim Dalkılıç¹, İbrahim Timuçin İnce², Josua \\ Meyer $^{3}$, Somchai Wongwises ${ }^{4}$
}

\section{ABSTRACT}

This paper presents a comprehensive review of research works on condensation and boiling heat transfer characteristics in horizontal, vertical and inclined tubes both smooth and enhanced. Although there are many studies examining two-phase flows inside tubes, it is almost impossible to find such a comprehensive study for two-phase flow in tubes. Moreover, while number of the studies concerning condensation or boiling inside tubes are limited, the present study covers almost all studies of condensation and boiling inside inclined tubes. Previous studies are classified into many subtitles according to configuration (horizontal, vertical or inclined) and roughness (smooth or enhanced) as well as aim of the study (researching the effect of parameters on the heat transfer coefficient, pressure drop or evaluation of prediction correlation). Such a wide range of classification and scope have no done before. Condensation and boiling phenomena are of great importance in heat exchangers, cooling systems, etc. due to their wide utilization in those devices. Additionally, two-phase flow and the associated heat transfer are becoming increasingly important in industrial applications because the heat transfer coefficient in twophase flows is much higher than in single-phase flows. In this research, major topics such as heat transfer, pressure drop, friction factor and void fraction were studied using active and passive techniques in the literature.

The fluids used in the reviewed studies diverse in a very wide range. For pure refrigerants (single component-fluorocarbon refrigerant), R11, R12, R22, R32, R-113, R123, R-124, R125, R134, R134a, R142b, R152a, R236fa, R245fa, R-600a, R1234ze, R1234yf and for zeotropic blend refrigerants, a mixture of two or more components having different boiling points, R410A, R404A, R407C, R447A are used. As zeotropic blend refrigerants, a mixture of two or more components that boil at the same temperature, R502. Besides, water (steam for condensation), FC72, CFC 113, Propane, HFE 7000 (1-methoxyheptafluoropropane), R744 ( $\left.\mathrm{CO}_{2}\right)$, and liquid nitrogen are involved in researchers' studies.

In the present review, effects of parameters on two-phase flow heat characteristics are evaluated. Based on the evaluation, it can be drawn that inclination angle have significant effect on both condensation and boiling heat transfer coefficient and pressure drop. On the other hand, it was found that vapour quality and roughness were the main parameters affecting two-phase flow heat transfer characteristics. Effects of all parameters are discussed in the corresponding section. When existing correlations in the literature on prediction flow boiling heat transfer coefficient are evaluated, correlations proposed by Müller-Steinhagen and Heck [103] and Friedel [113] were to be best for prediction well according to majority of researchers and for performance of prediction on pressure drop correlation by Müller-Steinhagen and Heck [103] stood out.

Keywords: Flow Boiling, Flow Condensation, Two-Phase Flow Heat Transfer, Inclined Tubes, Heat Transfer Coefficient, Pressure Drop, Comprehensive Review

\footnotetext{
This paper was recommended for publication in revised form by Regional Editor Mohsen Sheikholeslami

${ }^{1}$ Department of Mechanical Engineering, Yildiz Technical University, Istanbul, Turkey

${ }^{2}$ Department of Mechanical Engineering, Istanbul Arel University, Istanbul, Turkey

${ }^{3}$ Department of Mechanical and Aeronautical Engineering, University of Pretoria, Pretoria, South Africa

${ }^{4}$ Department of Mechanical Engineering, King Mongkut's University of Technology Thonburi, Bangkok, Thailand

*E-mail address: hakankarademir16@gmail.com, guvenozcelik@arel.edu.tr, oacikgoz@yildiz.edu.tr, dalkilic@yildiz.edu.tr, timucinince@arel.edu.tr, josua.meyer@up.ac.za,somchai.won@kmutt.ac.th

Orcid id: 0000-0002-7297-7879, 0000-0002-7091-6175, 0000-0002-0095-829X, 0000-0002-5743-3937, 0000-0003-0256-3619, 0000-0002-3675-5494, 0000-0003-2648-6814

Manuscript Received 26 September 2020, Accepted 22 January 2021
} 


\section{CONTENTS}

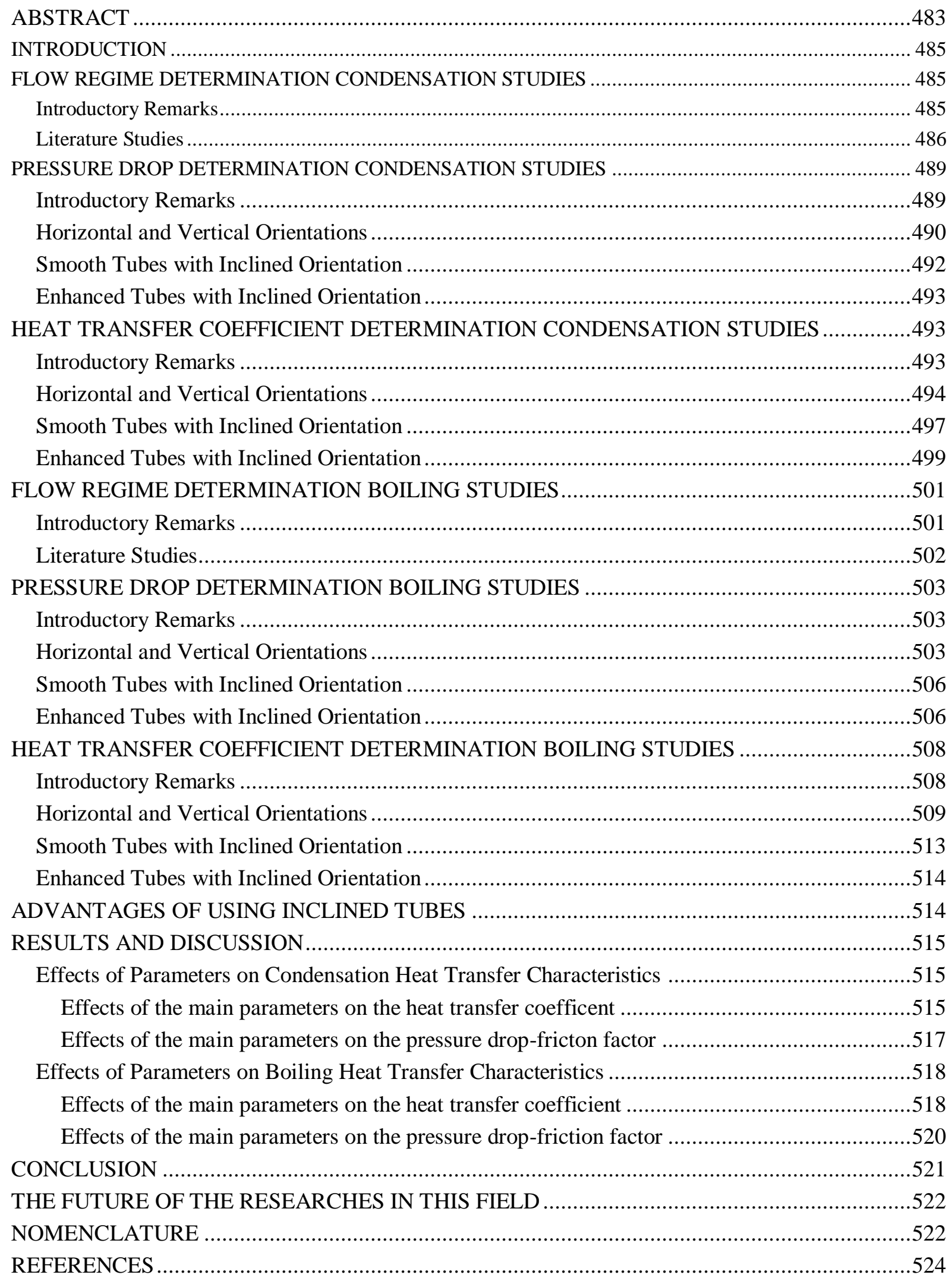




\section{INTRODUCTION}

Flow in pipes is the most widespread physical condition confronted in heating, cooling and air-conditioning systems. Devices known as heat exchangers are the main components of these systems and the primary source of this phenomenon. Lately, mini- and micro-devices especially have been of the utmost significance. Mini- and microscale mechanical devices have the advantage of being removed easily as well as being highly efficient. Thanks to these advantages, micro- and mini-heat exchangers have been utilised for a long time. Because boiling and condensation occur in these exchangers, it is very important to understand the phenomena of boiling and condensation.

Micro-channels have their essential advantages in heat exchangers. Thanks to having a larger contact area per unit volume than that of macro-channels, micro-channels withstand higher pressure than macro-channels do. Moreover, the heat transfer coefficient of micro-channels is much higher than that of macro-channels. Evaporative compact heat exchangers made of micro-channels are used in numerous applications that require high heat transfer through a restricted volume. These heat exchangers are operated for a microprocessor cooling application in a micro-heat pump or a portable cooling device [1].

Studies on compact heat exchangers have been conducted continuously. It is predicted that the need for higher heat dissipation per unit volume for these heat exchangers will increase in the near future, due to an increasing need to cool technology devices like microprocessors. Therefore, more energy-efficient heat exchangers are required to be made [2]. Condensation and flow boiling in narrow tubes could reach a higher rate of heat transfer than for single-phase cooling, thanks to its latent heat of vaporization. For this purpose, various methods, which are generally grouped as active and passive techniques, have been studied in numerous researches. External forces like vibration, electrostatic fields and fluid additives are needed for active techniques whereas special surface structures are the general improvement tool for passive techniques. This study focused on the passive techniques for condensation and boiling in inclined pipes.

Enhancement in heat transfer technology is vital to improve energy efficiency [3]. Heat transfer augmentation is completed successfully through adding enhanced heat transfer tubes thanks to their substantial potential in improving thermal performance. In recent years, numerous enhanced tubes have been developed and broadly used for cooling applications such as refrigeration, ventilation and many other fields.

Corrugated tubes are one of the passive techniques to improve the heat transfer coefficient. A corrugated tube has corrugation on its surface that can improve heat transfer through generating turbulence and restraining the progression of the thermal boundary layer. This augmentation in heat transfer is realised while a small increase in friction factor is seen [4].

This paper consists of two parts. In the first part, studies of condensation and boiling inside inclined tubes are reviewed (almost all the studies are experimental). The researcher reading this paper could find the studies of the hydrodynamic and thermal parameters of the channels in which fluids condense and boil in the literature. These parameters are the heat transfer coefficient, pressure drop, void fraction and flow patterns. The shape of the channels reviewed is mostly smooth and enhanced. In the context of this general inference, the paper presents recent improvements related to condensation and the boiling process in inclined pipes. Therefore, the paper should be an important up-to-date literature review of condensation and the boiling process in inclined pipes.

\section{FLOW REGIME DETERMINATION CONDENSATION STUDIES Introductory Remarks}

Condensation is one of the main physical events encountered in many heat transfer problems. Knowing the flow regimes in the processes where two-phase flow occurs aids in finding a solution. Therefore, re-evaluations of findings and new experimental numerical studies have resulted in comprehensive processing of these issues as well as improvements in the literature.

In practice, heat transfer and pressure characteristics vary depending on the two-phase flow regime and the internal structure of the pipe, gravity force, liquid-vapour distribution, etc.; in other words, factors known to be components affecting the flow regime [5]. In the case of two-phase flow in a channel, factors such as surface tension and shear force, which change depending on the inclination effect, lead to the emergence of different flow regimes. This creates a heat and momentum transfer process that is physically more complicated, considering the complex structure of the liquid-vapour flow [6]. If the system includes structures such as thin film flows, droplet impingements or microfluidic, surface tension and wettability are also important as well as transport properties. Although studies on these topics are insufficient in literature, it is known that the surface tension gain importance 
in nanofluids used in energy systems and heat exchangers. For instance, surface tension can be used to understand nanofluid boiling and stability of nanoparticles. In addition to the thermophysical properties, factors such as surface tension and wettability will also contribute to the understanding of two-phase flow properties and heat transfer characteristics. [7].

The flow regimes (or patterns) during condensing inside tubes are seen in Figure 1.

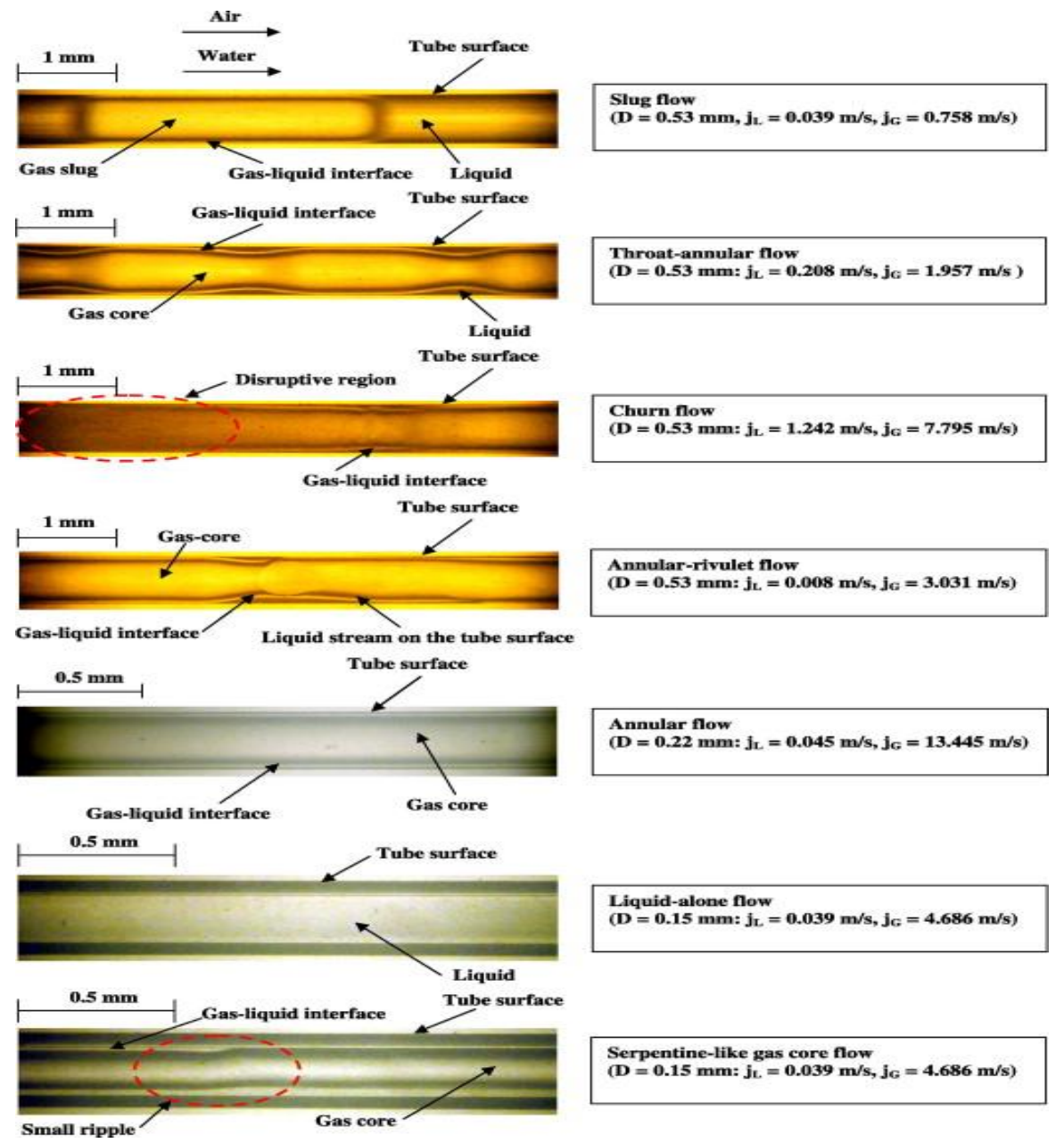

Figure 1. Photographs of two-phase flow patterns [From Saisorn and Wongwises [8], with permission from Elsevier.]

In investigating the literature, it became clear that the flow regime studies were mostly conducted for horizontal and vertical channels and at the first stage, the results of the inclined pipe experiments were observed by adapting the determined flow pattern map and methods to the inclined pipes. Furthermore, determining that inclination angle has an effect on the flow pattern even if the angle of inclination is too low, observing the deficiency in the operation of different fluids in both inclined and non-inclined channels (e.g. hydrocarbon mixtures, low global warming potential fluids), and the discovery of channels and geometrical arrangements (e.g. mini-channels, micro-fin channels, helically corrugated finned channels), which significantly affect the two-phase flow structure, have accelerated the flow regime studies in inclined pipes [5-9].

High-speed camera visualisation, flow visualisation and flow pattern maps are widely used in determining the flow regime, as indicated in Table 5. Some of the flow regime sketches, which are presented in detail in the literature survey with data and trends, are demonstrated in the figures in the last section.

\section{Literature Studies}

Barnea [10] developed a unified model for predicting flow pattern transitions in steady gas-liquid flow in pipes and also presented transition mechanisms for flow regimes. The model was compared with the experimental studies of air-water two-phase flow and the accuracy of the model was observed at various pipe inclinations. In 
conclusion, for different flow regimes, the friction factor for the gas-liquid interface was observed using available correlations with acceptable accuracy.

A flow regime determination study of steam condensation in a $13.4 \mathrm{~mm}$ tube with horizontal and $\pm 1^{\circ}$, $\pm 5^{\circ}$ and $\pm 10^{\circ}$ inclined orientations was carried out by Nitheanandan and Soliman [11] Measurements were taken when the flow became steady state. Annular, annular-wavy, wavy and slug flow regimes were identified. Experimental data sets were compared with adiabatic gas-liquid flow regime maps developed analytically and experimentally for horizontal and inclined tubes. While observing the effect of the inclination angle on two-phase flow regime, observations showed that there are very limited differences occurred in annular flow depending on inclination change. However, only $1^{\circ}$ (up or down) deviations from horizontal orientation caused significant changes in the wavy and slug flow regions. It has been stated that wavy flow is more conspicuous in downward orientations and slugs flow is more conspicuous in downward orientations. Shifts at transition boundaries are found to be insignificant due to changes in inclination angle between 5 to $10^{\circ}$. During condensation of the steam in the tube, no slugging was observed over the mass flux determined to be independent of the inclination and the flow regime progressed from annular to annular-wavy. The simple correlation revealed by analysis of the upper boundary of the slugging is well-matched with existing data, and comparisons with some of gas-liquid correlations show that the low-angle inclination (e.g., $\pm 1^{\circ}$ ) results are consistent with gas-liquid flow with a slight upward gradient to the angle studied. For larger inclinations (e.g., $5^{\circ}$ and $10^{\circ}$ ), the available data are compatible only at certain proximity, with certain correlations.

An experimental investigation of R11 was conducted by Wang et al. [12] for in-pipe condensation with various surface inclinations. Due to the surface inclination, gravitational force had a significant effect on the flow pattern and vapour-condensation distribution in the pipe. Different flow regimes occurred at different pipe inclinations, but generally, for all the cases, annular flow occurred at the entrance of the test tube. During the progress of flow, annular to annular-slug and slug flow regimes were observed along the pipe. In conclusion, transition mechanisms were suggested for the observed flow patterns.

Ghajar and Tang [13] investigated heat transfer coefficients locally and measured flow parameters for air-water flow in horizontal and slightly inclined $\left(+2^{\circ},+5^{\circ},+7^{\circ}\right)$ pipes. Utilising the flow visualisation technique, it was observed that the increase in the inclination angle increased the heat transfer for wavy, slug and annular flow patterns. In the case of wavy flow, an increase in inclination angle made fluid backwashing more important and contributed to the wave height and it also increased the average two-phase heat transfer coefficient, causing larger and more frequent jumps at the top of the inner-tube surface. Similarly, the mechanism of increasing the heat transfer for other flow regimes was introduced, and in the case of annular flow, the change of heat transfer coefficient was the least for different tube inclinations.

Kang et al. [14] experimentally studied the inclination effect on the flow regime of the condensation of steam in a large flattened tube. An air-cooled condensation process was carried out for power plants with mass flux of about $7 \mathrm{~kg} \mathrm{~m}^{2} \mathrm{~s}^{-1}$, length of $10.7 \mathrm{~m}$ and the tube orientation varied from horizontal up to $70^{\circ}$. A polycarbonate window was used for enabling simultaneous flow visualisation in heat transfer and pressure drop measurements. Experimental findings showed that the increased inclination angle led to a decrease in pressure drop due to gravityassisted drainage of the condensate. At low mass fluxes, tube inclination considerably affected the flow pattern, which was observed to be well separated stratified flow for downward orientations of the tube.

Steam condensation for an air-cooled condenser for a power plant was also studied experimentally by Davies and Hrnjak [15]. A flattened steel tube with brazed aluminum fins was used for the test section of the condenser. The length of the tube was $5.7 \mathrm{~m}$ and the inner dimensions were $216 \mathrm{~mm} \mathrm{X} 16 \mathrm{~mm}$. Cross-flow heat exchange provided 2.4 to $3.0 \mathrm{~ms}^{-1}$ cooling air at the fin inlet under conditions of 70 to $105 \mathrm{kPa}$ operation pressures and 0 to $49^{\circ}$ downward tube inclinations. With the help of adiabatic visualization sections, annular and stratified flow regimes were determined at the inlet and at the outlet respectively. The researchers noted that an increasing stratified condensate layer decreased the overall heat transfer coefficient, especially at the condenser outlet.

Cao et al. [16] studied R245fa condensation in phase separation shell-and-tube condenser. A condenser with mesh tubes inserted was $1600 \mathrm{~mm}$ long and had three $14.70 \mathrm{~mm}$ diameter copper tubes. Four mesh tubes, consisting of $15 \mu \mathrm{m}$ width mesh pore, were inserted into copper tubes and a comparative study was carried out for condensers with or without mesh tubes inserted. The flow pattern visualization results showed that heat transfer slowly decreased at low mass fluxes with an increase of inclination angles. A pressure difference was detected between the annular region and the core region, and this pressure difference caused a flow towards the core region, 
reducing the liquid film thickness at the bottom of the tube. When inclination angles varied from $-30^{\circ}$ to $30^{\circ}$, the pressure difference decreased but the liquid-mesh contact area increased.

Lips and Meyer [17] investigated the gravitational effect on R134a condensation in an inclined smooth tube. For various vapour qualities $(x=0.1-0.9)$ and mass fluxes $\left(\mathrm{G}=200-400 \mathrm{~kg} / \mathrm{m}^{2} \mathrm{~s}\right)$, a flow pattern, pressure drop and heat transfer coefficient were introduced as a function of the tube orientation. The maps of the inclination effect were drawn for the specified properties. Furthermore, the regions that were gravity-non-dependent and gravity-dependent were determined for the void fraction.

An upflow condensation study of R134a in an inclined tube with $5 \mathrm{~mm}$ diameter was conducted experimentally by Barbosa Jr. et al. [18]. Image processing techniques were used for identifying the onset of film flow reversal and properties of the interfacial waves. Oscillatory changes in the liquid velocity demonstrated the onset of flow reversal in the liquid film and ensuing transition to churn flow. High-speed video analysis revealed the existence of various flow regimes, namely stationary film, flow reversal, slug flow, climbing film and churn flow. Consequently, adaptations of present correlations for critical vapour velocity were related with wave frequency; and point-of-flow reversal was proposed.

Hanafizadeh et al. [19] conducted an experimental study of oil-water two-phase flow in a tube, which had $20 \mathrm{~mm}$ diameter and $6 \mathrm{~m}$ length with -45 to $+45^{\circ}$ inclination. For flow visualisation and flow regime detection, a digital high-speed camera was used. All the orientations of the tube and flow pattern maps were studied and analogised with available experimental literature. Different flow patterns were seen during the observations, such as bubbly, smooth-stratified, wavy-stratified, churn, slug and annular. Stratified flow and non-stratified flows such as slug and bubbly were dominant flow patterns for downward flows and upward flows respectively.

Different investigations for the condensation flow regime in inclined pipes have been carried out. Flow regime studies are also available for pipes in horizontal and vertical positions and some examples are presented below.

The inclination effect on flow patterns for low mass flux R134a $\left(52-225 \mathrm{~kg} / \mathrm{m}^{2} \mathrm{~s}\right)$ flow in U-bend tubes was visually observed and analyzed [20]. The findings of the research showed that the flow pattern was strongly influenced by gravitational and centrifugal forces, surface tension, shear stress and thus the inclination of the tube. In the light of the experimental outputs, horizontal, vertical upward and vertical downward cases of U-bend tube constituted further flow regime, according to other cases. The Weber number was selected as a correlating parameter for flow directions, inclination angles and mass fluxes associated with the presented flow patterns. The study indicated that annular flow was observed for high-vapour Weber numbers, while slug and stratified flows were observed for low-vapour Weber numbers. Furthermore, it was noted that there was no exact procedure for the liquid Weber number change and the Weber number decrease with increasing surface tension.

Xiao and Hrnjak [21] experimentally studied R134a flow, with 50 to $200 \mathrm{~kg} / \mathrm{m}^{2} \mathrm{~s}^{1}$ mass fluxes and 5 to $15 \mathrm{~kW} / \mathrm{m}^{2}$ heat fluxes, in a $6.1 \mathrm{~mm}$ diameter horizontal circular tube. All measurements were carried out at 1.319 MPa constant pressure corresponding to $50{ }^{\circ} \mathrm{C}$ saturation temperature. According to the flow visualisation results, the bulk superheated region was always the starting zone for condensation, which started as annular flow. The flow regime was exceedingly influenced by the mass flux. A new diabatic flow regime map, which showed that the early period of the condensation process was mostly found in the annular flow regime, was presented to better understand flow regimes in both the two-phase region and the condensing superheated region. Also, a film thickness measurement technique was defined for the circular tube.

Upflow condensation of FC-72 in a vertical tube was observed via high-speed video imaging and heat transfer measurements [22]. Four flow regimes, of which details were given in the research, were identified, namely falling film, oscillating film, flooding and climbing film. In accordance with the flow regime map, which properly presented flow regimes, the heat transfer coefficient for condensation axially decreased with increased liquid film thickness, except for high mass velocities. The presented annular flow model was feasible only for the climbing film regime that featured simultaneous liquid-vapour flows.

El Hajal et al. [23] and Thome et al. [24] proposed a new flow pattern map and heat transfer model for horizontally oriented in-tube condensation in a two-part study. The flow pattern map with flow transition criteria included a freshly identified logarithmic mean void fraction method and this flow pattern study was compared with up-to-date flow pattern researches. The heat transfer model predicted the condensation heat transfer characteristics for annular, stratified-wavy, fully stratified, intermittent and mist flow regimes. The proposed model examined into detail and tested for 24 to $1022 \mathrm{~kg} / \mathrm{m}^{2} \mathrm{~s}$ mass velocities, 0.03 to 0.97 vapour qualities, 3.1 to $21.4 \mathrm{~mm}$ tube diameters for the findings of 15 different working fluids. Generally, the heat transfer coefficients 
were predicted by the model within a $-20 \%$ accuracy for all flow regimes for $85 \%$ of the non-hydrocarbon database (1 850 points) and $75 \%$ of the whole database ( 2771 points).

The literature review indicated that the flow pattern was significantly affected by inclination angle or the gravitational effect in internal flows where condensation occurred and it was necessary to make detailed observations especially in the transition boundaries between the flow regimes. Furthermore, the heat transfer and pressure drop phenomena were also affected dramatically by the flow regime.

The increase in the inclination (for slightly inclined tubes) improved the two-phase heat transfer with the rise of the waves creating larger and frequent splashes for the wavy flow, while for the slug flow, the two-phase heat transfer improved with more intensive mixing effects depending on the change in the balance between the buoyant force and the inertia force [13]. Under low mass flux conditions and for large flattened steam condensing tubes, increasing the inclination angle caused a decrease in pressure drop; and the flow visualisation outputs indicated that large void fraction and low vapour velocity occurred at high inclination angles [14]. For U-bend tubes, stratified and stratified-wavy flow regimes appeared at low-vapour qualities, annular flow was observed at high-vapour qualities where the effects of gravitational and centrifugal forces could be neglected. In the same types of channels, with the increasing interfacial shear stress at high mass fluxes, the liquid separated from the channel walls and this phenomenon provided a basis for more stable flow characteristics and disappearing slug and slug/stratified-wavy flows [20].

In order to create more complicated results physically than those of research works on horizontal and vertical channels, a periodic review is necessary of flow pattern investigations into inclined pipes where many fluids are tested from water vapour in heat exchangers to FC-72 fluid used to maintain the heat balance of electronic systems, as well as the refrigerants (R-134a, R245fa, etc.) used in thermodynamic cycles.

\section{PRESSURE DROP DETERMINATION CONDENSATION STUDIES Introductory Remarks}

Although the pressure drop studies are especially important in piping systems, considering the effects on both system cost and heat transfer performance, they have also gained importance in processes where heat transfer occurs. In order to make a positive improvement to the stated cost and performance, the pressure drop in twophase flow systems in channels with different inclination angles has been investigated in many studies.

In condensation processes where two-phase flow occurs, experimental studies have shown that the inclination, as well as the shape of the channel and its internal structure, also has a significant effect on pressure drop characteristics. The pressure drop in a system basically includes three terms, namely the momentum pressure drop caused by the channel's inner-outer kinetic energy difference, the friction pressure drop caused by the shear stress between the liquid-vapour wall and the gravitational pressure drop that changes proportionally with the sinus of the inclination angle. Compared with the horizontal position in constant mass flux conditions, the pressure drop that increases with inclination in upward flows decreases with inclination in downward flows. The shear force is the more determining factor due to the gravitational force that loses its dominant feature in high mass fluxes and vapour qualities [14,17]. An example of the schematic diagram of the experimental apparatus and test section is seen in Figure 2 and Figure 3, respectively.

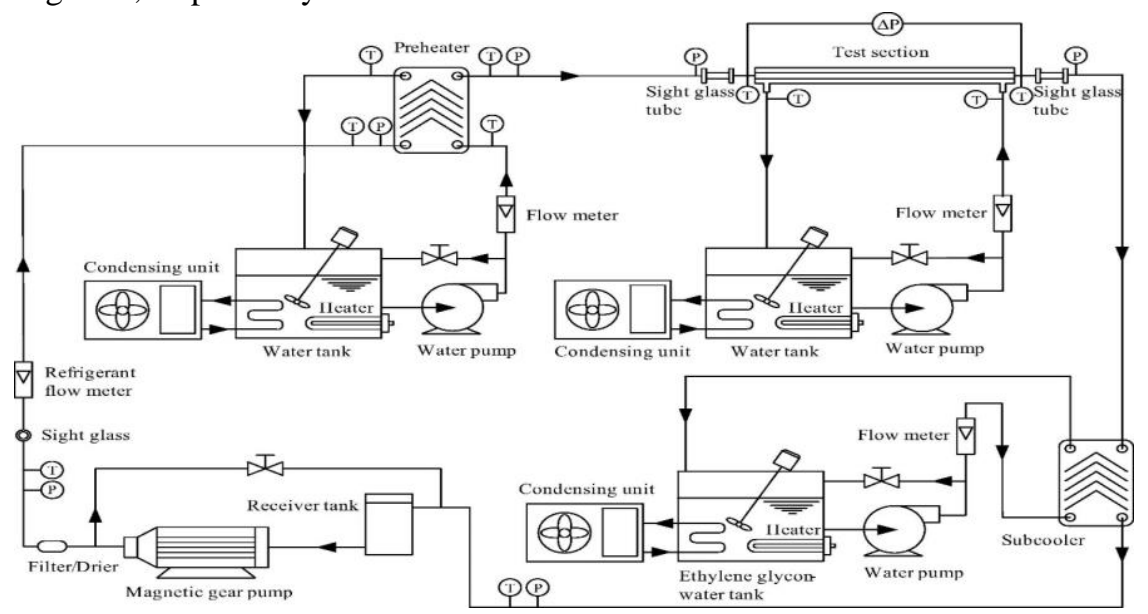

Figure 2. Schematic diagram of the experimental apparatus [From Aroonrat and Wongwises [25], with permission from Elsevier.] 


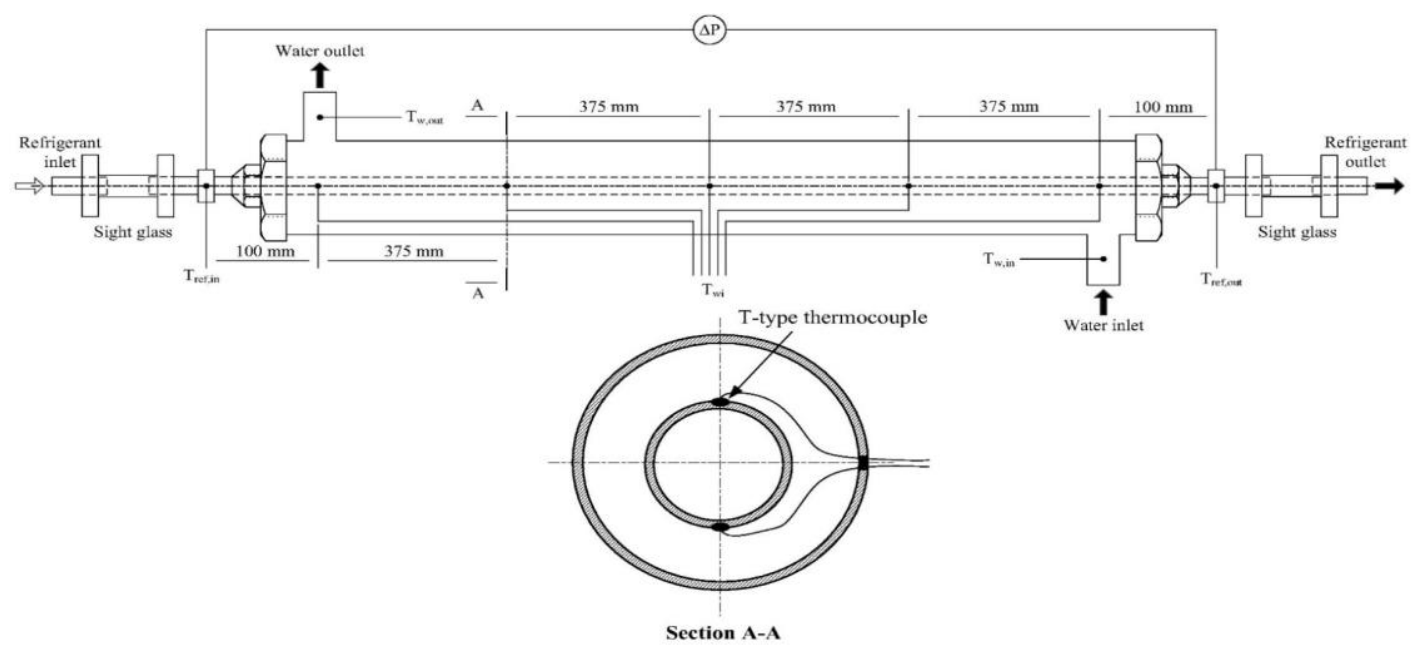

Figure 3. Schematic diagram of the test section [From Aroonrat and Wongwises [25], with permission from Elsevier.]

The literature review indicated that a low pressure drop but high heat transfer performance, which is a fundamental necessity in industrial applications, has recently been examined by using both traditional refrigerants and also a new type of pure-mixture refrigerant.

\section{Horizontal and Vertical Orientations}

Experimental research on condensation heat transfer and pressure drop properties in a horizontal smooth tube for R32, R134a, R125, R236ea and R410A was carried out by Cavallini et al. [26]. Saturation temperatures of 30 to $50{ }^{\circ} \mathrm{C}, 100$ to $750 \mathrm{~kg} /\left(\mathrm{m}^{2} \mathrm{~s}\right)$ mass fluxes and 0.15 to 0.85 vapour qualities were chosen for experimental runs and the effect on heat transfer and pressure drop of the chosen parameters was analysed according to the obtained results. While the pressure drop showed high values with high mass fluxes and vapour qualities, it showed low values for high saturation temperatures. The findings of this article were checked with the two-phase multiplier correlations that characterize the pressure drop.

Nualboonrueng and Wongwises [27] experimentally investigated the pressure drop characteristics of twophase forced flow for the pure R134 refrigerant in horizontally oriented smooth and microfin tubes. Internal diameter values, condensation temperatures and mass flux ranges of the condensation section varied between 8.12 and $8.92 \mathrm{~mm}, 30$ and $40{ }^{\circ} \mathrm{C}$, and 400 and $800 \mathrm{~kg} / \mathrm{m}^{2} \mathrm{~s}$ respectively. An increase in pressure drop was observed for increased vapour quality and mass flux for both smooth and microfin results, and it was determined that the pressure drop was 10 to $50 \%$ higher than for the smooth condition in the microfin case.

Tubes with twisted-wire inserts and enhanced microfin tubes were tested for repeatable CFC-113 condensation with downflow in a vertical tube by Briggs et al. [28]. The pressure drop findings for one smooth, nine microfin and four twisted-wire tubes indicated that the microfin structure produced $50 \%$ more pressure drop than for the smooth design, and the twisted-wire structure created more pressure drop with growing wire density. Also, in this study, measurements were taken for CFC-113/air mixtures.

Macdonald and Garimella conducted an experimental investigation into and model developing study $[29,30]$ of propane condensation in horizontal tubes. The conditions of the test runs well represented the characteristics of the process and HVAC\&R industries and the test was carried out for three different mass fluxes, two different pipe diameters and 0.25 to 0.95 reduced pressures. The findings of the study were compared with the existing models and because no model predicted the results properly, correlations for heat transfer and pressure drop were developed with a wide range of operating conditions, accompanied by the findings of the experiments. The pressure drop model described the pressure drop due to phase interactions and it provided improved estimates for existing correlations under larger pipe diameters and higher saturation pressures (lower friction pressure drop) conditions. In addition, the heat transfer model suggested a new method that took into account heat transfer from the upper liquid film characteristically formed in horizontal tubes. Both models were developed based on a database containing hydrocarbon data (propane and pentane), but the models were shown to accurately predict synthetic refrigerant behavior, and to predict friction pressure drop and heat transfer coefficient (for the propane database) with an average of $3 \%$ and $-1 \%$ deviation respectively. 
Kim et al. [31] conducted research into FC-72 condensation for parallel micro-channels with $29.9 \mathrm{~cm}$ length and $1 \mathrm{~mm}$ hydraulic diameter. Mass fluxes of 68 to $367 \mathrm{~kg} / \mathrm{m}^{2} \mathrm{~s}$ and saturation temperatures of 57.2 to 62.3 ${ }^{\circ} \mathrm{C}$ were determined as operating conditions for the flowing fluid. A comprehensive pressure model, which included various working parameters, was presented for pressure drop characteristics. Consequently, separated flow models predicted the results more accurately than the homogeneous flow model and the adiabatic and microchannel results were better predicted by separated models than the boiling and macro-channel results.

The condensation flow characteristics of various refrigerants (R22, R134a and R410A) flowing in a micro-tube with $1,220 \mathrm{~mm}$ length and $1.77 \mathrm{~mm}$ inner diameter were studied experimentally [32]. Tests applied to $40{ }^{\circ} \mathrm{C}$ saturation temperature and 450 to $1,050 \mathrm{~kg} / \mathrm{m}^{2} \mathrm{~s}$ heat fluxes. The pressure drop of R134a was higher than for R22 and R410A for the same mass flux. Also, a new model for pressure drop, which included a new factor C (predicting result mean and average deviations of $2.31 \%$ and $-8.7 \%$ respectively), was presented.

Condensation of R152a in a $1.152 \mathrm{~mm}$ diameter circular channel and of $0.952 \mathrm{~mm}$ hydraulic diameter rectangular channel was investigated experimentally by Liu et al. [33] Different mass fluxes, vapour qualities and saturation temperatures were selected for conducted tests and the effects of these parameters together with channel geometry on pressure drop properties were observed. The findings indicated that the pressure drop increased with increasing vapour quality and mass flux, whereas the pressure drop decreased with increasing saturation temperature and channel geometry almost not important for low mass fluxes. The results were analogised with theoretical and empirical correlations and the prediction qualities of these models were tested for the present experimental findings.

For a counter flow concentric double-tube heat exchanger model, the flow characteristics of R134a condensation in a smooth tube and a corrugated tube with 8.7 inner dimensions were investigated experimentally by Laohalertdecha and Wongwises [34]. $21.2 \mathrm{~mm}$ inner diameter copper tube was tested at 40 to $50{ }^{\circ} \mathrm{C}$ saturation temperatures, 200 to $700 \mathrm{~kg} / \mathrm{m}^{2} \mathrm{~s}$ mass fluxes and two different mass fluxes $\left(5\right.$ and $\left.10 \mathrm{~kW} / \mathrm{m}^{2}\right)$ for three different corrugation pitches and one fixed corrugated depth 5.08, 6.35, 8.46 and $1.5 \mathrm{~mm}$, respectively. The results of smooth and corrugated cases indicated that corrugation pitches had a considerable effect on the pressure drop increment.

The effects of twisted tapes on the pressure drop characteristics of R-404A condensation were studied by Salimpour and Yarmohammadi [35] in the case of a counter flow heat transfer process. The refrigerant flowed through the inner side of the tube, while cooling water flowed through the annulus side of the tube. Five different cases including smooth and twisted-tape situations were tested for various vapour qualities and mass fluxes. According to the authors, the twisted-tape cases created 89 to $239 \%$ higher pressure drop than for smooth case. In addition, a new correlation was developed for pressure drop prediction and this model determined the experimental data with $\pm 20 \%$ accuracy.

The influence of coiled-wire inserts on the pressure drop was analysed experimentally [36] for convective condensation of R-404A flow in one smooth case and five coiled-wire insert cases. Six different vapour qualities were tested for each mass flux and accompanied by outputs, it was determined that the pressure drop for the coiledwire insert case was $1200 \%$ higher than the pressure drop for the smooth case.

The pressure drop studies of horizontal and vertical channels made the following important contributions to the literature:

- For propane condensing in horizontal pipes with 7.75 and $14.45 \mathrm{~mm}$ inner diameter and specified conditions, the pressure drop increased with increasing mass flow and vapour quality, while the rising temperature decreased for the tube diameter [29].

- In order to improve the pressure drop correlation, flow visualisation studies used the horizontally oriented flow data of hydrocarbon condensation, which covered a wide range of operating conditions. The model, valid for 6 to $19 \mathrm{~mm}$ internal diameter, also explained additional friction pressures created by phase interactions [30].

-While the pressure drop increased with increasing mass flux in FC-72 condensing flow in square-shaped horizontally located $1 \mathrm{~mm}$ diameter micro-channels, the pressure drop decreased due to the flow deceleration caused by increasing the mass velocity of cooling water [31]. Similar trends were observed in studies where different fluids (R22, R134a, R152a, R404a, R410a, etc.) and different channel geometries (smooth, corrugated, twisted-tape inserts, etc.) were experimentally studied [32-36]. 


\section{Smooth Tubes with Inclined Orientation}

Although the hydrodynamic characteristics of condensation in the pipe have been studied mostly by using horizontal pipes, extensive studies have been conducted in inclined pipes in recent years. Lips and Meyer [37] investigated pressure drop and void fraction for different vapour qualities and mass fluxes of R134a flow in a pipe of different inclinations. The authors compared the findings with correlations in the literature and presented those correlations suitable for vertical upward flows but not for downward flows. For a restricted area with stratified flow, it was observed that the results of the slightly inclined pipe showed good agreement with the correlations. Furthermore, they stated that momentum and gravitational pressure drop should be known in order to know the void ratio. Considering the outcomes of this study, a more detailed investigation was conducted by Lips and Meyer [38] into stratified flow. Capillary forces and gravitational forces were considered for the determination of the liquid-vapour distribution in the pipe. The researchers proposed a mechanistic model for stratified flow and they pointed out that there was a need for the modelling of intermittent flows in upward pipes to fully understand the influence of gravitational forces on inclined two-phase flows.

A new heat transfer model package, which consisted of a momentum conservation model, flow regime prediction model and interface shape prediction model, was developed by Ahn et al. [39]. Upper and lower parts of the pipe were mechanically considered under separate flow conditions. When the void fraction was calculated using the developed methodology, the permanency of the values was provided during the transition to different flow regimes. The effect of gravity was considered, and the proposed model predicted the void fraction within 5\% of the mean deviation. Ahn et al. [40] investigated condensation characteristics in an inclinable circular pipe and proposed a condensation model. The researchers conducted 21 tests by changing the inclination angle, steam flow rate and inlet pressure. A correlation was proposed that correlated the two-phase multipliers and the void fraction. The new model was found to be consistent with the condensation experimental data.

Hydrodynamic characteristics were investigated by Würfel et al. [41] for two-phase flow, which included n-heptane/air, condensing $n$-heptane and water/air fluids in an inclined pipe. Special models were proposed for determining the flow characteristics and these were compared with existing literature. The researchers concluded that mass transfer intensity became effective on two-phase friction factor calculation and should not be neglected in experimental researches.

Laboratory experiments were conducted by Grolman and Fortuin [42] in horizontal and inclined pipes with different pipe orientations $\left(-3^{\circ}\right.$ to $\left.+6^{\circ}\right)$ and different experimental variables $(15 / 26 / 51 \mathrm{~mm}$ diameter, 0 to 0.42 liquid hold-up, 0 to $0.06 \mathrm{~m} / \mathrm{s}$ superficial liquid velocity, etc.). Discrete correlations were formulated by the authors such as liquid-to-wall friction factor, interfacial friction factor and wetted perimeter. Preliminary studies of this subject had been done by Grolman [43] before. On the whole, the data of 2400 well-controlled experiments were properly calculated by the introduced method.

Two different models for wall shear stresses and 22 different correlations for the interfacial friction factor, which included newly proposed ones, were studied by Ottens et al. [44]. The calculated results of the developed models were compared with experimental databases consisting of 3981 measurements. The experimental range of properties varied with pipe diameter of 12.7 to $95.3 \mathrm{~mm}$, density of 996 to $1120 \mathrm{~kg} / \mathrm{m}^{3}$, viscosity of 0.000852 to $0.092 \mathrm{~Pa} \cdot \mathrm{s}$, inclination angle of $-3^{\circ}$ to $+6^{\circ}$, etc. The authors pointed out that the separated flow model and coupling of the interfacial friction factor to the wave velocity produced better results.

For hydrodynamic characteristics of two-phase flow in an inclined pipe (inclination angles from $-90^{\circ}$ to $90^{\circ}$ ), a unified model was developed and validated in a two-part study by Zhang et al. [45-46]. The experimental outcomes were obtained with varied diameters of test pipe, physical properties of fluid, flow rates and flow patterns. Good agreement was achieved with predicted pressure gradient, liquid hold-up, slug characteristics and flow pattern transitions. The classification of the flow pattern was simplified and compared with two-phase flow at near-horizontal and upward orientations. Two-phase flow at vertically downward orientation was not investigated sufficiently.

Woldesemayat and Ghajar [47] conducted a detailed study which consisted of comparison of 68 void fraction correlations on the basis of 2845 points of data, of which 1542 were for inclined, 900 for horizontal and 403 for vertical pipe set-ups from previous studies. The doctoral thesis of Woldesemayat [48] provides necessary knowledge about previous investigations and a wide range of data sets. For the entire void fraction database, bestperforming correlations were developed on the basis of the drift flux model. A modified void fraction correlation was developed introducing proper physical parameters. 
Ewim and Meyer [49] measured the pressure drop at low mass fluxes $\left(50,75\right.$ and $\left.100 \mathrm{~kg} / \mathrm{m}^{2} \mathrm{~s}\right)$ in smooth inclined tubes with an inside diameter of $8.38 \times 10^{-3} \mathrm{~m}$. They conducted their investigation at different mean vapour qualities and temperature differences at an average saturation temperature of $40{ }^{\circ} \mathrm{C}$. It was found that the measured pressure drops increased with an increase in mass flux, temperature difference and vapour quality. They also found that the lowest and highest measured pressure drops were obtained during the downward and upward flows respectively.

Pressure drop studies of smooth inclined channels made the following important contributions to the literature:

- During the convective condensation of the R134a refrigerant, the increasing inclination and decreasing vapour qualities increased the pressure drop for the inclined orientation, while the reduced vapour qualities reduced the pressure drop for the horizontal and vertical upflow-downflow conditions [37].

- The effect of the mass transfer phenomenon on the two-phase friction coefficient and the effect of liquid hold-up and pressure gradient on the system performance under examination are important in inclined pipes [41, 42].

- In the developed flow models, examination of the wave velocity with the interfacial friction and verification of the flow pattern transitions with features such as liquid hold up and pressure gradient generated more accurate results $[44,45]$.

Existing studies should be evaluated by collating the effects of inclination angle on system pressure. This will provide a more accurate observation that takes into account all parameters of the process.

\section{Enhanced Tubes with Inclined Orientation}

Mozafari et al. [50] observed R-600a condensation and pressure characteristics in a helically inclined $\left(+30^{\circ},+60^{\circ},+90^{\circ}\right)$ counter flow heat exchanger. A $305 \mathrm{~mm}$ diameter coiled-tube heat exchanger model had properties of $35 \mathrm{~mm}$ pitch, $210 \mathrm{~mm}$ height and six turns of coil and tests conducted for both helical and straight heat exchangers at two different saturation temperatures $\left(38.5\right.$ and $\left.47^{\circ} \mathrm{C}\right), 155-265.5 \mathrm{~kg} / \mathrm{m}^{2} \mathrm{~s}$ mass fluxes and 0.11 to 0.78 vapour qualities. How heat transfer and pressure drop changed with inclination angle, vapour quality and mass flux was examined and the highest heat transfer at $30^{\circ}$ and the lowest heat transfer at $90^{\circ}$ were observed, while the maximum pressure drop was measured for the horizontal case. The performance index gave the following important outputs: 15 to $41 \%$ higher for the horizontal case than for the $90^{\circ}$ inclination case; for the helically coiled case, the pressure drop and the mean heat transfer coefficient increased in terms of the straight condenser between the range of 33 and $157 \%$ and 24 and $165 \%$ respectively.

$\mathrm{Li}$ et al. [51] numerically observed hydrocarbon mixture upflow condensation characteristics in smooth and spirally enhanced pipes with a $10^{\circ}$ inclination angle. They developed a numerical model and scrutinised the effects of geometrical variables. The increments of the heat transfer for spiral grooved, square corrugated and sinusoidal corrugated were 1.206 to $1.804,0.934$ to 2.052 and 1.103 to 2.216 times higher than for the smooth case, while the increments of the pressure drop for spiral grooved, square corrugated and sinusoidal corrugated were 0.851 to $3.587,1.805$ to 10.930 and 1.272 to 7.176 times higher than for the smooth case. The comprehensive heat transfer enhancement factor (CHF) was introduced, which indicated how heat transfer changed with geometric improvement. For the sinusoidal and square cases, an increase of corrugation height increased the CHF, whereas for the spiral grooved case, an increase of corrugation height decreased the CHF. However, it was observed that an increase of corrugation pitch influenced the CHF differently throughout the pipes.

At present, there is a dearth of research on pressure drop for condensation in inclined enhanced pipes in the literature. Current research has indicated that pressure drop is significantly affected by flow properties such as mass flux, steam quality (in helical tubes) and geometric parameters such as groove height and groove pitch (in spiral tubes).

\section{HEAT TRANSFER COEFFICIENT DETERMINATION CONDENSATION STUDIES Introductory Remarks}

In practice, one of the most required property in two-phase flows is the heat transfer phenomenon, where phase changes are present, significantly affecting flow characteristics and fluid properties. Condensation heat transfer characteristics in inclined channels have been provided in numerous studies.

The main physical reflection of the channel inclination (relative to the horizontal) is the increase in the downstream velocity and the decrease in the upstream velocity with the change of gravitational force. Factors such 
as mass flux, temperature and vapour quality, which affect properties such as flow velocity (Reynolds number), interface shear stress (frictional pressure drop), void fraction in two-phase flow, and have been studied in many studies, and their reflections on heat transfer, have been observed. Fluid type, channel geometry and channel inclination have been evaluated as variable parameters in these studies. It has been shown in many researches that the effects of flow on heat transfer are markedly variant at different channel inclinations. An example of the schematic of the experimental apparatus could be seen in Figure 4.

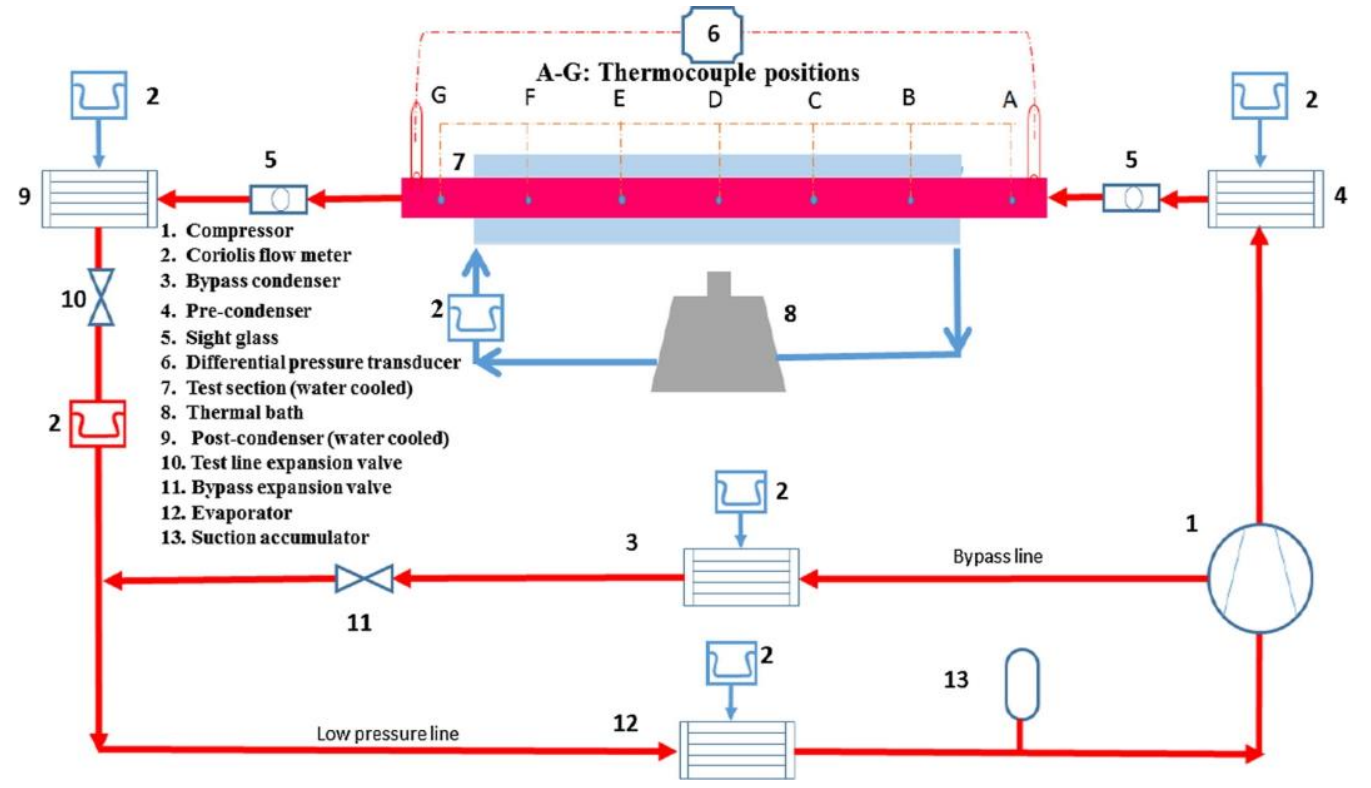

Figure 4. The schematic of the experimental apparatus [From Ewim and Meyer [49], with permission from Elsevier.]

\section{Horizontal and Vertical Orientations}

The condensation heat transfer coefficient of different types of pure refrigerants (R12, R22, R32, R123, R125, R134a and R142b) was studied experimentally by Jung et al. [52] with a three-part experimental device (a refrigerant loop part, a water loop part and a water-glycol loop part). When cooling water was flowing at the outside of the test tube, with $9.52 \mathrm{~mm}$ of diameter and $1 \mathrm{~m}$ of length, the test tube was filled with flowing refrigerant at $40{ }^{\circ} \mathrm{C}$ with 100 to $300 \mathrm{~kg} /\left(\mathrm{m}^{2} \mathrm{~s}\right)$ mass flux and 7.3 to $7.7 \mathrm{~kW} / \mathrm{m}^{2}$ heat flux. The research indicated that the heat transfer for R142b and R32 was higher than for R22, whereas the heat transfer for R12 and R125 was lower than for R22; on the other hand, the heat transfer for R123 and R134a was similar for the same mass flux, also the condensation heat transfer increased with increasing mass flux and increasing quality. Correlations in the literature estimated the experimental data suitably with mean deviations of less than $20 \%$ and a novel correlation, which had a mean deviation of $10.7 \%$ for all pure refrigerant data, was presented.

Improvements to refrigerants have been ongoing because they have various potentials for global warming. For instance, alternative working fluids such as R1234ze(E) and R1234yf were observed by Honeywell for organic Rankine cycle applications [53].

The condensation characteristics of working fluids of R245fa, Novec®649 and HFE-7000 for an organic Rankine cycle were experimentally studied by Ghim and Lee [54], in a $7.75 \mathrm{~mm}$ diameter horizontal tube at conditions of 150 to $700 \mathrm{~kg} / \mathrm{m}^{2} \mathrm{~s}$ mass flux, 0.05 to 0.95 quality and 0.05 to 0.15 reduced pressure. The results showed that environmentally friendly working fluids had lower heat transfer coefficients than those of R245fa; 141 measured coefficients of condensation heat transfer were compared with six correlations, of which the Shah correlation provided the best prediction.

Kim and Mudawar [55] investigated FC-72 condensation in $1 \mathrm{~mm}$ hydraulic diameter parallel square micro-channels where water rejected heat in a counter flow structure and they observed that the condensation heat transfer was highest for the thinnest liquid film. Heat transfer decreased throughout the channel and in the annular flow regions, more heat transfer enhancement occurred than in other parts of the flow area, and also previous macro-channel correlations indicated better predictions. Taking into account the observations of the research, a 
new correlation, which had a perfect predictive capacity for both FC-72 and inspected database of channels, was proposed.

Oh and Son [56] conducted experiments of R22, R134a and R410a condensation in a circular micro-tube, in 450 to $1050 \mathrm{~kg} / \mathrm{m}^{2} \mathrm{~s}$ mass flux and $40{ }^{\circ} \mathrm{C}$ saturation temperature conditions. For the same mass flux, condensation heat transfer of R410a was more effective than that of other refrigerants, whereas R22 and R134 showed an almost similar effect on heat transfer. The proposed correlations for a large diameter tube and single circular micro-tube predicted heat transfer poorly, and thus the authors concluded that it was necessary to propose a proper correlation for a single circular micro-tube.

For the range of 103 to $490 \mathrm{~kg} / \mathrm{m}^{2} \mathrm{~s}$ mass fluxes and 31 to $48{ }^{\circ} \mathrm{C}$ saturation temperatures in laboratory conditions, Yang and Jia [57] experimentally conducted upflow condensation tests of R410a with four different length vertical tubes, which had $8.02 \mathrm{~mm}$ inner diameter. The effects of length, condensing temperature and mass flux on condensation were examined for the test zone where the average steam qualities of 0.91 and 0.98 were captured. The observed results were compared with some of the existing correlations. As a result of experimental data that did not match the correlations with a certain percentage error, an original modified correlation was proposed and results were obtained with a deviation of $\pm 15 \%$.

Condensing heat transfer properties for R744/R32/R1234ze (E) refrigerant mixture with low global warming effect were examined by Kondou et al. [58] for different saturation temperatures, mass fluxes and heat fluxes in horizontal micro-fin tubes and comparisons were made with a mixture of R32/R1234ze (E) for different refrigerant percentages. For an average saturation temperature of $40{ }^{\circ} \mathrm{C}$, mass flow of $200 \mathrm{~kg} / \mathrm{m}^{2} \mathrm{~s}$ and heat flux of $10 \mathrm{~kW} / \mathrm{m}^{2}$, the condensation heat transfer coefficient of mixture R744/R32/R1234ze (E) (9/29/62 mass\%) was identified lower than for mixture R32/R1234ze(E) (40/60 and 30/70 mass\%). In addition, single-component refrigerants were also studied, and the experimental pressure gradient was found to be compatible with the predictions recommended for single-component cases, which could also predict the pressure gradient of mixtures. In all cases, the pressure gradients remained nearly the same in measurement uncertainty.

For the R1234yf refrigerant, which has a global warming potential of less than 1 and can be useful for future engineering technologies, condensation characteristics were studied in a micro-fin pipe at 0.2 to 0.95 vapour qualities, 100 to $1000 \mathrm{~kg} / \mathrm{m}^{2} \mathrm{~s}$ mass fluxes and 30 and $40{ }^{\circ} \mathrm{C}$ saturation temperatures [59]. Experimental results showed that mass flux and vapour quality properties had strong effects on heat transfer and it was determined that the heat transfer coefficient increased with the increase of these two properties. Furthermore, the friction pressure gradient increased with mass flux in the case of constant vapour quality, while it varied with vapour quality in the case of constant mass flux.

In the conditions of 5.7 to 5.9 bar saturation pressure, 20 to $100 \mathrm{~kg} / \mathrm{m}^{2} \mathrm{~s}$ mass flux and 1.7 to $5.3 \mathrm{~kW} / \mathrm{m}^{2}$ heat flux, Arslan and Eskin [60] experimentally studied vapour condensation of pure R134A in a helically inclined $\left(18{ }^{\circ} \mathrm{C}\right)$ micro-fin tube. They also observed the effectiveness of temperature difference and mass flux on heat transfer in terms of experimental data. Some of the outcomes of the study were that the fins performed as turbulence increasing in all experiments, the heat transfer enhancement ratio (1.59-1.71) was always higher than the heat transfer area enhancement factor (1.55), and condensate Nusselt number was found to be independent of the temperature difference in conditions where the temperature difference was higher than $2.58^{\circ} \mathrm{C}$. The most-used correlations in the literature for micro-fin tubes were applied to the experimental data and the most appropriate correlations estimated the results with an absolute mean deviation of $17 \%$ to $19 \%$.

Heat transfer and pressure characteristics for R410A and R22 refrigerants flowing in a herringbone-type micro-fin tube were investigated together with the data of the helical micro-fin and plain tube by Miyara et al. [61]. In the region where high mass flux was available, higher heat transfer provided in the herringbone-type tube than for the helical micro-fin case, whereas heat transfer showed the opposite character for the low mass flux region. Moreover, the pressure drop was higher in the herringbone micro-fin tube than in the helical micro-fin tube. Preliminary correlations were proposed for the herringbone-type pipe because for the heat transfer coefficient and pressure drop, the present correlations agreed well with the findings for the helical micro-fin tube, while the findings obtained for the herringbone-type tube were higher than those predicted values.

For a straight tube and nine corrugated tubes (for different pitches and depths) in conditions of mass fluxes of 187 to $561 \mathrm{~kg} / \mathrm{m}^{2} \mathrm{~s}$, steam qualities of 0.18 to 0.85 and condensation temperatures of 29.2 to $35.8^{\circ} \mathrm{C}$, the characteristics of R-404A refrigerant were experimentally studied in a $8.7 \mathrm{~mm}$ inner diameter channel inside the test section designed as a $1 \mathrm{~m}$ length, water-cooled, horizontal counter flow heat exchanger [62].In this research, in which artificial neural network and multi-purpose genetic algorithm were used to determine the optimum 
working conditions during condensation of R-404A, new experimental correlations were proposed for the determination of the heat transfer coefficient and pressure drop, and consequently, it was stated that if a corrugated channel was used, the heat transfer coefficient could be up to 115\% higher than that of the straight tube.

$\mathrm{Li}$ et al. [63] experimentally investigated and theoretically analysed the heat transfer characteristics of R447A (R32/R1234ze/R125), which was a triple mixture, flowing in horizontal multi-port extruded micro-tubes with a hydraulic diameter of $0.86 \mathrm{~mm}$ for variable saturation temperatures, steam qualities and mass fluxes. Some of the findings of the study were as follows: the heat transfer coefficient of R447A was greatly more than that of R32 and slightly lower than that of R134A, whereas higher than that of R1234ze; R447A refrigerant performed better than R32/R134a (51/49 mass\% and 24.5/76.5 mass\%), R32/R1234ze (45/55 mass\% and 21/79 mass\%) mixtures and R410A in terms of heat transfer; the condensation heat transfer coefficients determined by the reviewed correlations estimated the experimental results within the mean absolute error of $30 \%$.

The condensing properties of R134a in a dimpled tube were tested experimentally by Aroonrat and Wongwises [24] in a test chamber in which cold water flowed on the annulus side and which was designed as a double-tube heat exchanger, one of the inner tubes was made of copper, one smooth and the other dimpled, and located horizontally. The trends of heat transfer and pressure drop were examined in the experiments carried out in a test tube of $1500 \mathrm{~mm}$ length and $8.1 \mathrm{~mm}$ inner diameter in conditions of 40 to $50^{\circ} \mathrm{C}$ saturation temperatures, 10 to $20 \mathrm{~kW} / \mathrm{m}^{2}$ heat fluxes and 300 to $500 \mathrm{~kg} / \mathrm{m}^{2} \mathrm{~s}$ mass fluxes. Comparing data for dimpled and smooth tubes, the heat transfer and pressure drop were observed to be higher for the dimpled case than for the smooth case and the Nusselt number was observed to be 1.3 to 1.5 higher for the dimpled case than for the smooth case depending on the increase in equivalent Reynolds number.

Meyer and Ewim [64] measured the heat transfer coefficients during the condensation of R134a at low mass $\left(50-200 \mathrm{~kg} / \mathrm{m}^{2} \mathrm{~s}\right)$ fluxes in a smooth horizontal tube by varying the temperature differences. Investigations were carried out at an average saturation temperature of $40{ }^{\circ} \mathrm{C}$ at different vapour qualities. They found that the heat transfer coefficients decreased with an increase in temperature difference. They also found that most correlations in the open literature failed to predict their experimental results and for that reason, they suggested an amendment to an existing correlation. It was found that the proposed amendment was able to estimate their results with errors of $\pm 5 \%$.

In 1958, Akers et al. [65] proposed a two-phase multiplier-based correlation. In their test, R-12, Propane and Methanol were chosen as refrigerants and they condensed the refrigerants inside horizontal tube during annular flow regime. Akers et al. [65] converted $G_{e q}$, equivalent all-liquid mass flux, into $R e_{e q}$, equivalent all liquid Reynolds number. And their correlation became known as " equivalent Reynolds number" model.

$$
\begin{gathered}
N u_{l}=5.03 \operatorname{Re}_{e q}{ }^{1 / 3} \operatorname{Pr}_{l}{ }^{1 / 3} \quad R e_{e q} \leq 5 \times 10^{4} \\
N u_{l}=0.0265 \operatorname{Re}_{e q}{ }^{0.8} \operatorname{Pr}_{l}{ }^{1 / 3} \quad R e_{e q}>5 \times 10^{4}
\end{gathered}
$$

where; $\quad N u_{l}=\frac{h D_{h}}{k_{l}}, R e_{e q}=\frac{G_{e q} D_{h}}{\mu_{l}}, G_{e q}=G\left[(1-x)+x\left(\frac{\rho_{l}}{\rho_{v}}\right)^{0.5}\right]$

For developing the correlation above, they used heat-momentum analogy, which defines the relation between heat transfer and wall shear stress. Because in a single-phase flow, with increasing wall shear stress leads to an increase in the heat transfer coefficient as similar to two-phase flow. Therefore, they were able to replace allliquid flow by a condensing two-phase flow.

Heat transfer studies in horizontal and vertical channels made the following important contributions to the literature:

- For FC-72 condensation, because of gradual thickening of the liquid film and eventual collapse of the annular regime, the heat transfer coefficient decreased along the micro-channel.

- At the given mass flux, in comparison with three refrigerants, the condensation heat transfer coefficient of R- 410A was higher than that of R-22 and R-134a.

- Due to its superior thermophysical properties, the condensation heat transfer coefficient of R32 alone was somewhat higher than that of R1234ze(E), as predicted by the correlations. However, the heat transfer coefficient values of single components were drastically higher than those of the binary and ternary mixtures. 
Fluids with low global warming potential and fluids used in technological cooling have also been studied recently. Technological developments and the widespread use of environmentally friendly practices demonstrate that research in this direction will increasingly continue.

\section{Smooth Tubes with Inclined Orientation}

The inclination effect on condensation characteristics for smooth pipes was investigated in a sophisticated two-part study by Lips and Meyer [37, 66]. They demonstrated the alteration of flow pattern, heat transfer coefficient, void fraction and pressure drop for all the various inclination angles at experimental set-up. The selected refrigerant $\mathrm{R} 134 \mathrm{a}$ at a saturation temperature of $40{ }^{\circ} \mathrm{C}$ circulated inside a smooth pipe with an inner diameter of $8 \mathrm{~mm}$. Mass fluxes ranged from 200 to $600 \mathrm{~kg} / \mathrm{m}^{2} \mathrm{~s}$ and vapour qualities ranged from 0.1 to 0.9 . They observed that flow profile and condensation heat transfer were strongly influenced by inclination angle. In the downward flows, $15^{\circ}$ angle in the pipe increased the heat transfer coefficient up to $20 \%$, whereas in the upward flows, declines could be observed. The experimental data of Lips and Meyer [37, 66] were used to develop correlations to predict heat transfer and pressure drop characteristics of flow [38]. The authors focused on the stratified flow model and thus they investigated heat transfer characteristics, flow behaviour and pressure drop. According to the experimental findings, the maximum heat transfer coefficient occurred at about an inclination angle of $15^{\circ}$. It was shown that the capillary forces and gravitational forces were dominant in conditions of twophase stratified flow. New correlations for heat transfer and pressure drop calculations were developed and compared with existing experimental literature. It was observed that the developed correlations were compatible with the data in the literature and further experimental research was needed for better understanding of flow characteristics in inclined pipes.

An example of schematic diagram of the test apparatus and test condenser could be seen in Figure 5 and Figure 6, respectively.

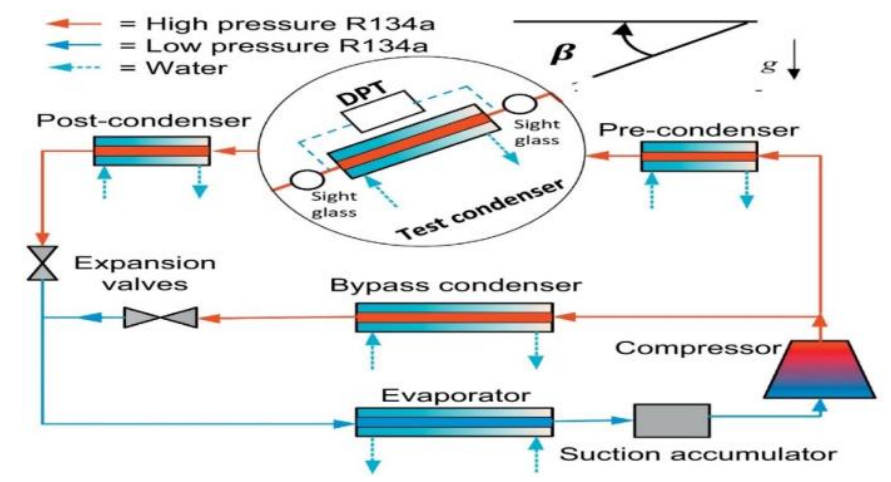

Figure 5. Schematic diagram of the test apparatus. [From Adelaja et al. [67], with permission from Elsevier.]
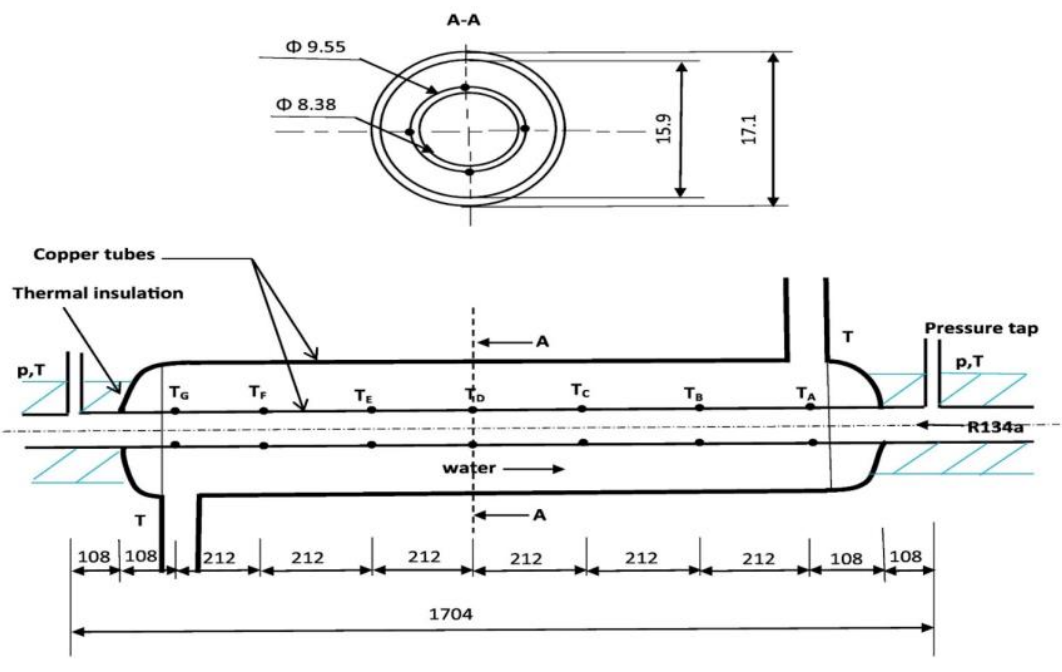

All dimensions in mm

Figure 6. Schematic diagram of the test condenser [From Adelaja et al. [67], with permission from Elsevier.] 
An experimental investigation of convective condensation of R134a flow in an inclined smooth copper pipe was conducted by Adelaja et al. [68]. Experiments were performed in the following conditions: $8.38 \mathrm{~mm}$ inner diameter of pipe, 200 to $400 \mathrm{~kg} / \mathrm{m}^{2} \mathrm{~s}$ mass flux of flow, $-90^{\circ}$ to $+90^{\circ}$ inclination angle of pipe, $40{ }^{\circ} \mathrm{C}$ mean saturation temperature of liquid and 0.1 to 0.9 vapour quality of fluid. According to the results, the vapour quality and inclination angle had a strong influence on the heat transfer. The developed correlation by the authors yielded the following: for horizontal flow, mean and average deviations of $9.22 \%$ and $3.44 \%$ respectively; for vertical downward flow, $19.41 \%$ and $5.25 \%$ respectively. As in the previous studies $[6,8,9]$ it was stated that the inclination angle was more effective at low mass flux.

Mohseni et al. [69] performed an experiment on a testing apparatus which contained a plain pipe with different inclination angles from $-90^{\circ}$ to $+90^{\circ}$. Refrigerant R134a flowed in the system with mass fluxes ranging from 53 to $212 \mathrm{~kg} / \mathrm{m}^{2} \mathrm{~s}$ for each inclination case. The research showed that pipe inclination substantially affected vapour and condensed liquid distribution, and consequently, also the condensation heat transfer, especially at low mass flux and vapour quality. The researchers reported that the optimum heat transfer coefficient occurred at an inclination angle of $+30^{\circ}$ and the minimum heat transfer coefficient occurred at an inclination angle of $-90^{\circ}$. The developed correlation could predict the experimental data accurately within $\pm 14 \%$.

Xing et al. [70] experimentally investigated condensation heat transfer during the flow of refrigerant R245fa in a pipe with a length of $1200 \mathrm{~mm}$ and a diameter of $14.81 \mathrm{~mm}$. The refrigerant mass fluxes, vapour qualities and the inclination angle of pipes varied from 191.3 to $705.4 \mathrm{~kg} / \mathrm{m}^{2} \mathrm{~s}, 0.191$ to 0.947 and $90^{\circ}$ to $90^{\circ}$ respectively. The major flow patterns in the condenser pipes were stratified-smooth, intermittent and stratifiedwavy flows. The best-performing heat transfer coefficient occurred at inclination angles of $-15^{\circ}$ and $+30^{\circ}$. The research indicated that the inclination angle had a strong effect on the heat transfer coefficient for the nearhorizontal position of the pipe. A new experimental correlation for condensation heat transfer was developed, which was in good agreement with vapour mass quality and Froude number.

On the vertical and the inclined thermosyphons, both theoretical and experimental investigations were conducted by Wang and Ma [71]. $+15^{\circ}$ to $+90^{\circ}$ inclination angle of pipe was arranged for the experimental setup in conditions that were 10 to $40 \mathrm{~kW} / \mathrm{m}^{2}$ heat flux of condenser and 8 to $15 \mathrm{kPa}$ of vapour pressure. The research indicated an inclination angle effect on the condensation heat transfer coefficient and $+20^{\circ}$ to $+50^{\circ}$ of inclination presented the optimum heat transfer. Finally, a semi-empirical correlation was presented. Wang and Du [72] proposed an analytical model for predicting condensation heat transfer in inclined small/mini-diameter pipes. Four different pipes were investigated in this research. It was shown that the effect of the inclination angle would increase if the pipe diameter increased, but the effect of the inclination angle on Nusselt number was complex for different sizes of pipes. Gravity had a decreasing effect on flow condensation, according to the results of this paper.

For a nearly horizontal pipe, Ahn et al. [39] developed a new model that included convective heat transfer and film condensation. Heat transfer characteristics at inclination angles of $0^{\circ}$ to $+3^{\circ}$ and diversified separated flow regimes were investigated for air-water and steam-water conditions. The proposed method properly predicted the characteristics of flow considering the experimental observations. Ahn et al. [40] also studied separated flow regimes in the case of pure saturated steam flow in a $40 \mathrm{~mm}$ inner diameter pipe at inclination angles of $-10^{\circ}$ to $0^{\circ}$. Multidimensional parameters for local condensation heat transfer were selected as saturated steam at 1 to 5 bar of pressures and 10 to $50 \mathrm{~kg} / \mathrm{m}^{2} \mathrm{~s}$ of mass fluxes in an inclinable pipe with a length of $3 \mathrm{~m}$. The proposed model predicted the heat transfer coefficient according to the experimental data with an average deviation of $6.2 \%$. The authors anticipated that this model could be applicable to 35 to $40 \mathrm{~mm}$ of inner diameter pipes, 1 to $67 \mathrm{bar}$ of pressure and 10 to $329 \mathrm{~kg} / \mathrm{m}^{2} \mathrm{~s}$ of mass fluxes.

Steam condensation heat transfer characteristics in a $30^{\circ}$ inclined pipe were experimentally studied by Yang et al. [73]. The empirical correlation developed by the researchers predicted the condensation heat transfer coefficient better for large-diameter inclined pipes than the correlations examined in the study. The researchers concluded that heat transfer coefficients in inclined pipe were nearly 1.06 to 2.98 times better than for the horizontal orientation.

A theoretical analysis was conducted by Hussein et al. [74] for laminar film condensation. An inclined wickless heat pipe flat-plate solar collector was used for this purpose. It was concluded that condensation heat transfer strongly influenced by the inclination angle and condenser section dimensions ratio. The authors pointed out that the proposed equation for condensation heat transfer was valid for inclination angles of $0^{\circ}$ to $+90^{\circ}$.

One of the most comprehensive research works in the literature was carried out by Shah [75] as a result of a detailed examination of the available experimental data from previous studies. The new correlation for heat 
transfer was developed for conditions of pipe diameter of 2 to $49 \mathrm{~mm}$, mass flux of 4 to $820 \mathrm{~kg} / \mathrm{m}^{2} \mathrm{~s}$, Reynolds number of 68 to 85000 , reduced pressure of 0.0008 to 0.9 and Prandtl number of 1 to 18 . The experimental data used for the validation of the developed correlation included 22 fluids (water, organics, hydrocarbon refrigerants, halocarbon refrigerants) condensation in horizontal, vertical and downward-inclined pipes. The proposed correlation showed good agreement with the vertical and horizontal orientations but not with the slightly inclined orientation. Especially at $\operatorname{Rev}<16000$, further investigations were needed for both horizontal and slightly inclined cases. The author investigated condensation heat transfer in smooth conventional pipes as well as mini and micropipes in another research paper [76]. Different types of pipe channels (rectangular, round, triangular, etc.), different pipe orientations $\left(-90^{\circ}\right.$ to $\left.+90^{\circ}\right)$, different flowing fluids (33 fluids) and different experimental variables ( 0.1 to 49 $\mathrm{mm}$ diameter, 1.1 to $1400 \mathrm{~kg} / \mathrm{m}^{2} \mathrm{~s}$ mass flux, etc.) were analysed in detail and comprehensive correlations predicting 4063 data points with nearly 17\% mean absolute deviations were developed.

Camaraza-Medina et al. [77] studied film condensation in pipes with various orientations observed from available data in the literature. A new model was proposed and verified with 22 different flowing fluids for 2 to $50 \mathrm{~mm}$ inner diameter, 0.1 to 0.9 steam quality, 3 to $850 \mathrm{~kg} / \mathrm{m}^{2}$ s mass flux and other parameters mentioned in the research paper. The developed model showed good agreement with all cases of pipe orientation and could be considered proper for practical designs. Würfel et al. [41] investigated two-phase friction factor, heat transfer, film thickness and also entrainment for $\mathrm{n}$-heptane/air, condensing $\mathrm{n}$-heptane and water/air fluid flow in an inclined pipe. The authors proposed a special model for local condensation heat transfer in terms of the experimental outcomes.

Ewim et al. [78] measured the heat transfer coefficients and flow patterns during the condensation of $\mathrm{R} 134 \mathrm{a}$ in a smooth inclined tube at low mass fluxes at a mean saturation temperature of $40{ }^{\circ} \mathrm{C}$. They carried out experiments for various mean vapour qualities between 0.1 to 0.9 in a test section with an inside diameter of 8.38 $\times 10^{-3} \mathrm{~m}$ and a length of $1.5 \mathrm{~m}$. It was found that altering the inclination angles significantly altered the heat transfer coefficients and flow patterns. For instance, the highest heat transfer coefficients were found at inclinations of $-15^{\circ}$ and $-30^{\circ}$ and the corresponding lowest temperature difference was tested for in each case. In general, it was observed that the heat transfer coefficients were more sensitive to downward flows than to upward flows. It was also found that the heat transfer coefficients for downward and upward vertical orientations $\left(+90^{\circ}\right.$ and $\left.-90^{\circ}\right)$ were not dependent on the temperature difference. It was also found that the inclination effect decreased with an increase in temperature difference and increased with a decrease in mass flux and vapour quality.

Most recently, Adelaja et al. [67] proposed a model capable of predicting the heat transfer coefficients during condensation inside inclined tubes subject to diabatic conditions. They used an extensive database of experimental results collected from the research group led by Professor Josua Meyer to develop the model. It was found that this new proposed model showed an excellent agreement with the experimental data within a global average and mean absolute deviations of $-5.74 \%$ and $1.13 \%$ respectively. The performance of the new model was also compared with results from three different laboratories and the new model predicted them with a high level of accuracy.

Heat transfer studies in smooth inclined channels made the following important contributions to the literature:

- Heat transfer coefficients in inclined tubes were approximately 1.06 to 2.98 times higher than those in horizontal tubes due to tilting influences of the heat transfer during condensation in a tube.

- The condenser section dimensions ratio had a significant effect on the condensation heat transfer coefficient inside the inclined wickless heat pipes.

The work on smooth straight pipes has been more intensely studied due to the absence of structures such as fins that disrupt the flow characteristics. However, straight pipes are less efficient than enhanced pipes considering the limitations in the ability to improve the thermophysical properties of the flow and the disadvantages such as taking up more space.

\section{Enhanced Tubes with Inclined Orientation}

Akhavan-Behabadi et al. [79] studied refrigerant R134a condensation in a micro-fin pipe with different orientations of the inclination angle between the range of $-90^{\circ}$ and $+90^{\circ}$. Three mass velocities were also tested at 54,81 , and $107 \mathrm{~kg} / \mathrm{m}^{2} \mathrm{~s}$. The heat transfer coefficient greatly increased with slightly inclined horizontal orientations and the inclination of $+30^{\circ}$ generated the highest value of the experiments. However, the lower heat transfer was observed for vertical orientations. Research revealed a 32 to $48 \%$ difference between the best 
performance and the worst performance. Finally, for the more accurate prediction of experimental data, a new Nusselt number correlation was developed. An example of the schematic diagram of the experimental apparatus and section of the enhanced tube is shown in Figure 7 and Figure 8, respectively.

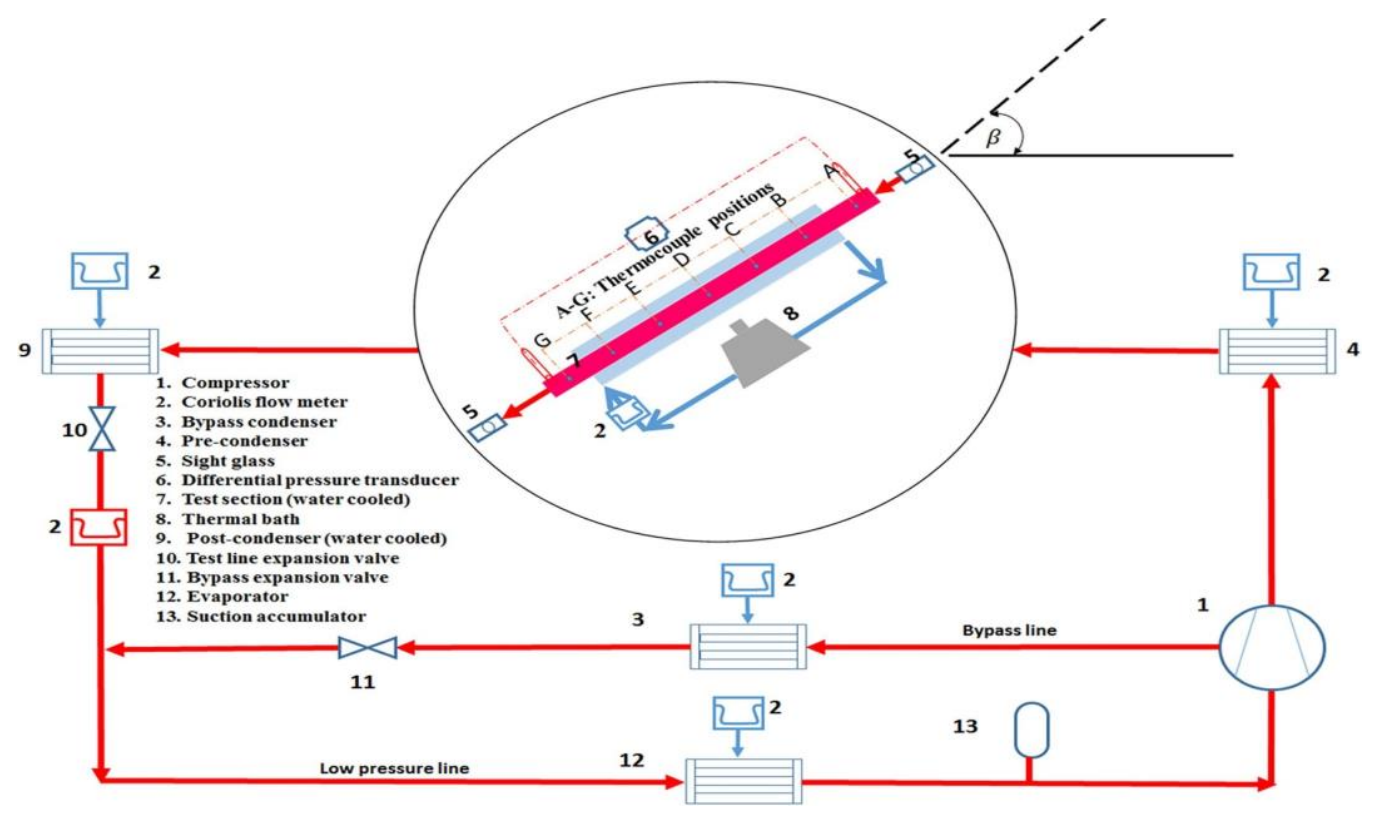

Figure 7. The schematic diagram of the experimental apparatus [From Adelaja et al.[80], with permission from Elsevier.]

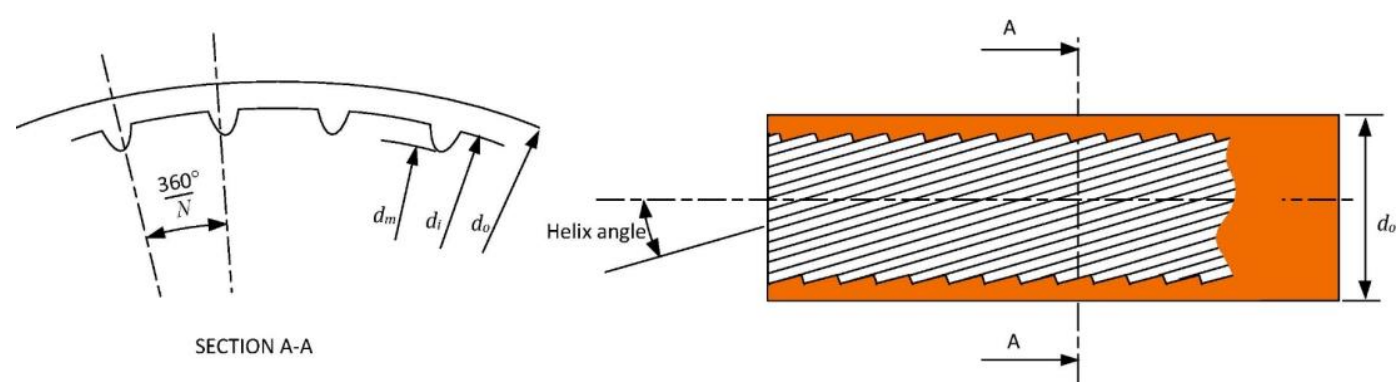

Figure 8. The section of the enhanced tube [From Adelaja et al. [80], with permission from Elsevier.]

An experimental investigation was conducted by Khoeini et al. [81] to analyse condensation heat transfer inside a corrugated pipe in the case of R-134a flow with different inclination angles of $-90^{\circ}$ to $+90^{\circ}$. Mass fluxes were between 87 and $253 \mathrm{~kg} / \mathrm{m}^{2}$ s and the vapour quality was between 0.2 and 0.8 in the test condenser. The researchers pointed out that the change in pipe inclination had a strong influence on condensation heat transfer, especially at low vapour qualities and low mass fluxes. The optimum condensation heat transfer coefficient was 1.41 times greater than the worst case and it occurred for $\alpha=+30^{\circ}$. An empirical correlation was proposed based on the experimental data.

Yildiz et al. [82] also investigated heat transfer during condensation for a micro-fin pipe in conditions of different inclination angles. In this research paper where reflux condensation was taken into account, the optimum heat transfer coefficient occurred at $+30^{\circ}$ inclination angle. It was observed that heat transfer at this orientation was quadruplicate that of heat transfer in the vertical case. Also, it was evident that the micro-fin structure created better heat transfer characteristics than for the smooth structure. The authors pointed out the difficulty of investigating reflux condensation in inclined enhanced pipes, as well as the dearth of investigations into the condensation of inclined enhanced pipes in the literature. The developed correlations for condensation in inclined enhanced pipes are shown in Table 2.

Adelaja et al. [80] measured heat transfer coefficients (HTC) and pressure drop during condensation inside inclined smooth and micro-fin tubes. For the micro-fin tube, they obtained maximum heat transfer coefficient at tube inclinations of between -15 and $-5^{\circ}$ (downward flows), while for the smooth tube, the 
maximum HTC was found at inclinations of between -30 and $-15^{\circ}$ (downward flows). The HTC enhancement factors were found to be between 0.98 and 2.38 depending on the angle of inclination. For both tubes, it was found that higher mass fluxes generally led to increased frictional pressure drop. It was also found that the lowest frictional pressure drop occurred at either horizontal tube positions or vertical downward flow inclinations. It was concluded that penalty factors ranged between 0.8 and 4 and were dependent on the mass flux, inclination and vapour quality.

Current studies have indicated that the change in tube inclination has a significant effect on condensation heat transfer of the flow and the highest heat transfer coefficient occurs when the micro-fin tube is horizontal at high-vapour qualities and is $+30^{\circ}$ inclined at low-vapour qualities. It has been observed that the condensation heat transfer coefficient in enhanced pipes should be studied in the literature by using different working fluids and widely varying inclination angles.

\section{FLOW REGIME DETERMINATION BOILING STUDIES}

\section{Introductory Remarks}

The importance of flow regimes in boiling is substantial because the flow regime is one of the most important factors in any two-phase flow problem. The flow regimes affect the behaviour of a gas-liquid mixture in a significant way. Moreover, it is essential to understand the behaviour of the gas-liquid mixture to solve the main relations that are needed for the calculation of two-phase conservation equations. Methods for predicting the major two-phase flow regimes are required to model and analyse two-phase flow systems [83].

Although the classification of flow boiling regimes is not yet clear in adiabatic vertical flow, most researchers accept four major flow regimes: bubbly flow, slug and cap-slug flow, churn flow, annular flow. These regimes are identified as follows:

1. Bubbly flow: Small dispersed spherical bubbles flow in a liquid-phase continuum. In very low gas flow rates, the bubbles have little interaction, but when gas flow rates are increased, the bubbles increase in number density. When gas flow rates continue to increase, the bubbles' interaction leads to their coalescence and breakup [83].

2. Slug flow and cap-slug flow: In high gas flow rates, the bubble coalesces and this situation leads to an increase in the number density of tiny bubbles and the forming of bigger bubbles. This is defined as slug flow. In a situation in which the annulus gap size is smaller than the distorted bubble limit, the cap bubbles cannot be seen. Therefore, a growing bubble is radially enclosed by the inner and outer walls until reaching the maximum distorted bubble. The cap bubble squeeze between the inner and outer walls occurs if bubbles continue to grow [84].

3. Churn flow: This type of flow develops at high gas flow rates due to large Taylor bubbles. In the churn regime, chaotic motion of the irregularly shaped gas pockets takes place, with literally no obvious interfacial shape [83].

4. Annular flow: This type of flow replaces churn flow at higher gas flow rates. The gas phase flows in the center of the gap and the liquid phase flows along the walls as a film. The droplets are usually 10 to $100 \mu \mathrm{m}$ in diameter [85]. Mostly, part of the liquid phase is entrained as small droplets in the gas core [83].

The flow regimes of boiling inside vertical and inclined tubes are shown in Figure 9 and Figure 10, respectively.

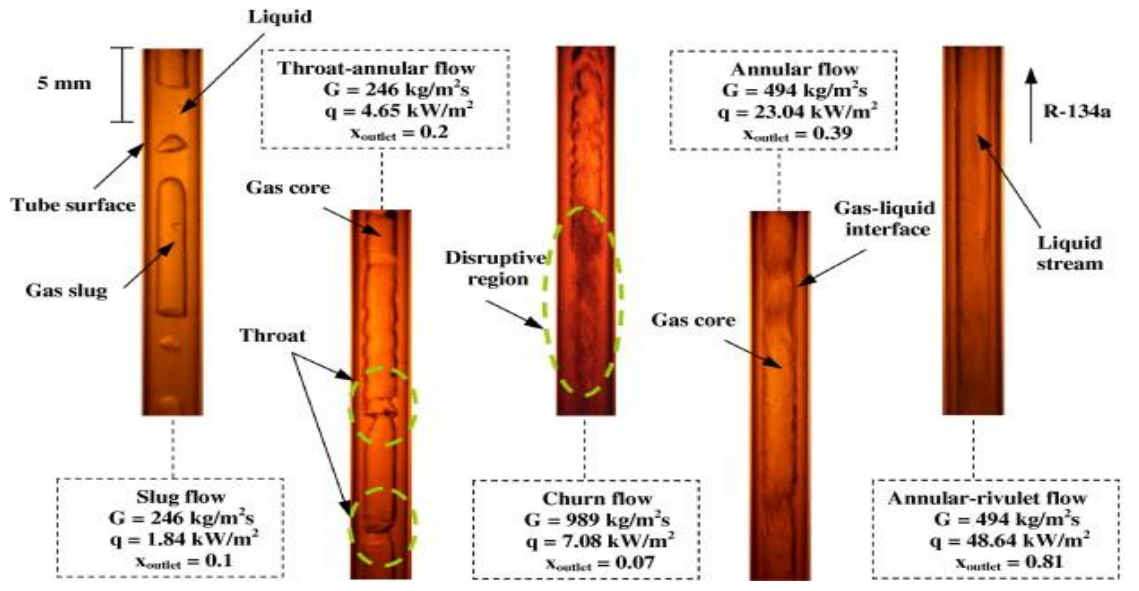

Figure 9. Flow regimes for vertical upward flow [From Sairson et al. [86], with permission from Elsevier.] 

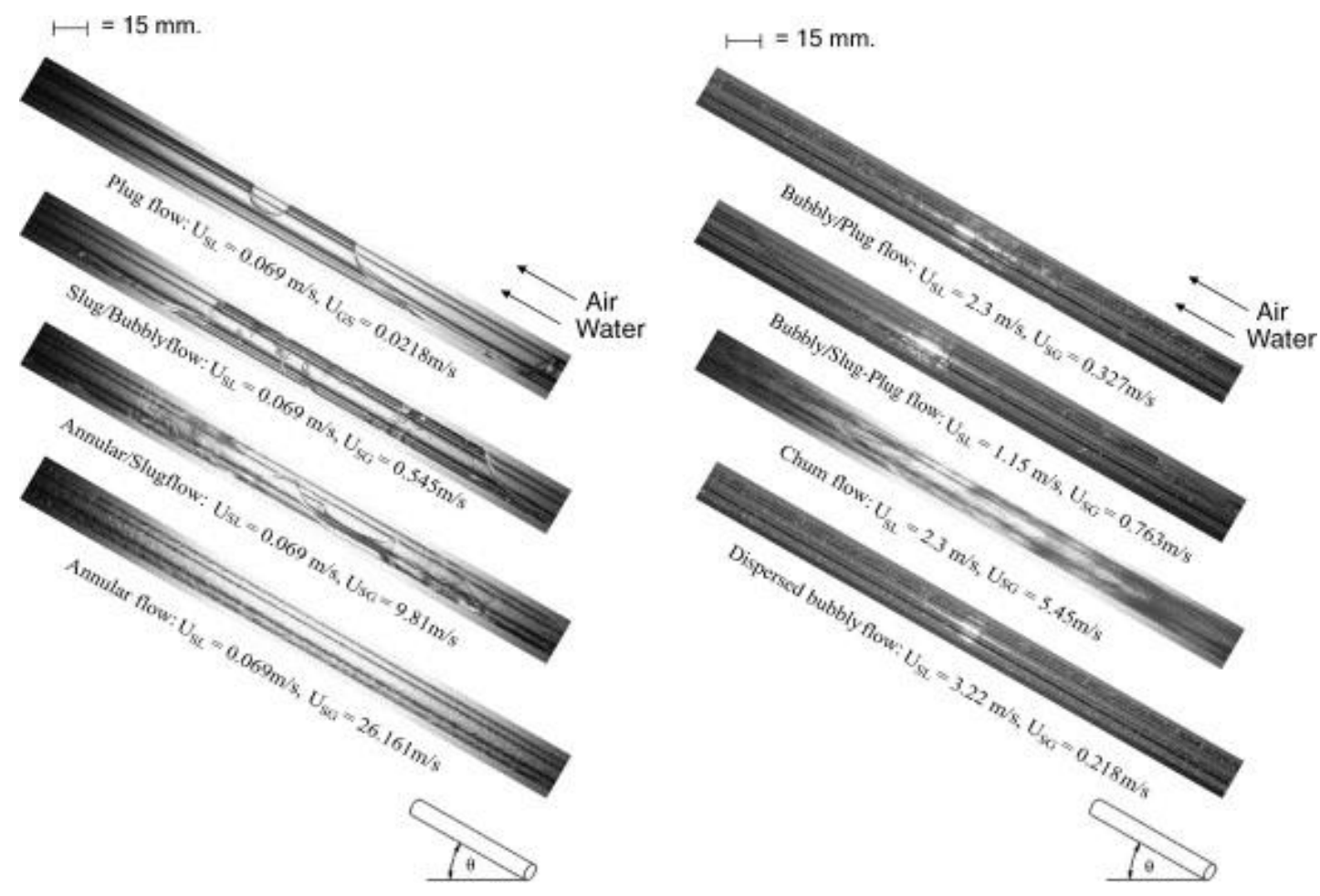

Figure 10. Flow regimes for two-phase flow (for Do $=12.5 \mathrm{~mm}$, Do $=8.0 \mathrm{~mm}, \mathrm{~h}=30$ ) [From Wongwises and Pipathattakul [87], with permission from Elsevier.]

\section{Literature Studies}

Hernández et al. [88] sought to determine the identification of flow regime in boiling two-phase flow in a vertical tube. They focused on boiling heat transfer. The flows were upward and the tubes were vertically oriented. They operated tubes having inner diameters of $19.1 \mathrm{~mm}$ and outer diameters of $38.1 \mathrm{~mm}$. They measured conductivity in nine radial locations for each of the five ports to ascertain the bubble chord length distribution for each flow situation. The calculated practical matrix covered test cases at different inlet pressures, ranged between 200 and $950 \mathrm{kPa}$.

Layssac et al. [89] conducted practical research on heat transfer during R245fa flowing in a $1.6 \mathrm{~mm}$ inner diameter of tube. The investigation segment consisted of a sapphire tube covered with ITO, which enabled the evaporator to be visible. They observed that the nucleate boiling and the convective boiling modes were in competition. The results were approved with the track of the flow in the evaporator. The influence of the orientation on heat transfer was then investigated and it revealed that almost no differences were recorded. This situation was attributed to the effects of the discontinuous tube flow regime transition and the transition from nucleate to flow boiling heat transfer regime.

A set of experiments was run by Krishnamurthy and Peles [90] on the subject of flow boiling heat transfer on a microchannel into which micro-pin fins had been placed. In their test, forced convection boiling of 1-methoxy heptafluoropropane (HFE 7000) in $222 \mu \mathrm{m}$ hydraulic diameter channels containing a row of 24 in-line $100 \mu \mathrm{m}$ pin fins was examined. Flow visualisation showed the presence of isolated bubbles, bubbles interacting, multiple flow and annular flow. In conclusion, the authors compared a plain microchannel with micropin fins entrenched for a thermal performance evaluation, and found that the existence of pin fins clearly enhanced the characteristics of heat transfer.

Zhang et al. [91] experimentally worked on flow boiling of liquid nitrogen in oriented tubes. They also tracked the velocities and length distributions of Taylor bubbles. In their tests, they aimed at reaching a further conclusion on the phenomena of boiling flow of liquid nitrogen in inclined tubes having a closed bottom. In the test, tubes of 0.014 and $0.018 \mathrm{~m}$ inner diameter were used individually both at lengths of $1.0 \mathrm{~m}$. The researchers oriented the tubes at degrees ranging from 0 to $45^{\circ}$ from the horizontal. They used a statistical method to assess the practical data. The impact of the inclination angles on the velocities and the length distributions of the nitrogen Taylor bubbles at different positions through the tubes were analysed. The authors reasoned that the average velocity of nitrogen Taylor bubbles was in rise through the annular channel when the annular channel was oriented 
at $0^{\circ}, 10^{\circ}$ and $20^{\circ}$. On the other hand, when the inclination angle was $30^{\circ}$, it was observed that the velocity grew first, and then descended along the tubes; when the inclination angle was $45^{\circ}$, the velocity diminished along the tubes. At the same x/D location, the velocity of the Taylor bubbles ascended first, and then fell with the increase of $\theta$.

Cornwell and Kew [92] intended to determine the flow regimes of R-113 flow boiling inside parallel rectangular channels. A compact multi-channel plate was used. In the test, they used 75 channels with $1.2 \mathrm{~mm}$ wide $\mathrm{x} 0.9 \mathrm{~mm}$ deep dimensions and 36 channels with $3.25 \mathrm{~mm}$ wide $\mathrm{x} 1.1 \mathrm{~mm}$ deep dimensions with vertical orientation. Mass fluxes varied from $124 \mathrm{~kg} / \mathrm{m}^{2} \mathrm{~s}$ to $627 \mathrm{~kg} / \mathrm{m}^{2} \mathrm{~s}$ as the heat fluxes were between 3 and 33 $\mathrm{kW} / \mathrm{m}^{2}$. The mass fluxes and the mean heat fluxes were controlled and mean heat transfer coefficient was recorded together with the flow regime by use of photographic and high-speed video techniques. They plotted a heat flux and heat transfer coefficient graph showing the results for each zone and each geometry. Also, flow regimes were observed. They observed that the flow was unstable at low flow rates. As a conclusion, they developed new Nusselt number equations for each type of flow.

Kandlikar et al. [93] studied the flow boiling of water and observed the flow using a high-speed video camera. In the test, multi-channel evaporators were made of six parallel channels on which heat flux was applied electrically. They observed typical bubbly flow, annular flow and slug flow as well as nucleation. Moreover, to understand the important fluctuations, visual confirmation of complete flow reversal in some of the channels was made.

Lakshminarasimhan et al. [94] conducted practical research into flow boiling of R-11 in order to observe the location at the beginning of nucleation. The channel used in the test was $20 \mathrm{~mm}$ wide $\times 357 \mathrm{~mm}$ long. The wall of the channel was heated. The nucleation on the front was seen clearly in the laminar flow region. When the turbulent region was seen on the front of the channel due to an increase in the flow rate, onset nucleate boiling could not be determined clearly. However, onset nucleate boiling may have occurred at separate locations.

In conclusion, flow boiling inside horizontally, vertically or otherwise oriented tubes and channels was investigated to determine flow regimes. The fluids which were examined for flow boiling were R245fa, R-11 and R-113 liquid nitrogen HFE 7000. Hernández et al. [88] determined bubble chord length distribution for each flow situations. Layssac et al. [89] researched the effects of discontinuous tube flow pattern transition and nucleation. Krishnamurthy and Peles [90] observed isolated bubbles, bubbles interacting, multiple flow and annular flow. Zhang et al. [91] found that the average velocity of nitrogen Taylor bubbles was in rise through the annular channel when the annular channel was oriented at $0^{\circ}, 10^{\circ}$ and $20^{\circ}$. Cornwell and Kew [92] observed isolated bubbles, confined bubbles and annular flow occurring at the same time. Kandlikar et al. [93] observed typical bubbly flow, slug flow and annular flow as well as nucleation. Lakshminarasimhan et al. [94] aimed to observe the location of the beginning of nucleation.

\section{PRESSURE DROP DETERMINATION BOILING STUDIES Introductory Remarks}

As the pressure drop flow boiling is closely associated with the flow regimes, many researchers have been interested in local pressure drop in well-analysed two-phase flow patterns. Therefore, the prediction of two-phase pressure drop is a principal factor in designing a wide range of applications. The total pressure drop of fluid occurs because of the variation of the kinetic and potential energies as well as the friction at the wall of the flow channel. The total pressure drop can be calculated as:

$$
\Delta P_{\text {Total }}=\Delta P_{\text {static }}+\Delta P_{\text {momentum }}+\Delta P_{\text {frictional }}
$$

The frictional pressure gradient is crucial for the total pressure drop. Two-phase frictional pressure drop is dependent on mixture density, vapour quality and void fraction, velocity of vapour and liquid. It can be seen that total pressure drop is the sum of acceleration, static and frictional pressure drop [95].

\section{Horizontal and Vertical Orientations}

Brutin and Tadrist [96] investigated the pressure drop of forced convection boiling in a mini-channel to determine the effect of the inlet condition on two-phase flow stability. They used a rectangular mini-channel of $0.5 \times 4 \mathrm{~mm}$ cross-section (hydraulic diameter: $889 \mu \mathrm{m}$ ). They investigated two-phase flow pressure drop at several different mass fluxes for a specific heat flux. Steady and unsteady thermo-hydraulic performances were observed. 
Steady and unsteady behaviours were calculated to be a function of the upstream boundary conditions. For the steady state, a pressure loss model was suggested based on a homogeneous assumption.

Zhang et al. [97] did research on two-phase frictional pressure drop and void fraction in mini-channels. They used the separated flow and drift-flux models in their research. They noted that the non-dimensional Laplace constant was a principal parameter to correlate the Chisholm [98] parameter as well as the distribution parameter in mini-channels. In conclusion, they stated that the Dukler [99] correlation, which is based on a homogeneous model, conformed well with adiabatic two-phase flow as well as liquid-vapour flow, while prediction of the flow boiling data was not good. The Mishima-Hibiki [100] correlation also showed best performance when the existing void fraction correlations were reviewed extensively.

Celen et al. [101] researched the forced convection boiling heat transfer and pressure drop tryouts in order to examine augmentation of the micro-fin tube for the heat transfer rate. They compared the results with those of a plain tube. The practical boiling heat transfer coefficient and total pressure drop of R134a boiling inside the micro-fin tube were measured to be 1.9 and 3.0 times higher than for the plain tube for the same fin root diameter respectively. They also found that total pressure drop ascended with an increase in vapour quality, saturation temperature and mass flux. The heat transfer coefficient increased up to 1.9 times owing to an increase in heat transfer area, wetted perimeter and contribution of micro-fins to radial flows in the tube. The results also presented a disadvantageous situation: higher roughness and micro-fins affected the friction factor considerably, hence it was found that the pressure drop increased up to three times in the micro-fin tube.

Tong et al. [102] conducted practical research on pressure drop with highly subcooled forced convection boiling in small-diameter tubes. They experimentally determined the parameters having an important effect on pressure drop in highly subcooled flow boiling. These parameters were mass flux, internal diameter, aspect ratio, inlet temperature and exit pressure. The tube in the test had inner diameters which ranged from 1.05 to $2.44 \mathrm{~mm}$. Other parameters were mass fluxes of 25000 to $45000 \mathrm{~kg} / \mathrm{m}^{2} \mathrm{~s}$, exit pressure was 4 to $16 \mathrm{bar}$ and inlet temperatures ranged from 22 to $66^{\circ} \mathrm{C}$. They concluded that mass flux, tube inner diameter and aspect ratio were the parameters which most affected the pressure drop. In two-phase flow, the pressure drop went up with an increase in mass flux and with a decrease in aspect ratio. According to them, both inlet temperature and exit pressure affected two-phase boiling significantly.

Müller-Steinhagen and Heck [103] investigated pressure drop of flow boiling in tubes and presented a simple pressure drop correlation. Furthermore, they controlled the suggested correlation and 14 other correlations in the literature, which measured 9300 data points for frictional pressure drop for numerous fluids. They observed that the best agreement between predicted and measured values was reached by using the correlation developed by Bandel [104].

Yan et al. [105] conducted a test on the pressure drop of water flow boiling. The test situation was highly subcooled and under high heat and mass fluxes. The tube oriented vertically and had a diameter of $9 \mathrm{~mm}$ and length of $400 \mathrm{~mm}$. Other parameters were 0 to $12.5 \mathrm{MW} / \mathrm{m}^{2}$ for heat fluxes, and 6000 to $10000 \mathrm{~kg} / \mathrm{m}^{2} \mathrm{~s}$ for mass fluxes, 3 to $5 \mathrm{MPa}$ for pressure and 6 to $224^{\circ} \mathrm{C}$ for liquid subcooling. According to their observations, the subcooled boiling pressure drop went up when heat and mass fluxes increased. However, the pressure drop decreased with increasing pressure. They concluded that there was a huge difference between correlations used and the test results because of varying parameters and fluids.

Tran et al. [106] conducted tests experimentally on two-phase pressure drop of fluids flowing in small channels and compared the results with correlations in the literature. By improving these correlations, they suggested a new correlation. R-134a, R-12 and R-113 were used as refrigerants. The pressure drop ranged from 138 to $856 \mathrm{kPa}$ and two different size tubes and one channel were used. One tube had a diameter of $2.46 \mathrm{~mm}$ and the other tube had a diameter of $2.92 \mathrm{~mm}$. The dimensions of the rectangular channel were $4.06 \times 1.7 \mathrm{~mm}$. They used state-of-the-art correlations by employing the R-134a data. As a result, the new correlation was compared with the experimental data for the three fluids and the deviation was found to be $\pm 20 \%$.

Ribatski et al. [107] analysed the practical data for two-phase frictional pressure drop in micro-channels and compared the prediction methods. They obtained the experimental data from the literature. The pressure drop data covered both adiabatic and diabatic conditions with eight fluids. Mass fluxes ranged from 23 to $6000 \mathrm{~kg} / \mathrm{m}^{2} \mathrm{~s}$. They analysed the data and compared the data with 12 two-phase frictional pressure drop prediction correlations. They reported that Müller-Steinhagen and Heck [103] and Mishima and Hibiki [100] presented the best predictions 
besides the homogeneous model. However, the data and correlations showed poor agreement at vapour qualities higher than 0.5 .

Steinke and Kandlikar [108] researched forced convection boiling and pressure drop in micro-channels during laminar flow. An experimental test was conducted and the characteristics of both heat transfer and pressure drop were analysed. Six parallel channels with diameter of $0.207 \mathrm{~mm}$ in which water flowing inside were tested. They found that the adiabatic friction factor calculated was in good agreement within the $\pm 10 \%$ error range.

Yun et al. [109] carried out tests on evaporative heat transfer and pressure drop of R410A in rectangular micro-channels. The channels had hydraulic diameters of 1.36 and $1.44 \mathrm{~mm}$. The saturation temperatures were 0 , 5 and $10{ }^{\circ} \mathrm{C}$ as constant. The mass flux ranged from 200 to $400 \mathrm{~kg} / \mathrm{m}^{2} \mathrm{~s}$ with 10 to $20 \mathrm{~kW} / \mathrm{m}^{2}$ as heat flux. They observed that the correlations in the literature predicted the two-phase pressure drop well. Moreover, the pressure drop of R410A was similar to that in larger-diameter tubes.

The pressure drop of R-134a in a small annular-shaped channel oriented horizontally was researched by Yan and Lin [110]. The pipe was circular and had a diameter of $2.0 \mathrm{~mm}$. They investigated pressure drop characteristics in order to design effective evaporators for cooling systems. They reported that the pressure drop calculated was higher with an increase in the mass rates and heat flux. According to the data obtained, they presented empirical correlations for the friction factors of the evaporation.

Mancin et al. [111] conducted practical research on R134a flowing inside a micro-fin tube, which had a diameter of $3.4 \mathrm{~mm}$. The inside part of the tube was coated with copper and heated electrically. The test was conducted at constant saturation temperature of $30{ }^{\circ} \mathrm{C}$. The mass fluxes were between $190 \mathrm{~kg} / \mathrm{m}^{2} \mathrm{~s}$ and 940 $\mathrm{kg} / \mathrm{m}^{2} \mathrm{~s}$ and heat fluxes were 10,25 and $50 \mathrm{~kW} / \mathrm{m}^{2}$ with the vapour quality between 0.2 and 0.99 . They measured the total pressure drop at $25 \mathrm{~kW} / \mathrm{m}^{2}$ heat flux. At constant mass velocity, they observed that the two-phase frictional pressure drop increased with increasing vapour quality until a certain value of vapour quality. After some point, the two-phase flow friction factor decreased with an increase in vapour quality. Regarding the constant vapour quality, the pressure drop increased with an increase in mass velocity.

Park and Hrnjak [112] experimentally researched the forced convection boiling heat transfer and pressure drop of $\mathrm{CO} 2, \mathrm{R} 410 \mathrm{~A}$ and $\mathrm{R} 22$. The test was conducted at adiabatic conditions and constant wall temperature and at low temperatures in horizontal plain tube, which had a diameter of $6.1 \mathrm{~mm}$. Other parameters were -15 and -30 ${ }^{\circ} \mathrm{C}$ evaporation temperatures and 100 to $400 \mathrm{~kg} / \mathrm{m}^{2}$ s mass flux and heat flux of 5 to $15 \mathrm{~kW} / \mathrm{m}^{2}$; the vapour quality ranged from 0.1 to 0.8 . They calculated various mass fluxes, evaporation temperatures and qualities. According to their calculations, the Müller-Steinhagen and Heck [103] and Friedel [113] correlations predicted the best within the $\pm 30 \%$ error range.

Kuo and Wang [114] experimentally studied forced convection boiling of R22 and R407C. A microfin tube having nominal diameter of $9.52 \mathrm{~mm}$ was used. The researchers investigated two-phase heat transfer coefficient characteristics as well as pressure drop. The test was conducted under the condition of evaporation pressure of $600 \mathrm{kPa}$. It was found that the pressure drop of R407C was 30 to $50 \%$ lower than for R22. They implemented another approach to lessen the two-phase friction data. They produced new parameters: two-phase friction factor $\mathrm{f}_{\mathrm{tp}}$ consisting of a mean two-phase viscosity, $\bar{\mu}$. They also expressed two-phase friction factors consisting of two-phase friction factor $\mathrm{f}_{\mathrm{tp}}$. as shown in Table 15.

Rollmann and Spindler [115] presented new models for boiling heat transfer of R407C and R410A inside horizontal microfin tubes. They also researched pressure drop characteristics. The experiments were carried out at saturation temperatures between -30 and $+10^{\circ} \mathrm{C}$ and heat fluxes between 1000 and $20000 \mathrm{~W} / \mathrm{m}^{2}$. The mass flux ranged from 25 to $300 \mathrm{~kg} / \mathrm{m}^{2} \mathrm{~s}$ and vapour quality was between 0.1 and 1.0. They yielded a correlation for the total pressure drop as shown in Table 15. The mean deviation of the measured values from the experimental ones was $18.1 \%$.

Didi et al. [116] researched the prediction of the boiling pressure drop of refrigerants in horizontal tubes. They aimed to compare the prediction methods in the literature. The authors used the data obtained from Kattan [117], who did tests under the conditions of mass flux between 100 and $500 \mathrm{~kg} / \mathrm{m}^{2} \mathrm{~s}$ and vapour quality between 0.04 and 1.0. The refrigerants of the research were R-134a, R-123, R-402A, R- 404A and R-502 flowing inside two horizontal tubes having diameters of 10.92 and $12.00 \mathrm{~mm}$. The prediction methods of Lockhart and Martinelli [118], Friedel [113], Grönnerud [119], Chisholm [120], Bankoff [121], Chawla [122] and Müller-Steinhagen and Heck [103] were compared. They reported that Müller-Steinhagen and Heck [103] and Grönnerud's [119] methods were the best method for predicting annular flow. Friedel 114's method came third in prediction accuracy. 
In this section, pressure drop of horizontally and vertically oriented tubes as presented in the literature were investigated. Experimental tests were conducted at different mass flow rates, heat fluxes and vapour qualities. The findings were compared with the outcomes of correlations based on the homogeneous model and found to be in good agreement. In the studies, the errors ranged from $\pm 10 \%$ to $\pm 30 \%$.

\section{Smooth Tubes with Inclined Orientation}

Maddi and Rao [123] conducted practical tests on forced convection boiling in tubes inclined in solar collectors. They tested 700 sets of heat transfer coefficients and 900 sets of pressure drop in inclined flow boiling. They reported that the heat transfer and frictional pressure drop in flow boiling were influenced by the angle of inclination in the bubbly and discontinuous flow regimes, while the inclination was marginally affected in the tube flow regime.

Wang et al. [124] investigated the effect of inclination on the flow boiling efficiency of a microchannel heat sink. In the research, HFE-7100 was used as fluid. The heat sink consisted of a multi-port microchannel having a hydraulic diameter of $0.825 \mathrm{~mm}$. The microchannel heat sink was oriented from $-90^{\circ}$ to $+90^{\circ}$. They found that the heat transfer coefficient of the channel oriented vertically was similar to that of the channel oriented horizontally. Comparing the channel oriented $45^{\circ}$ upwards with the other channel inclinations, it was found that the $45^{\circ}$ inclination angle had the highest heat transfer rate.

Jang et al. [125] investigated flow boiling pressure drop of FC-72 in small channel heat sinks. The heat sinks, which were used for cooling of electronic devices, had an inner diameter of $2 \mathrm{~mm}$ and outer diameter of 4 $\mathrm{mm}$ with $100 \mathrm{~mm}$ length. The heat flux was applied to the copper block with the magnitude of 0.5 to $3.0 \mathrm{~W} / \mathrm{cm}^{2}$. They modified the current pressure drop correlations according to data obtained. The homogeneous pressure drop model predicted the pressure drop at $0.9 \%$ for average and $27.0 \%$ for mean deviations, while the average and mean deviations of the original homogeneous model were $-41 \%$ and $49.8 \%$ respectively.

Wongwises and Pipathattakul [87] researched pressure drop of two-phase flow in an inclined channel. The two-phase flow was gas-liquid flow in a narrow annular channel. The research was done experimentally. The round-shaped channel in the test section had an inner diameter of $8 \mathrm{~mm}$ and outer diameter of $12.5 \mathrm{~mm}$. In this test, flow patterns were also observed through a high-speed camera. They observed slug flow regime in the horizontal channel. At low liquid velocity in the horizontal channel, the presence of slug flow slowed down the pressure drop for a short time, then raised the pressure drop after the air velocity increased. According to their observation, with channel orientations at $30^{\circ}$ and $60^{\circ}$, the pressure did not increase suddenly with slug-bubbly flow.

Tshuva et al. [126] conducted a practical test on two-phase flow in inclined parallel tubes. Two-phase flow in parallel tubes was used in the direct steam generation by solar heating. In the test, two pipes were placed parallel and the third one was for control. The pipes had a diameter of $24 \mathrm{~mm}$ and length of $300 \mathrm{~cm}$. The pipes were oriented from $0^{\circ}$ to $90^{\circ}$. They used physical models to calculate the pressure model. Firstly, they determined the flow pattern then the pressure drop was obtained by physical models. They concluded that the symmetric distribution of the two phases yielded less pressure drop than that of all the other combinations of gas and liquid.

In this part of the literature review, the presented degree of tube inclinations ranged from $-90^{\circ}$ to $+90^{\circ}$. Maddi and Rao [123] found that in bubbly and discontinuous flow regimes, the inclination affected the flow regime in an important manner. Wang et al. [124] observed that the results were best at $45^{\circ}$ inclination angle. Jang et al. [125] compared their results with the homogeneous model. According to them, the homogeneous model predicted the pressure drop with average and mean deviations of $0.9 \%$ and $27.0 \%$. Wongwises and Pipathattakul [87] found that slug flow slowed down the pressure drop for a short time, then raised the pressure drop after the air velocity increased. Tshuva et al. [126] concluded that the symmetric distribution of the two phases yielded less pressure drop.

\section{Enhanced Tubes with Inclined Orientation}

An example of the schematic diagram of test apparatus and sketch and real photo of the enhanced tube could be seen in Figure 11 and Figure 12, respectively. 


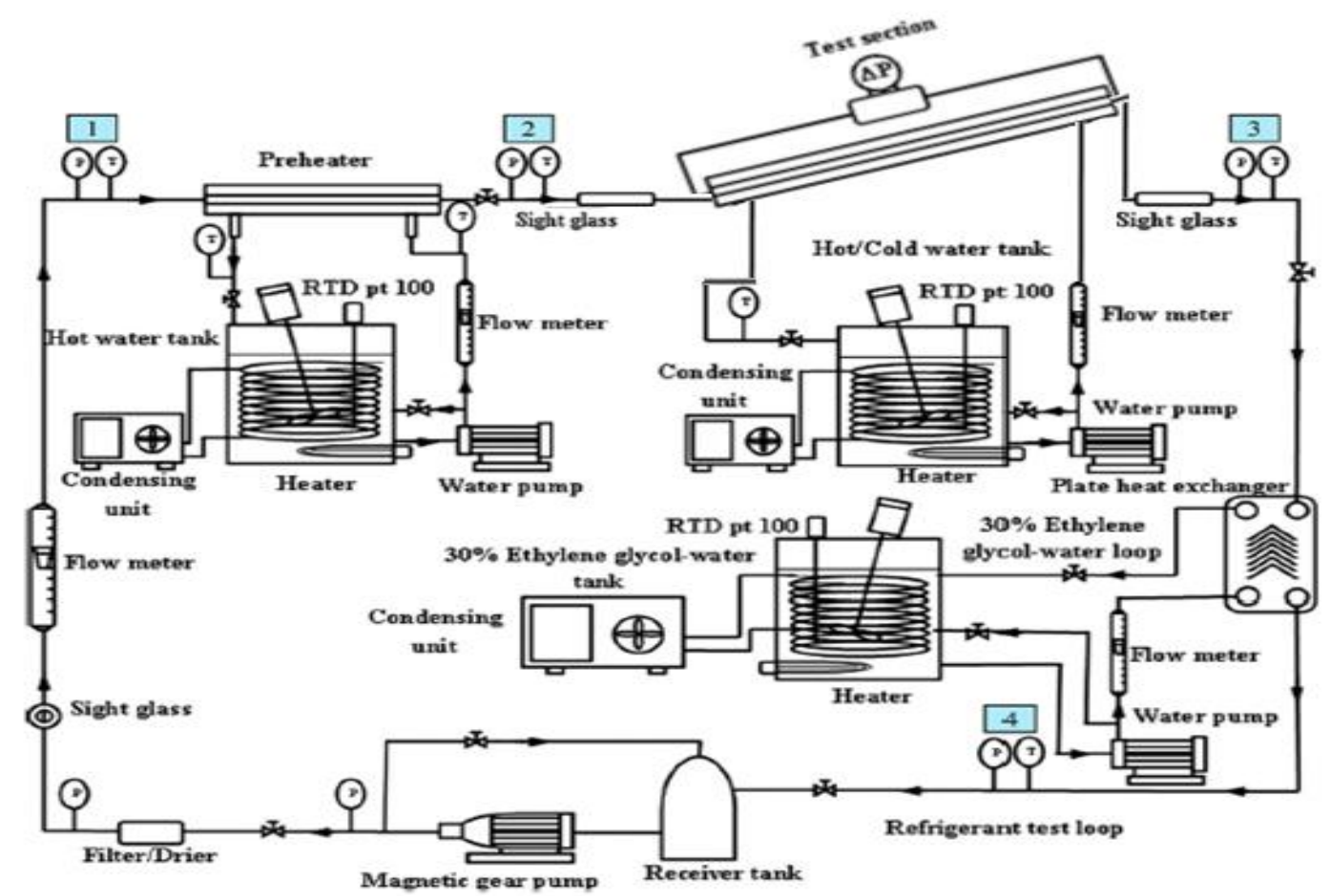

Figure 11. The schematic diagram of the experimental apparatus [Adapted from Laohalertdecha and Wongwises [127], with permission from Elsevier.]

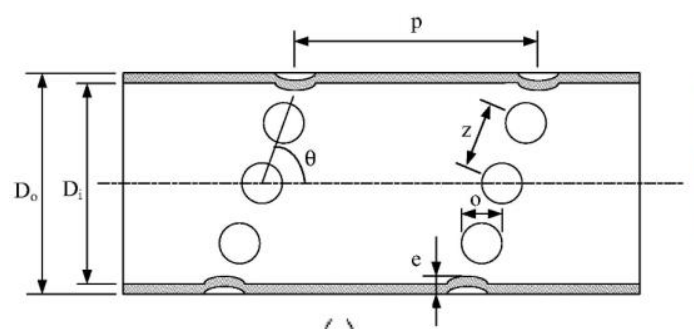

(a)

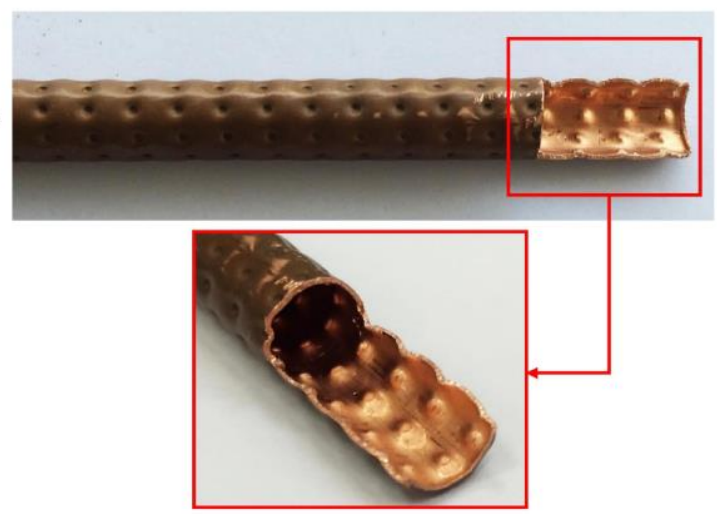

(b)

Figure 12. The sketch (a) and photo (b) of the enhanced tube [From Aroonrat and Wongwises [25], with permission from Elsevier.]

Piasecka [128] investigated the effect of the parameters on forced convection boiling heat transfer and pressure drop in mini-channels. The mini-channels were rectangular shaped with measurements $1 \times 40 \times 360 \mathrm{~mm}$. The fluid flowing inside the channel was Fluorinert FC-72. The test region was heated by a micro-structured foil. The researcher measured the local values of heat transfer coefficient and the pressure drop for different positions of the mini-channel. The data for the flow boiling pressure drop were compared with the values calculated by using nine correlations from the literature. The researcher found that most of the correlations could be used to determine the two-phase pressure gradient within a small error range $( \pm 30 \%)$ of between $90^{\circ}$ and $-45^{\circ}$. The worst compatible situation happened for the horizontally oriented.

Piasecka [128] researched flow boiling of Fluorinert FC-72 inside a foil microstructure. According to him, the correlations could be used to determine the two-phase pressure drop gradient within a small error range $( \pm 30 \%)$ between $90^{\circ}$ and $-45^{\circ}$. 


\section{HEAT TRANSFER COEFFICIENT DETERMINATION BOILING STUDIES Introductory Remarks}

Flow boiling in channels is dominated by two phenomena: convective boiling and nucleate boiling. There has been a debate on which effect is dominant in flow boiling, while many boiling correlations have been proposed for determining the characterictics of heat transfer and pressure drop. Nonetheless, it is generally accepted that at high heat fluxes or low qualities, nucleate boiling is more dominant than convective boiling [129]. An example of the experimental apparatus and cross-section of the enhanced tube could be seen in Figure 13.

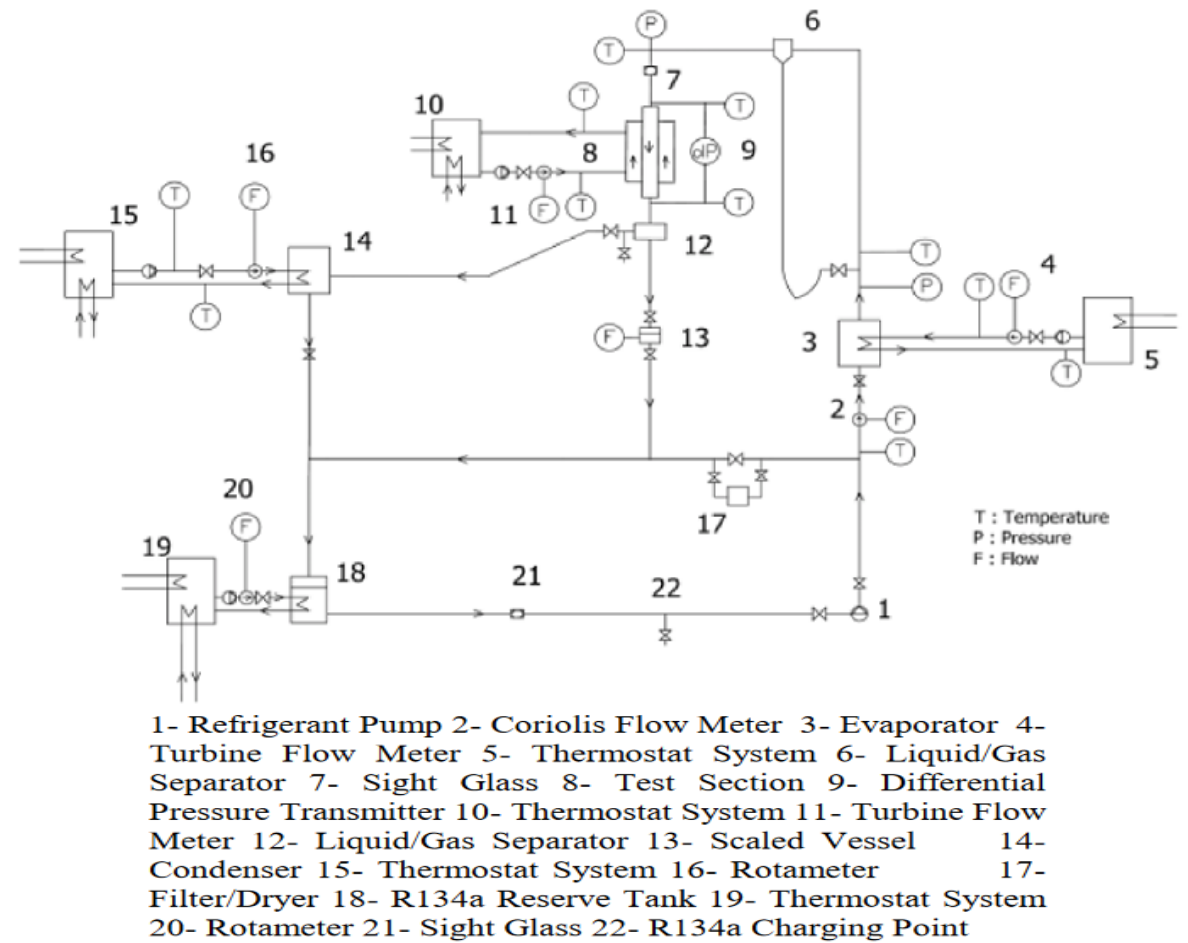

(a)

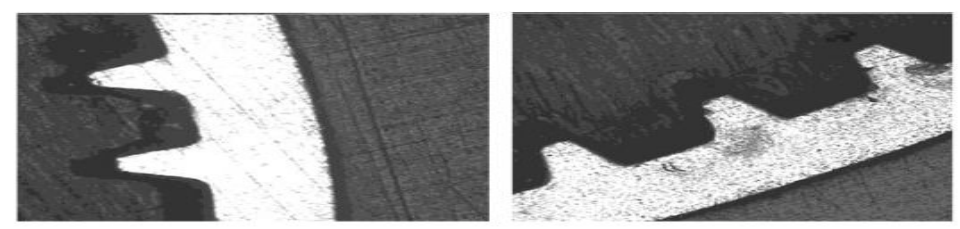

(b)

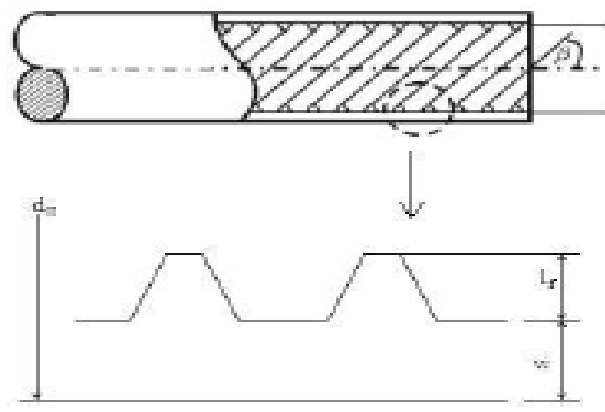

(c)

Figure 13. (a) The experimental apparatus (b) Cross-section of the micro-fin tube (c) Schematic photo of the micro-fin tube. [From Dalkılıç et al. [130], with permission from Journal of Thermal Science and Technology]

The local heat transfer coefficient can be calculated based on the heat gained by fluids inside an evaporator and the temperature difference between the inside wall of the test evaporator and boiling refrigerant. It can be shown as follows:

$$
h=\left[\frac{\pi D L\left(T_{w o}-T_{S}\right)}{Q}-\frac{D}{2 k} \ln \left(\frac{D_{o}}{D}\right)\right]^{-1}
$$


The outside-tube-wall temperature, $T_{\text {wo }}$, was taken as the arithmetic mean of outside-tube-wall temperatures at top, two sides and bottom positions [131].

It is also important to identify the channels according to sizes. The researcher [132] classified the channels according to hydraulic diameters as follows:

- Classical channels $\rightarrow 3 \mathrm{~mm}$

- Mini-channels $-200 \mu \mathrm{m}$ to $3 \mathrm{~mm}$

- Micro-channels -10 to $200 \mu \mathrm{m}$

\section{Horizontal and Vertical Orientations}

By the time Gungor et al.'s [133] proposed correlation on flow boiling in single-tube and two-pipe tubes, there were almost no general correlations in the literature covering both subcooled and saturated boiling. All of them, focused only subcooled boiling or saturated boiling separately. So Gungor et al.'s [133] correlations could be seen as a leading work. In the study, they used a wide range of data, 4300 data points with seven fluids and 28 authors. They started off developing the correlations with the widely-used equation below,

$$
h_{t P}=E h_{1}+S h_{\text {pool }}
$$

In this equation, the term $h_{1}$ are calculated by Dittus-Bolter equation, which is presented below,

$$
h_{1}=0.023 \operatorname{Re}_{l}^{0.8} \mathrm{Pr}_{l}^{0.4} k_{l} / d
$$

But this equation couldn't be able to use for two-phase flow since it was only suitable for liquid flows. Because the two-phase flow includes higher velocities and void fraction, it needed to increase the heat transfer by a factor. The factor was defined as Enhancement Factor. Then Gungor et al. [133] defined the enhancement factor as a function of Boiling Number and Martinelli Parameter in order to making it suitable for two-phase flow.

$$
E=f\left(X_{t t}, B o\right)
$$

As the superheated liquid forms a boundary layer, the heat transfer coefficient must be lowered by a factor. This factor are called suppression factor $\mathrm{S}$ and are involved in the Equation (6) as second term. Gungor et al. [133] used the two-phase Reynolds number that had a impact on the extent of suppression. As suggested before, they used the two-phase Reynolds number in the form below,

$$
R e_{t p}=E^{n} R e_{l}
$$

After these important definitions, they combined the other necessary factors and equations and came to the final equations below for saturated boiling

$$
\begin{gathered}
E=1+24000 B o^{1.16}+1.37\left(1 / X_{t t}\right)^{0.86} \\
S=\frac{1}{1+1.15 \times 10^{-6} E^{2} R e_{l}^{1.17}}
\end{gathered}
$$

Then the heat transfer coefficient could be calculated by using the two factors above in the equations. They used the expression suggested by Cooper [134] for the term $h_{\text {pool }}$ as shown below,

$$
h_{\text {pool }}=55 P_{r}^{0.12}\left(-\log _{10} P_{r}\right)^{-0.55} M^{-0.5} q^{0.67}
$$

Boiling in Annuli

$$
\begin{aligned}
& d_{e}=\frac{4 \times \text { flow area }}{\text { wetted perimeter }} \quad \text { for gap }>4 \mathrm{~mm} \\
& d_{e}=\frac{4 \times \text { flow area }}{\text { heated perimeter }} \quad \text { for gap }<4 \mathrm{~mm}
\end{aligned}
$$

where $d_{e}$ refers to equivalent diameter. 


\section{Subcooled Boiling}

They used the equation below instead of the Equation (6) because there were differences at temperatures of nucleate boiling and forced boiling. Also, there was almost no vapor, the enhancement factor should have been removed.

$$
q=h_{1}\left(T_{w}-T_{b}\right)+S h_{\text {pool }}\left(T_{w}-T_{s}\right)
$$

After comparing the measured heat two-phase heat transfer coefficients with calculated ones by using their suggested new equations, they concluded that they found the mean deviations were $21.4 \%$ for saturated boiling and $25.0 \%$ for subcooled boiling.

Özdemir [135] researched single-phase flow and forced convection boiling of water in metallic microchannels. He scrutinised the characteristics of the single-phase flow and flow boiling heat transfer. Four oxygenfree copper test sections were operated throughout the experiments. Three microchannel test sections, which had the same length $(\mathrm{L}=62 \mathrm{~mm})$ and hydraulic diameter $\left(\mathrm{D}_{\mathrm{h}}=0.561 \mathrm{~mm}\right)$ but different aspect ratios $(\beta=0.5,2.56$ and 4.94), were investigated to determine the influence of channel aspect ratio on single-phase flow and flow boiling. Furthermore, a longer test section $\left(D_{h}=0.561 \mathrm{~mm}, \mathrm{~L}=86.8 \mathrm{~mm}\right.$ and $\left.\beta=2.56\right)$ was examined in order to display the effect of channel heated length. The influences of heat flux were evident on boiling curves, while the effect of the mass rates on the boiling curves was insignificant. The heat transfer coefficient increased with increasing heat flux and was not dependent on the local vapour quality at low and medium heat fluxes. However, the heat flux had no impact on the heat transfer coefficient at high heat fluxes. The heat transfer coefficient diminished when the mass flux increased owing to the high pressure drop.

Lazarek and Black [136] conducted tests on the evaporative heat transfer of a small vertical tube carrying R-113. Also, pressure drop and critical heat flux were reviewed. In the tests, an annular channel was employed. The tube had an internal diameter of $0.031 \mathrm{~mm}$. The experiments consisted of vertical, co-current upflow and downflow configurations. The authors presented an equation for the local heat transfer coefficient and the Nusselt number consisting of liquid Reynolds number and boiling number. According to the researchers, the subcooled and saturated boiling sections of the boiling curve were very reproducible throughout the tests. Initial nucleation, for example, took place at different combinations of increasing heat flux for the inlet and discharge tubes.

$\mathrm{Li}$ and $\mathrm{Wu}$ [137] experimentally investigated the characteristics of saturated flow boiling heat transfer for both multi- and single-channels in micro- and mini-channels. The authors employed 3700 data points, including numerous working fluids, operational conditions and different diameters of microchannel. The complete record was assessed by means of various extant correlations to prove their relevant accuracies. However, no extant correlation could define the data set exactly. A general correlation consisting of Reynolds number, boiling number and Bond number was given for boiling heat transfer in micro- and mini-channels.

Ong and Thome [2] conducted experimental research on flow boiling of R134a, R236fa and R245fa in a horizontally oriented $1.030 \mathrm{~mm}$ tube in order to find true flow boiling heat transfer outcomes. The researchers analysed the boiling phenomena for mass fluxes varying between 200 and $1600 \mathrm{~kg} / \mathrm{m}^{2} \mathrm{~s}$, heat fluxes between 2.3 $\mathrm{kW} / \mathrm{m}^{2}$ and $250 \mathrm{~kW} / \mathrm{m}^{2}$ at $\mathrm{T}_{\text {sat }}=31{ }^{\circ} \mathrm{C}$ and $\Delta \mathrm{T}_{\text {sub }}$ from 2 to $9 \mathrm{~K}$. They deduced that the heat transfer coefficients of R134a and R236fa increased with the rise in heat flux for numerous qualities at low mass fluxes. Furthermore, they observed that the fluid characteristics significantly affected the heat transfer characteristics of the fluid.

Candan et al. [138] experimentally investigated flow boiling heat transfer in mini-channels. In their measurements, they employed five single-channel heat sinks which had the same hydraulic diameter but with different width and depth. In order to perceive the boiling mechanism meticulously, flow visualisation tests were conducted. Also, temperature and pressure measurements were taken. They acquired the influences of different values of the mass flux, vapour quality, heat flux and aspect ratio (ratio of width to depth) on heat transfer coefficient and pressure drop. They also gained the optimum value of the aspect ratio for a broad range of working parameters. It was found that two-phase flow local heat transfer coefficient did not ascend or descend monotonically according to the aspect ratio. On the whole, the best performance for heat transfer was enabled when AR was equal to 1 with the worst performance when the aspect ratio equaled 0.25 . The heat transfer coefficient increased with increment in heat flux, mass flux and vapour quality. The authors compared their study with that of Markal et al. [139] and found that in contrast with the Markal et al. [139] study, in their own study, nucleate boiling was dominant because the heat transfer mechanism and flow patterns in micro-channels were clearly different. They noted that the cause of the differences was the effects of restrictions. They also concluded 
that the heat transfer coefficient increased with an increase in the heat flux, mass flux, and the local vapor quality. The total pressure drop increased with increasing heat flux, mass flux and vapour quality.

Markal et al. [140] conducted tests on flow boiling in micro-channels. They measured pressure, temperature, flow rate and heat fluxes and detailed flow visualisation using a high-speed camera. They did the tests under different geometrical dimensions, various mass and heat fluxes. They investigated the influences of mass flux, vapour quality, aspect ratio (ratio of width to length), hydraulic diameter and heat flux on the two-phase heat transfer coefficient and total pressure drop. The authors ascertained the heat transfer coefficients by applying obtained values and existing correlations. They also derived a novel correlation. They found that flow boiling in micro-channels had unique characteristics according to the experimental study and flow visualisation, and hence the characteristics of micro-channels differed from those of macro-channels. Moreover, when flow patterns were visualised, the authors noted that the main flow patterns were extended bubble flow and annular flow, adding that the dominant heat transfer mechanism was convective boiling and aspect ratio and hydraulic diameter parameters impacted flow and heat transfer characteristics

Nedaei [141] researched subcooled flow boiling in enhanced micro-channels. The researcher also made modifications on surface characteristics. The test consisted of two parts. In the first part, the researcher covered the inner wall of the stainless steel micro-tubes with polyhydroxyethylmethacrylate (pHEMA)/polyperfluorodecylacrylate (pPFDA) by means of applying an initiated chemical vapour deposition (iCVD) method in order to examine the wettability along the surface. The outcomes of the work were contrasted with those of a bare tube surface. In conclusion, pertaining to the first part of the study, the researcher found subcooled boiling heat transfer to be remarkably increasing with covering, as the highest heat transfer coefficient to arise when the pHEMA was coated with a $64 \%$ increase in heat transfer. In the second part of the study, a horizontal aluminum microchannel having a length of $14 \mathrm{~cm}$, width of $1.5 \mathrm{~cm}$ and depth of $500 \mu$ was taken into account. Subcooled boiling heat transfer was reviewed. The tests were run for the different fluxes of 70, 100 and $125 \mathrm{kWm}^{-2}$. The researcher concluded that plates sanded with grit sizes of 400 and 1000 improved heat transfer coefficient.

Kandlikar [142] presented a general correlation for two-phase flow boiling heat transfer in vertical and horizontal annular channels. The author suggested a simple correlation to find saturated flow boiling heat transfer coefficients for horizontal and vertical tubes. It was in accordance with a model benefitting the contributions owing to nucleate boiling and convective mechanism. The correlation given accounted for both these cases.

Passos et al. [143] implemented convective boiling measurements of R- 407c. In their tests, refrigerant R- 407c flowed inside horizontal tubes. The tests were realised for two types of tubes, microfin having an outside diameter of $12.7 \mathrm{~mm}$ and smooth tubes having outside diameters of $7 \mathrm{~mm}$. Practical outcomes on the nucleate and flow boiling of R-407c were gained. The data were obtained for heat fluxes at 10 and $20 \mathrm{kWm}^{-2}$. The results obtained are summarised as follows: for tubes having outside diameter of $7 \mathrm{~mm}$, the heat transfer coefficient for the micro-fin tubes was found to be greater (100\%) than that of the smooth ones and the enhancement was larger than the rise in the heat transfer surface area of the microfin tubes with a surface factor of 1.46.

Dalkılıç et al. [144] conducted practical research on the flow boiling of R134 in a microchannel heat sink. They employed rectangular micro-channels as heat sinks. The channel in the test was made of copper and had a width of $0.382 \mathrm{~mm}$ and a depth of $0.407 \mathrm{~mm}$ as well as a fin thickness of $0.416 \mathrm{~mm}$. Total of 27 parallel rectangular micro-channels in heat sinks were operated. In these measurements, the inlet saturation temperatures of fluid were constant at $18{ }^{\circ} \mathrm{C}, 23{ }^{\circ} \mathrm{C}$ and $28{ }^{\circ} \mathrm{C}$. The mass fluxes were altered from $800 \mathrm{~kg} / \mathrm{m}^{2} s$ to $1200 \mathrm{~kg} / \mathrm{m}^{2} \mathrm{~s}$. In each test, they launched the heat flux at the wall as $50 \mathrm{~kW} / \mathrm{m}^{2}$ and increased it to reach the critical heat flux. Throughout the tests, the vapour quality at the entrance of the micro-channels was kept constant. They concluded that at low vapour quality, the heat transfer coefficient notably went up with increment in heat flux. Moreover, the mass flux was seen to have almost no effect. The authors added that with an increase in heat flux, convective boiling increased more than nucleate boiling. After this transition, the heat transfer coefficient was found to increase with the rise in vapour quality and mass flux until dryout point. It was observed that the heat transfer coefficient ascended with increase in saturation temperatures for all conditions.

Özdemir et al. [145] conducted a practical study of single-phase and boiling flow in micro-channels. The researchers did their work at high flow rates. They divided the test into two parts. In the first part, fluid flow was examined within a wide range of mass velocities with different inner diameters in micro-channels. They employed deionised water as working fluid. The wall temperatures and pressure drop were measured. As a result, the heat transfer coefficient was acquired. Afterwards, they calculated Nusselt numbers and friction factors by executing 
the obtained parameters. The results were consistent with the existing theory, which was for flows in microscale and under both laminar and turbulent behaviour. In the second part of their study, boiling heat transfer characteristics were examined in the identical microchannel conditions. For this part, they deduced that high heat removal could be enabled at high flow rates for subcooled boiling situations. In addition to this, they determined that heat transfer coefficients increased with rising mass velocities while falling with heat flux. They concluded their study by comparing the experimental outcomes with extant partial boiling correlations in the relevant literature, and fully developed flow correlations.

Wambsganss et al. [146] presented the results of their research on boiling heat transfer of R-113 in a horizontal small-diameter tube of $2.92 \mathrm{~mm}$ diameter. Local heat transfer coefficients were calculated for a range of heat flux $\left(8.8-90.75 \mathrm{~kW} / \mathrm{m}^{2}\right)$. Mass flux varied between 50 and $300 \mathrm{~kg} / \mathrm{m}^{2} \mathrm{~s}$ and equilibrium mass quality was between 0 and 0.9 . They developed 10 different heat transfer correlations by using the experimental results of local heat transfer coefficients. The researchers observed that small channels showed a slug flow pattern for a variety of parameters compared with higher-diameter channels. Having occurred high boiling number and slug flow pattern brought about a domination by nucleation mechanism. They observed that the two-phase correlations agreed well when the physical parameters were modelled properly. They concluded that the results were strong functions of heat flux and only slightly dependent on mass rates. They reported that the values they calculated in their study complied with the measured values of Reid et al. [147] at relatively high boiling numbers and dominant flow of nucleation in large regions.

The findings by Tran et al. [148] in determining the dependency of the heat transfer coefficient in boiling were surprising. They noted that the heat transfer coefficients were influenced by heat flux only. These results were uncommon. The mass flux had reportedly no effect on the heat transfer coefficient. These findings were supported by Kasza et al. [149], who researched the flow boiling of water in rectangular channels with $2.5 \mathrm{~mm} \mathrm{x}$ $6 \mathrm{~mm}$ dimensions. They found that high heat transfer coefficient in mini- channels occurred thanks to an increase in bubble activity in thin liquid film

Shiferaw et al. [150] conducted experimental research on flow boiling of R134a. R134a flowed in a tube of $1.1 \mathrm{~mm}$ internal diameter. They also presented a three-zone flow model. In the test, the mass flow rate was between 100 and $600 \mathrm{~kg} / \mathrm{m}^{2} \mathrm{~s}$ and pressure was between 6 and 12 bar and heat flux was 16 and $150 \mathrm{~kW} / \mathrm{m}^{2}$. For low heat and mass flux when the quality was below $50 \%$, the heat transfer coefficient was dependent on heat flux and pressure because it was independent of the vapour quality and the effect of mass flux was negligible. They noted that the three-zone evaporation agreed fairly well with the experimental results. Though the dryout region was observed at high quality, it was quite higher than the model predicted.

Ravigururajan et al. [151] tested the flow boiling of R-124 in micro-channels which had $0.27 \mathrm{~mm} \times 11$ $\mathrm{mm}$ cross-section. They observed that an increase in quality led to a decrease in heat transfer coefficient, which fell from $11 \mathrm{~kW} / \mathrm{m}^{2}{ }^{\circ} \mathrm{C}$ at $\mathrm{x}=0.01$ to $8 \mathrm{~kW} / \mathrm{m}^{2}{ }^{\circ} \mathrm{C}$ at $\mathrm{x}=0.65$. These results indicated that the higher vapour fraction caused flow oscillations in multi-channels and increased the heat transfer coefficient.

In and Jeong [1] have made experimental investigation in order to search characteristics of flow boiling inside micro tubes having $1.9 \mathrm{~mm}$ inner diameter. R123 and R134a were used as fluid in their tests. Heat fluxes and mass velocities were $10,15,20 \mathrm{~kW} / \mathrm{m}^{2}$ and $314,392,470 \mathrm{~kg} / \mathrm{m}^{2} \mathrm{~s}$ respectively while vapor qualities ranged from 0.2 to 0.85 and different saturation pressures $(158,208 \mathrm{kPa}$ for R123; 900, $1100 \mathrm{kPa}$ for R134a). They found that the suppression of nucleate boiling at low vapor quality determines the heat transfer tendency and mechanism in the flow boiling of micro channels.

The reviewed heat transfer determination studies were summarised in this section. Flow boiling of R-124, R134a, R-113, R134, R- 407c, R236fa, R245fa and water inside horizontal and vertical tubes was investigated in the condition of subcooled and saturated flow boiling. The studies were conducted at different mass fluxes, heat flux rates and qualities. Shiferaw et al. [150] found that the heat transfer coefficient was dependent on heat flux and pressure, while it was independent of the vapour quality. Tran et al. [148] noted that heat transfer coefficients were affected by heat flux only. Wambsganss et al. [146] concluded that the results were strong functions of heat flux and only weakly dependent on mass rates. Özdemir [145] deduced that high heat removal could be enabled at high flow rates for subcooled boiling situations. Dalkılıç et al. [144] found that the heat transfer coefficient notably went up with increment in heat flux at low vapour quality. Passos et al. [143] found that for tubes having an outside diameter of $7 \mathrm{~mm}$, the heat transfer coefficient for the micro-fin tubes was calculated as greater (100 $\%)$ than for the plain tubes. 


\section{Smooth Tubes with Inclined Orientation}

Kundu et al. [152] investigated the influences of mass fluxes, heat fluxes and tube inclination angles on the boiling heat transfer coefficient. In their experimental test, refrigerant R407C was boiling flowing through a plain tube with $7.0 \mathrm{~mm}$ hydraulic diameter at different tube inclinations. They proposed new correlations. The tests involved five different tube inclination angles which varied from $0^{\circ}$ to $90^{\circ}$ of the direction of the refrigerant flow. The test indicated that the heat transfer coefficient increased with an increase in mass velocity and heat flux. The angle of tube inclination had a substantial influence on the flow boiling heat transfer coefficient of R407C. The highest heat transfer coefficient of $90^{\circ}$ was achieved in the route of fluid flow for all mass velocities. It was found that the error range of the proposed new correlations was $\pm 20 \%$ and $-3.68 \%$ of MPE, an MAE of 10.44 $\%$ and an RMSE of $12.68 \%$.

Kundu et al. [153] conducted a practical test to determine the characteristics of flow boiling heat transfer of R134a and R407C in a plain tube at different inclinations. They conducted a practical analysis of using R134a and $\mathrm{R} 407 \mathrm{C}$ in a smooth copper tube. Tubes had inclination angles ranging between $0^{\circ}$ and $90^{\circ}$ for five different angles. The practical data were attained for a mass velocity ranging from 100 to $300 \mathrm{~kg} / \mathrm{m}^{2} \mathrm{~s}$, heat flux range of 3 to $10 \mathrm{~kW} / \mathrm{m}^{2}$ with inlet temperature of 5 to $9^{\circ} \mathrm{C}$ and vapour quality ranging from 0.1 to 0.9 . The tube length tested was $1.2 \mathrm{~m}$, the plain tube which was made of copper had an inner diameter of $7.0 \mathrm{~mm}$ and outside diameter of 9.52 $\mathrm{mm}$.

Gang et al. [154] researched forced convection heat transfer characteristics of inclined tubes. Tests were carried out to study the flow boiling heat transfer of water in an inclined upward tube oriented at $20^{\circ}$. The other conditions were that the tube had an inner diameter of $26 \mathrm{~mm}$. They found that the dissipation of heat transfer characteristics through the circumference of the inclined tube was non-uniform. The wall temperature was in decrease, and therefore, the heat transfer coefficient increased with an increase in circumferential angle.

Morcos et al. [155] experimentally examined boiling heat transfer in rectangular channels. The channels were oriented horizontally as well as inclined. They conducted the test under a relatively low heat flux. The test facility included aluminum rectangular channels, which were electrically heated and had aspect ratios of 2.67 and 0.37 . The practical consequences of the two-phase Nusselt number for the two aspect ratios and for the inclination angles of 0, 15, 30 and 45 degrees were correlated with a ratio of the two-phase to the liquid-phase Reynolds number for the forced convection vaporisation region. The test outcomes revealed that $\mathrm{Nu}_{\mathrm{TP}}$ for a given aspect ratio and inclination angle depended not only on $\mathrm{Re}_{\mathrm{TP}}$ but also on the mass velocity $\mathrm{G}$. For the given values of $\mathrm{Re}_{\mathrm{TP}}$ and $\mathrm{G}$, increasing the aspect ratio led to an increase in $\mathrm{Nu}_{\mathrm{TP}}$. Furthermore, the optimal value of the inclination angle which yielded the maximum value of $\mathrm{Nu}_{\mathrm{TP}}$ was calculated the same at $30^{\circ}$. In the flow boiling region, the practical consequences of $\mathrm{Nu}_{\mathrm{TP}}$ for horizontal and inclined channels were very well correlated using a ratio of $\mathrm{Re}_{\mathrm{TP}}$ to $\mathrm{Re}_{1}$. They found that the correlations fairly complied with the practical data of previous investigations.

Wang et al. [156] conducted practical research into the characteristics of heat transfer of water flowing inside an inclined downward tube. Tests were run through a supercritical pressure CFB boiler. The tube in the test was oriented at $45^{\circ}$ from the horizon with an inner diameter of $20 \mathrm{~mm}$. The tests were conducted in the following conditions: heat flux from 50 to $585 \mathrm{~kW} / \mathrm{m}^{2}$, pressure from 11.5 to $28 \mathrm{MPa}$, mass flux from 450 to $1550 \mathrm{~kg} / \mathrm{m}^{2} \mathrm{~s}$. It was shown that the heat transfer characteristics of water in the inclined downward tube were not uniform along the circumference from the top surface to the bottom surface. When the heat flux increased, non-uniformity increased. When pressures were diminished under subcritical conditions, both dryout and departure from nucleate boiling (DNB) occurred at the top surface of the tube. Conversely, dryout was only observed on the bottom surface of the tube and in the vertical downward tube.

Jeong and Kim [157] investigated the subcooled boiling impact of an inclined downward-facing surface. In the work, the channel was settled to be $10^{\circ}$ upwards from the horizon. The researchers employed a copper block as a test heater, which was placed above the flow channel to simulate the passive cooling system of an ex-vessel core catcher designed for nuclear power plants. Low mass flux and subcooled boiling conditions ranged between 40 and $300 \mathrm{~kg} / \mathrm{m}^{2} \mathrm{~s}$ and 5 to $25 \mathrm{~K}$ respectively. A slight dependence of critical heat flux on the subcooling was seen with the conditions up to subcooling of $15 \mathrm{~K}$.

This section reviewed research on oriented smooth tubes and channels to determine heat transfer rates. Kundu et al. [152] found the highest heat transfer rate at $90^{\circ}$ in the route of fluid flow for all mass velocities. Gang et al. [154] noted that the heat transfer coefficient increased with increasing circumferential angle. Morcos et al. [155] concluded that the correlations were in fair compliance with the practical data of previous investigators. 
Wang et al. [156] found that the heat transfer characteristics of water in an inclined downward tube were not uniform along the circumference from the top surface to the bottom surface. Jeong and Kim [157] found a slight dependence of critical heat flux on the subcooling with the conditions up to subcooling of $15 \mathrm{~K}$.

\section{Enhanced Tubes with Inclined Orientation}

An example of the experimental apparatus of flow boiling inside inclined boiling and photo of the enhanced tube could be seen in Figure 11 and Figure 12 (a) and (b) respectively.

Akhavan-Behabadi et al. [131] experimentally conducted tests on evaporative heat transfer of R-134a boiling inside a microfin tube. The tube in the test could be oriented at different angles. They divided the angle $\alpha$, in a range of $-90^{\circ}$ to $+90^{\circ}$ into seven different angles from the horizontal. They found that the tube inclination angle, $\alpha$, affected the boiling heat transfer coefficient hugely. For all working fluid mass velocities, the highest heat transfer rates were achieved for an inclination angle of $a=+90^{\circ}$. The influence of tube inclination angle, $\alpha$, on heat transfer coefficient, h, was more noticeable at low vapour quality as well as at mass velocity. An experimental correlation was obtained to predict the heat transfer coefficient for flow boiling inside the tube.

Akhavan-Behabadi et al. [131] concluded that the tube inclination angle had a strong effect on the heat transfer coefficient. Moreover, for all mass fluxes, the highest heat transfer rates were obtained at $+90^{\circ}$ inclination angle.

\section{ADVANTAGES OF USING INCLINED TUBES}

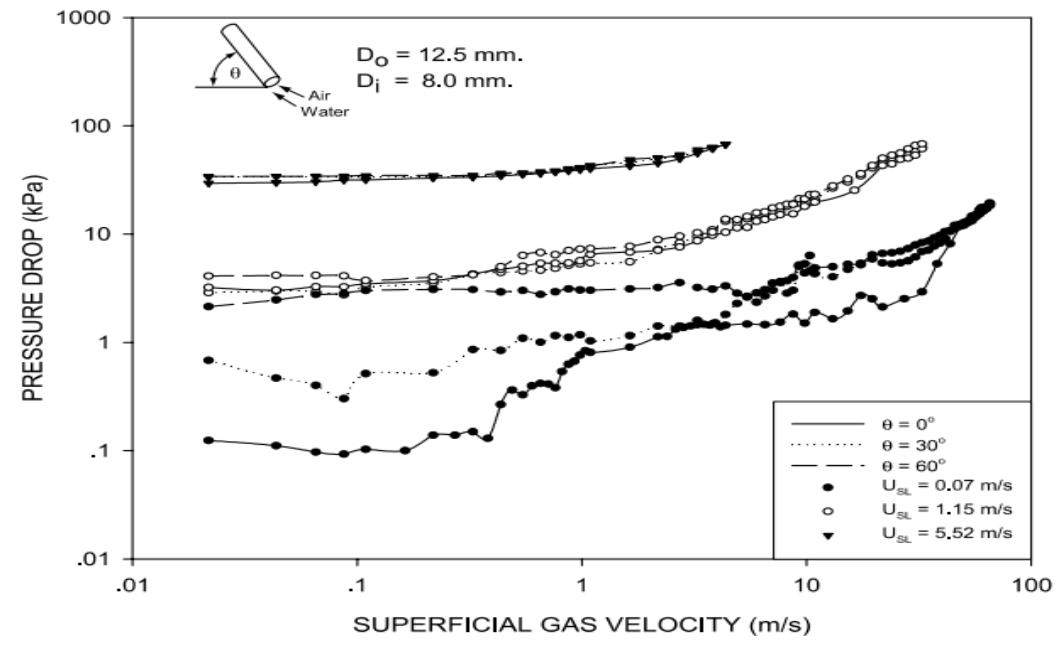

Figure 14. Pressure drop-superficial vapor velocity relationship [From Wongwises and Pipathattakul [87], with permission from Elsevier.]

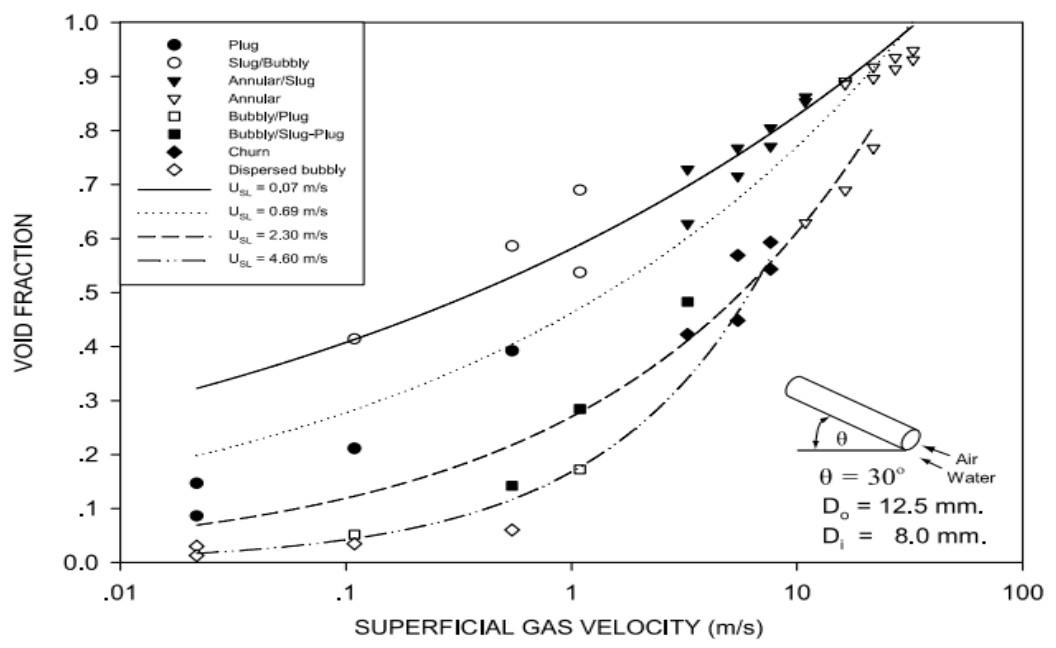

Figure 15. Void fraction-superficial vapor velocity relationship [From Wongwises and Pipathattakul [87], with permission from Elsevier.] 
In two-phase flow, phenomena that affect the performance of the system in the first order, such as heat transfer and pressure drop, occur in a complex way depending on liquid-vapor distribution, steam quality, mass flux, channel geometry and channel inclination. For instance, at high velocities, as the increase in the flow velocity will increase the heat transfer due to the turbulence effects and at the same time increase the pressure drop, both phenomena should be taken into account in order to determine the system performance. Besides these main phenomena, void fraction also affects system performance. In a sample curved pipe model to be considered, the gravity effect will be more dominant compared to the horizontal position with respect to the direction of flow (upflow or downflow). The flow that slows down or accelerates with this effect will adopt different flow regimes depending on the internal structure of the geometry. The balance of gravity and inertial forces will affect the liquidvapor distribution. As the angle of inclination increases, liquid splashes will develop and flow characteristics will change significantly. Vapor bubbles in liquid or liquid droplets in vapor will exhibit more unstable movements than horizontal orientation. All of this shows why it took many years to develop correlations for wide flow velocities and wide databases of fluid flow types. However, research in the literature has shown that the use of inclined channels in a two-phase flow with well-defined boundary conditions can significantly improve system performance. It is a much easier solution to incline the channel to increase performance rather than to create different geometry structures or to have additional power-consuming systems at these well-defined intervals. In addition, as the studies progress, when inclined flows are provided in enhanced channels, much more compact and less space-consuming, high-performance systems can be developed.

As seen in the Figure 14, the pressure drop depends on the flow regime and the velocity of the vapor and liquid. As the gas velocity increases until sufficiently turbulent flows, the pressure drop increases. The inclined channel structure slows down the turbulent flow occurrence with the effect of gravity. High vapor and liquid velocities reduce the gravitational effect on the flow, resulting in pressure drop similar to the horizontal orientation. This system shows that it is highly possible to create structures where inclined pipes would be advantageous for a system in which heat transfer coefficient improvement can be achieved. In Figure 15 it is seen that the increase in vapor velocity also increases the void fraction. In addition, it can be said that the system performance can improved with the void fraction decreasing and the gas-liquid transitivity changing in different flow regimes when the inclination increases. The part to be noted here is the determination of the best performance inclinations for flows by conducting preliminary research and narrowing the inclination angles to be studied.

\section{RESULTS AND DISCUSSION}

In this literature review, condensation and boiling heat transfer characteristics in horizontal, vertical and inclined tubes were scrutinized. Nearly all research subjects were summarised as presented in the literature, such as boiling heat transfer studies according to inclined tubes and tube geometry (plain and enhanced tubes). In the last section of this paper, the tables summarizes the literature studies of condensation and boiling in inclined pipes in order to present in a single publication current correlations for inclined pipes, information from recent experimental studies as well as recommendations for improvements for future studies.

In the light of studies in the literature, the objectives of this research were to extend our understanding of flow condensation and flow boiling heat transfer characteristics in inclined tubes and channels, evaluate the effects of roughness, heat flux, vapor quality, inclination angle, mass flux, saturation temperature, aspect ratio and other parameters on condensation and boiling, evaluate the performance of correlations in prediction of two-phase heat transfer, present the researchers' new correlations and compare them with their own empirical results. The effects of parameters on both condensation and boiling heat transfer coefficient inside tubes are summarised below.

\section{Effects of Parameters on Condensation Heat Transfer Characteristics}

\section{Effects of the main parameters on the heat transfer coefficient}

\section{Roughness:}

Channels with enhanced surfaces where the effect of roughness is important has been extensively studied on horizontal and vertical pipes, and there are very limited studies on inclined pipes.

In the vapor condensation study of pure R134a in a helically inclined $\left(18^{\circ}\right)$ microfin tube studied by Arslan and Eskin [60], the fins performed turbulence increasing properties for all experiments.

Yarmohammadi \& Farhadi [62] investigated straight and corrugated tubes for R-404A condensation and they conclude heat transfer coefficient in corrugated channels could be up to $115 \%$ higher than that of the straight tube. 
Yildiz et al. [82] take into account reflux condensation in their research and microfin pipe experiments showed optimum heat transfer coefficient occurred at $+30^{\circ}$ inclination angle and microfin structure created better heat transfer characteristics according to the smooth structure.

For R134a, in microfin tube condensation maximum heat transfer coefficient occurred at tube inclinations of between $-15^{\circ}$ and $-5^{\circ}$ (downward flows) whereas in smooth tube condensation maximum heat transfer coefficient occurred at tube inclinations of between $-30^{\circ}$ and $-15^{\circ}$ (downward flows).

\section{Vapor quality:}

Steam condensation study [40] in horizontal and inclined tubes demonstrated that measured heat transfer coefficient increases with increasing steam quality or increasing mass flux and decreasing pressure.

Jung et al. [52] performed experimental study on different types of pure refrigerants (R12, R22, R32, $\mathrm{R} 123$, R125, R134a and R142b) and they found the heat transfer for R142b and R32 was higher than for R22, whereas the heat transfer for R12 and R125 was lower than for R22; on the other hand, the heat transfer for R123 and R134a was similar for the same mass flux, also the condensation heat transfer increased with increasing mass flux and increasing quality.

The research [59] on R1234yf refrigerant which has low global warming potential vapour quality properties had strong effects on heat transfer and it was determined that the heat transfer coefficient increased with the increase of vapor quality.

Mohseni et al. [69] investigated R134a condensation and they concluded pipe inclination substantially affected vapour and condensed liquid distribution, and consequently, also the condensation heat transfer, especially at low mass flux and vapour quality.

Ewim et al. [78] deduced the inclination effect decreased with an increase in temperature difference and increased with a decrease in mass flux and vapour quality for R134a condensation in a smooth inclined tube.

\section{Inclination Angle:}

An experimental investigation [68] of convective condensation of R134a was stated that heat transfer coefficient increases with increasing inclination angle for $\alpha<0^{\circ}$, inclination angle affects the heat transfer coefficient differently with various mass flows for $\alpha>0^{\circ}$.

R245fa condensation study [70] presented that the inclination angle had a strong effect on the heat transfer coefficient for the near-horizontal position of the pipe and the best-performing heat transfer coefficient occurred at inclination angles of $-15^{\circ}$ and $+30^{\circ}$.

Steam condensation in a $30^{\circ}$ inclined pipe experimentally studied by Yang et al. [73] and research propounded that heat transfer coefficients in inclined pipe were nearly 1.06 to 2.98 times better than for the horizontal orientation.

A theoretical analysis [74] for laminar film condensation concluded that condensation heat transfer strongly influenced by the inclination angle and condenser section dimensions ratio.

Adelaja et al. [83] concluded heat transfer coefficient enhancement factors were found to be between 0.98 and 2.38 depending on the angle of inclination.

\section{Mass flux:}

Lips and Meyer [38] concluded that the increase of the mass flux causes the increase in the heat transfer due to the increase of the convective effect for higher mass fluxes.

Condensation heat transfer increases with increasing mass flux and decreasing condensation saturation temperature according to Yang and Jia [57].

Heat transfer characteristics for R410A and R22 refrigerants flowing in a herringbone-type microfin tube [61] were demonstrated that in the region where high mass flux was available, higher heat transfer provided in the herringbone-type tube than for the helical microfin case, whereas heat transfer showed the opposite character for the low mass flux region.

Condensation study of R134a in a smooth inclined tube at low mass fluxes at a mean saturation temperature of $40{ }^{\circ} \mathrm{C}[78]$ showed that the inclination effect decreased with a decrease in mass flux and vapour quality.

An experimental investigation of R-134a flow with different inclination angles of $-90^{\circ}$ to $+90^{\circ}$ inside a corrugated tube [81] pointed out that the change in pipe inclination had a strong influence on condensation heat transfer, especially at low vapour qualities and low mass fluxes. 


\section{Saturation temperature:}

Condensate Nusselt number was found to be independent of the temperature difference in conditions where the temperature difference (difference with saturation temperature and wall temperature) was higher than $2.58{ }^{\circ} \mathrm{C}$ in study of Arslan and Eskin [60].

Evim et al. [78] pointed out the heat transfer coefficients for downward and upward vertical orientations $\left(+90^{\circ}\right.$ and $\left.-90^{\circ}\right)$ were not dependent on the temperature difference. It was also found that the inclination effect decreased with an increase in temperature difference.

\section{Other parameters:}

Condensation heat transfer model package development study by Ahn et al. [39] presented that ratio of Nusselt number increases with vapour Reynolds number (for film condensation heat transfer).

The research on the heat transfer characteristic of steam condensation [73] concluded heat transfer coefficient increases with increasing Reynolds number and decreases with increasing tube axial distance.

\section{Effects of the main parameters on the pressure drop-friction factor \\ Roughness:}

Channels with enhanced surfaces where the effect of roughness is important has been extensively studied on horizontal and vertical pipes, and there are very limited studies on inclined pipes.

Experimentally investigation on the pressure drop characteristics of two-phase forced flow for the pure R134 [27] revealed the pressure drop was 10 to $50 \%$ higher than for the smooth condition in the micro-fin case.

For a counter flow concentric double-tube heat exchanger model R134a condensation in smooth and corrugated tubes investigated [34] and researchers presented corrugation pitches had a considerable effect on the pressure drop increment.

The research on R-600a condensation [50] revealed the pressure drop and the mean heat transfer coefficient increased according to the straight condenser between the range of 33 and $157 \%$ and 24 and $165 \%$ respectively.

Numerical research of hydrocarbon mixture upflow condensation characteristics in smooth and spirally enhanced pipes [51] demonstrated that the increments of the pressure drop for spiral grooved, square corrugated and sinusoidal corrugated were 0.851 to $3.587,1.805$ to 10.930 and 1.272 to 7.176 times higher than for the smooth case.

\section{Vapor quality:}

Experimental investigation of condensation of R134a [27] presented the increase in pressure drop was observed for increased vapour quality for both smooth and micro-fin structures.

For propane condensing in horizontal pipes [29] the pressure drop increased with increasing mass flow and vapour quality, while the rising temperature decreased for the tube diameter.

R152a condensation study [33] in a $1.152 \mathrm{~mm}$ diameter circular channel and of $0.952 \mathrm{~mm}$ hydraulic diameter rectangular channel demonstrated the pressure drop increased with increasing vapour quality. Pressure drop study at low mass fluxes for R134a [49] showed that pressure drops increased with an increase in vapour quality.

R-600a condensation in a helically inclined counter flow heat exchanger studied by Mozafari et al. [50] and results demonstrated that higher condensation frictional pressure drop occurred when the vapor quality increases.

\section{Mass flux:}

Pressure drop properties in a horizontal smooth tube for R32, R134a, R125, R236ea and R410A condensation was carried out by Cavallini et al. [26] and they concluded that while the pressure drop showed high values with high mass fluxes and vapour qualities, it showed low values for high saturation temperatures.

FC-72 condensation in parallel micro-channels [31] the pressure drop increased with increasing mass flux of condensing FC-72 whereas the pressure drop decreased due to the flow deceleration caused by increasing the mass velocity of cooling water [31]

Findings of condensation study of R152a [33] indicated that the pressure drop increased with increasing vapour quality and mass flux, whereas the pressure drop decreased with increasing saturation temperature and channel geometry almost not important for low mass fluxes. 
Pressure drop characteristics investigated for low mass fluxes R134a condensation [49] and it was found that the measured pressure drops increased with an increase in mass flux, temperature difference and vapour quality.

In experimentally study of R134a flow [21] flow visualisation results showed the flow regime which determine heat transfer characteristics was exceedingly influenced by the mass flux.

\section{Inclination Angle:}

Experimental findings in large flattened-tube steam condensers [14] showed that the increased inclination angle led to a decrease in pressure drop due to gravity-assisted drainage of the condensate.

The research on R245fa condensation in phase separation shell-and-tube condenser [16] pointed out when inclination angles varied from $-30^{\circ}$ to $30^{\circ}$, the pressure difference decreased but the liquid-mesh contact area increased.

During the convective condensation of the R134a refrigerant, the increasing inclination and decreasing vapour qualities increased the pressure drop for the inclined orientation [37]

Condensation heat transfer of R245fa studied by Xing et al. [70] and attained general trend is that the pressure drop increases with increasing inclination angle, except for partial decreases.

A two-phase gas-liquid flow investigation [87] presented the inclination angle has significant effect on pressure drop and void fraction. Increasing inclination leads to more turbulent flow and more prominent friction effect.

\section{Saturation temperature:}

Experimental investigation for R32, R134a, R125, R236ea and R410A was carried out by Cavallini et al. [26] and they concluded the pressure showed low values for high saturation temperatures.

The pressure drop decreased with increasing saturation temperature and channel geometry almost not important low mass fluxes according to R152a condensation study [33]

\section{Other parameters:}

For horizontal and inclined upward air-water two-phase flow in a mini-gap annular channel, pressure drop increases with increasing superficial gas velocity and void fraction increases with increasing superficial gas velocity [87]

The study on the convective condensation of R134a presented the void fraction decreases with increasing inclination angle [38]

\section{Effects of Parameters on Boiling Heat Transfer Characteristics Effects of the main parameters on the heat transfer coefficient Roughness:}

The studies reviewed have showed that the roughness had huge effect on flow boiling heat transfer coefficient. Celen et al. [101] found that enhanced tube (micro-fin tube) had 1.9 times higher heat transfer coefficient compared to plain one having same fin root diameter. The findings by Passos et al.[143] were similar with similar geometry, $9.52 \mathrm{~mm}$ and $7.0 \mathrm{~mm}$ outside diameter of the micro-fin tube for Celen [101] and Passos' studies [143] respectively. Passos et al. [143] have calculated that heat transfer coefficient of micro-fin tubes were $100 \%$ higher compared to smooth one and this was higher than surface factor found as 1.46 for micro-fin tube. The main reason why the heat transfer coefficient increases more than the surface factor is that micro-fin tubes contribute to their radial flow.

\section{Heat flux:}

Almost all researches in our study, it was expected that, found that heat flux has influenced the boiling heat transfer coefficient over wide range of amount. However, Tran et al. [148] stated that at wall superheats < $2,75^{\circ} \mathrm{C}$, the heat transfer coefficient was independent of heat flux, just dependent on the mass flux contrary to Özdemir's [135] findings that the heat transfer coefficient was only dependent on heat flux rather than mass flux. This difference occurred due to the fact that Tran et al. defined their results within a very low wall superheats. To express special case, Özdemir [135] found that the heat flux had no impact on heat transfer coefficient at high heat fluxes. 


\section{Vapor quality:}

Trend was generally that with increasing vapour quality resulted in increase in heat transfer coefficient. Findings by researcher Candan et al. [138], Celen et al.[101], Krishnamurthy \& Peles [90], Kundu et al. [153], Ravigururajan et al. [151] were in comply with this. But there were some exceptions: Özdemir [135] and Markal et al. [139] found the correlation in contrast with them, presenting no heat transfer increment with increasing heat flux. And some researchers found that increasement in boiling heat transfer coefficient with increasing vapour quality occurred until certain vapour quality, Jang et al. [125] and Akhavan-Behabadi et al. [131] obtained these vapour qualities as 0,25 and $0,70-0,85$ respectively.

\section{Inclination Angle:}

There were limited researchers who examined effect of inclination angle on heat transfer coefficient. Simply there were two groups: researchers who observed that inclination angle considerably has affected heat transfer coefficient and researcher in other group who did no see any enhancement in heat transfer coefficient. While Maddi and Rao [123] just stated that inclination angle had influence on heat transfer coefficient marginally without presenting at which inclination angles obtained best results, other researchers defined the best angle of inclination that had highest heat transfer coefficient. Although Akhavan-Behabadi et al. [131] and Kundu et al. [152] achieved the highest heat transfer rate at inclination angle of $90^{\circ}$ (upflow), Wang et al. [124] obtained the highest rate at $45^{\circ}$, and Morcos et al. [155] had the best results at $30^{\circ}$ incliantion angle. Moreover, none of the researchers had highest performance for downflow.

\section{Mass flux:}

The findings regarding the relation between heat transfer coefficient and mass flux was same, with the exception of Dalkılıç et al. [144]'s findings,: the heat transfer coefficient increased with increasing mass flux. Candan et al. [138] and Morcos et al. [155] have reached these results with channels while Akhavan-Behabadi et al.[131], Özdemir [145], Kundu et al. [152], and Kundu et al. [153] have obtained these results with tubes. And this situation shows us whether it is a channel or tube do not change the tendency that increasing mass flux results in increasing heat transfer coefficient.

Dalkılıç et al. [144] found that mass flux did not affect the transfer coefficient at low vapour quality. However, Dalkılıç et al. have increased the heat flux and found that the heat transfer has increased with increasing mass flux until dryout point. In addition to the statements above, the trend was independent of fluid types. The authors have gained these results with different types of fluids. R407C, R134a, and water was used for different studies.

\section{Saturation temperature:}

Celen et al. [101], Dalkılıç et al. [144], observed that the heat transfer coefficient has increased at all saturation temperatures. This situation was expected. Because the saturation temperatures were relatively low. Park and Hrnjak [112] compared the two saturation temperatures, and found that the two-phase flow heat transfer coefficient at $-15{ }^{\circ} \mathrm{C}$ saturation temperature was always higher than that of $-30^{\circ} \mathrm{C}$ saturation temperature. They explained this situation by stating that the nucleate boiling heat transfer was reduced with decrease in saturation temperature.

On the other hand, Jang et al. [125] managed the test within a wide range of temperatures. Jang found that the heat transfer coefficient has increased until $65^{\circ} \mathrm{C}$ but decreased beyond $65^{\circ} \mathrm{C}$ for saturation temperatures. However, there was researcher who stated that trend of the heat transfer coefficient was dependent on the experimental conditions. In and Jeong [1] indicated that the change in the heat transfer coefficient by saturation pressure (saturation temperature) was insignificant at the high mass velocity and small at the low mass velocity.

\section{Aspect Ratio:}

Although some researchers indicated a profound relation between aspect ratio and heat transfer coefficient for all conditions, there were other researchers who found this relation dependent on operating conditions. Researcher Candan et al. [138] and Özdemir [135] stated that aspect ratio affected the heat transfer coefficient highly in some conditions. Candan et al. [138] expressed that two-phase flow local heat transfer coefficient did not ascend or descend monotonically according to the aspect ratio but showed best performance when AR was equal to 1 with the worst performance when the aspect ratio equaled 0.25 .

On the other hand, Özdemir [135] have seen high effect on local heat transfer coefficient of channel aspect ratio at the low/medium heat flux and up to vapor quality of 0.2. But he did not see important effect at the 
conditions of high heat flux. However, researcher Morcos et al. [155] found that Nusselt Number NuTP have increased with increasing aspect ratio and Markal et al. [140] stated aspect ratio affected heat transfer characteristics.

\section{Other parameters:}

There were other parameters other than aspect ratio, mass flux, heat flux, inclination angle, saturation temperature, vapor quality and roughness. These were effect of covering, Wall temperature and Reynold Number. Nedaei [141] found that when the tube was covered with pHEMA, the heat transfer coefficient has raised by $64 \%$ compared to the bare tube. Gang et al. [154] found that the dissipation of heat transfer characteristics through the circumference of the tube was uniform and with decreasing wall temperature, the heat transfer coefficient increased with increasing circumferential angle. On the other hand, Morcos et al. [155] in addition to finding that $\mathrm{Nu}_{\mathrm{TP}}$ for a given aspect ratio and inclination angle depended on $\mathrm{Re}_{\mathrm{TP}}$, They also stated that the practical consequences of $\mathrm{Nu}_{\mathrm{TP}}$ for horizontal and inclined channels were very well correlated using a ratio of $\operatorname{Re}_{\mathrm{TP}}$ to $\mathrm{Re}_{\mathrm{l}}$. They found that the correlations fairly complied with the practical data of previous investigations.

\section{Performance of existing correlations in prediction of boiling heat transfer}

There were some authors who compared the experimental results obtained with the proposed correlations in the literature. Park and Hrnjak [112] for various mass fluxes, evaporation temperatures and qualities. They found that the Müller-Steinhagen and Heck [103] and Friedel [113] correlations predicted the best within the $\pm 30 \%$ error range. This result could be commented that the correlations were in comply with the experimental results. Similarly, Özdemir et al. [145] found that the results were consistent with the existing theory, which was for flows in microscale and under both laminar and turbulent behavior.

However, $\mathrm{Li}$ and $\mathrm{Wu}$ [137] in their study including evaluation of 3700 data points indicated that no extant correlation could define the data set exactly. But these results covered just saturated boiling not subcooled flow boiling. At the end of their study, they proposed a general correlation consisting of Reynolds number, boiling number and Bond number was given for boiling heat transfer in micro- and mini-channels.

\section{Effects of the main parameters on the pressure drop-friction factor Flow Regime:}

Effect of flow regimes were investigated by Wongwises and Pipathattakul [87] and Tshuva et al. [126]. According to Wongwises and Pipathattakul [87], they have seen slug flow regime and the presence of slug flow slowed down the pressure drop for a short time, then raised the pressure drop after the air velocity increased at low liquid velocity in the horizontal channel. However, they found that the channel oriented at $30^{\circ}$ and $60^{\circ}$, the pressure did not increase suddenly with slug-bubbly flow. On the other hand, in their practical research Tshuva et al. [126] found that the symmetric distribution of the two phases yielded less pressure drop than that of all the other combinations of gas and liquid.

\section{Roughness:}

Celen et al. [101] investigated the forced convection boiling heat transfer and pressure drop tryouts in order to examine augmentation of the micro-fin tube for the heat transfer rate. They compared the results with those of a plain tube. They found that total pressure drop of R134a boiling inside the micro-fin tube were calculated to be 3.0 times higher than for the plain tube. Moreover, they stated that that total pressure drop ascended with an increase in vapour quality, saturation temperature and mass flux.

\section{Mass flux:}

Researchers investigated effect of mass flux on pressure drop within wide range. While Tong et al. [102] studied with high mass fluxes, from 25000 to $45000 \mathrm{~kg} / \mathrm{m}^{2} \mathrm{~s}$, Mancin et al. [111] conducted their research within low mass flux, $190 \mathrm{~kg} / \mathrm{m}^{2} \mathrm{~s}$ and $940 \mathrm{~kg} / \mathrm{m}^{2} \mathrm{~s}$. As expected, most researcher found that pressure drop have increased with increasing mass flux. This trend was seen in boiling inside both enhanced tubes and plain tubes. As Mancin et al. [111], Celen et al. [101] had this trend with micro-fin tubes, Tong et al. [102] Yan et al. [105] Yan and Lin [110] had with plain ones.

\section{Inclination Angle:}

Maddi and Rao [123] investigated their tests on forced convection boiling in tubes inclined in solar collectors. They stated that frictional pressure drop in flow boiling were influenced by the angle of inclination in the bubbly and discontinuous flow regimes, while the inclination was marginally affected in the tube flow regime. 


\section{Vapour quality:}

Some researchers studied effects of vapour quality on pressure drop in micro-fin tubes. Celen et al. [101] and Mancin et al. [111] studied in boiling inside micro-fin tubes with R134a fluid. While Celen et al. [101] found that total pressure drop has increased with increasing vapour quality for all mass fluxes, Mancin et al. [111] had this trend until certain value of vapour quality. After some point, the two-phase flow friction factor decreased with an increase in vapour quality. On the other hand, Jang et al. [125] have found that total pressure drop has increased with increasing vapour quality for heat sinks.

\section{Reynold number:}

The effects of Reynold Number on pressure drop have changed according to wide range of Reynolds Number. Brutin \& Tadrist [96] found that pressure drop have increased with increasing Reynold Number until the Reynolds number nears 25000, then decreased until the Reynolds number nears 5500, then again increased with the Reynolds number more than 5500.On contrary to Brutin \& Tadrist [96], Özdemir [145] have obtained that friction factor decreased with increasing Reynolds number between 250 and 900 and nearly constant with increasing Reynolds number between 900 and 1300 and decreased a little with increasing Reynolds number between 1300 and 1900 .

\section{Other parameters:}

Tong et al. [102] have made practical research on pressure drop with highly subcooled forced convection boiling in small-diameter tubes. They found that in two-phase flow, the pressure drop went up with decreasing aspect ratio. Besides, both inlet temperature and exit pressure affected two-phase boiling significantly. On the other hand, Yan et al. [105] found that pressure drop decreased with increasing pressure. Kuo and Wang [114] produced new parameters: two-phase friction factor $\mathrm{f}_{\mathrm{tp}}$ consisting of a mean two-phase viscosity, $\bar{\mu}$.

\section{Performance of existing correlations in prediction of pressure drop}

It is obvious that two-phase flow pressure drop correlations in literature can be classified in different ways. So evaluation of performance of these correlations should also be made based on different ways. Here evaluation of existing correlations ranked according to researchers' findings.

In this article, many researchers have evaluated the existing correlations and when we make evaluation on the basis of their findings on performance of evaluation of correlations on prediction for pressure drop, the correlation of Müller-Steinhagen and Heck [103] was found to be best for prediction by Didi et al. [116], Park and Hrnjak [112] and Ribatski et al. [107]. On the other hand, Müller-Steinhagen and Heck [103] found the correlation by Bandel [104] best correlation. Then it came second best correlation by Mishima and Hibiki [100]. Ribatski et al. [107] and Zhang et al. [97] found the Mishima and Hibiki's correlation [100] second best correlation. Friedel's correlation [113] was to be third best correlation when Didi et al. [116] and Yun et al. [109] statements are evaluated. On the other hand, Dukler [99] and Zhang et al. [97]'s correlations had the small mean deviation in all existing correlations evaluated in this article with $18.0 \%$ and $20 \%$ mean deviations respectively.

\section{CONCLUSION}

In this comprehensive literature review, flow condensation and flow boiling heat transfer characteristics in horizontal, vertical and inclined tubes were scrutinised. Nearly all research subjects were summarised as presented in the literature, such as boiling heat transfer studies according to inclined tubes and tube geometry (plain and enhanced tubes). In the last section of this paper, the tables summarizes the literature studies of condensation and boiling in inclined pipes in order to present in a single publication current correlations for inclined pipes, information from recent experimental studies as well as recommendations for improvements for future studies.

In the review, effects of parameters on two-phase flow heat characteristics are evaluated. Based on the evaluation, it can be drawn that inclination angle have significant effect on both condensation and boiling heat transfer coefficient and pressure drop. On the other hand, it was found that vapour quality and roughness were the main parameters affecting two-phase flow heat transfer characteristics. Effects of all parameters are discussed in the corresponding section.

When existing correlations in the literature on prediction flow boiling heat transfer coefficient are evaluated, correlations proposed by Müller-Steinhagen and Heck [103] and Friedel [113] were to be best for 
prediction well according to majority of researchers and for performance of prediction on pressure drop correlation by Müller-Steinhagen and Heck [103] stood out.

From the literature studies, despite of their importance in the condensation and boiling heat transfer characteristics, two-phase flow inside inclined tubes are very limited. There is lack of experimental results in this subject. In order to improve our knowledge of two-phase flows inside both inclined and horizontal-vertical tubes, authors highly recommend to do further researches.

\section{THE FUTURE OF THE RESEARCHES IN THIS FIELD}

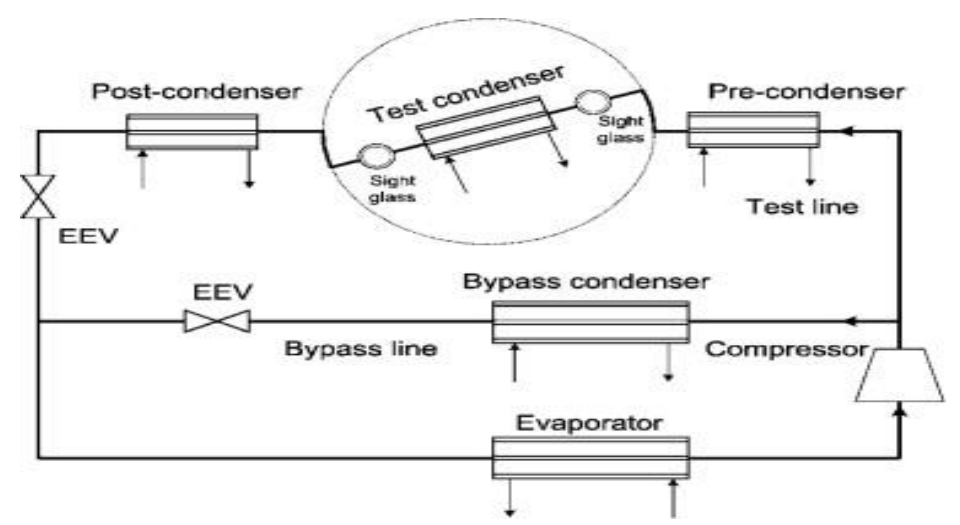

Figure 16. Schematic diagram of an exemplary experimental setup [From Lips and Meyer [66], with permission from Elsevier.]

The present review shows that researches on inclined pipes are carried out in restricted flows and channel cross-section geometries. The plain flow channel structure seen in the experimental setup in Figure 16 covers more than $90 \%$ of the inclined two-phase flow inclinations in the literature. This assessment demonstrates of the gaps that can be closed in future researches. Researches conducted within the enhanced channel structures in inclined flows should be increased. Using new generation refrigerants and organic fluids, the efficiency of utilization of inclined pipes should be studied. In order to determine more efficient working equipment and conditions, it is necessary to intensify the investigations in this research field. More comprehensive correlations should be developed using the literature database.

\section{NOMENCLATURE}

A Comprehensive factor; cross-sectional area, $\mathrm{m}^{2}$

Bo Boiling number

Bd Bond number

C Wave velocity, $\mathrm{m} / \mathrm{s}$

$\mathrm{c}_{\mathrm{p}} \quad$ Constant pressure specific heat, $\mathrm{J} / \mathrm{kg} \cdot{ }^{\circ} \mathrm{C}$

$\mathrm{c}_{\mathrm{pf}} \quad$ Specific heat of liquid refrigerant, $\mathrm{J} \mathrm{kg}^{-1} \mathrm{~K}^{-1}$

$\mathrm{C}_{\mathrm{f}} \quad$ Coefficient of film condensation heat transfer

$D \quad$ Internal diameter of test section, $\mathrm{m}$

$\mathrm{D}_{\mathrm{o}} \quad$ Outside diameter of test section, $\mathrm{m}$

$\mathrm{D}_{\mathrm{i}} \quad$ Inner diameter of test section, $\mathrm{m}$

E Enhancement factor

$g \quad$ Gravity, $\mathrm{m} / \mathrm{s}^{2}$

$\mathrm{G} \quad$ Mass flux, $\mathrm{kg} / \mathrm{m}^{2} \mathrm{~s}$

$f \quad$ Friction factor

$\mathrm{F}_{\alpha} \quad$ Inclination factor

$\mathrm{F}_{\mathrm{TM}} \quad$ Two-phase multiplier

Fr Froude number

$\mathrm{F}_{\alpha} \quad$ Inclination factor

$\mathrm{F}_{\mathrm{C}} \quad$ Mass transfer resistance factor

$\mathrm{f}(\theta) \quad$ Floating constant

$h \quad$ Condensation heat transfer coefficient, $\mathrm{W} / \mathrm{m}^{2 .}{ }^{\circ} \mathrm{C}$

$h_{\mathrm{I}} \quad$ Heat transfer coefficient for reference [20]

$h_{f} \quad$ Liquid layer height, $\mathrm{m}$ 


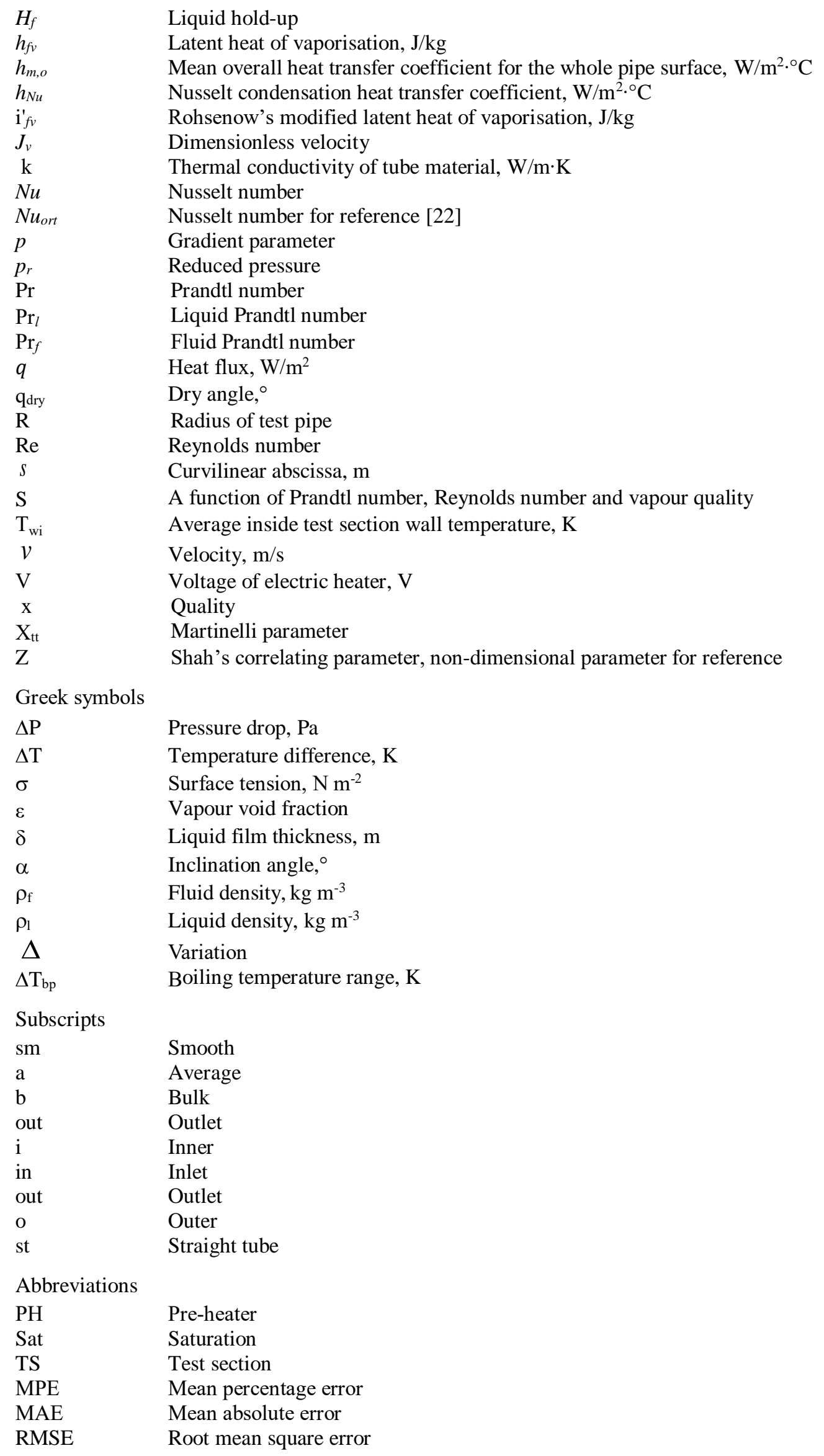




\section{REFERENCES}

[1] In S, Jeong S. Flow boiling heat transfer characteristics of R123 and R134a in a micro-channel. International Journal of Multiphase Flow. 2009 Nov 1;35(11):987-1000.

[2] Ong CL, Thome JR. Flow boiling heat transfer of R134a, R236fa and R245fa in a horizontal $1.030 \mathrm{~mm}$ circular channel. Experimental Thermal and Fluid Science. 2009 Apr 1;33(4):651-63.

[3] Li W, Ma X, Sun ZC, He Y, Sherif SA, Zhang JH, Zhu HT. Evaporation heat transfer characteristics of R410A inside horizontal three-dimensional enhanced tubes. International Journal of Thermal Sciences. 2019 Mar 1;137:456-66.

[4] Akhavan-Behabadi MA, Esmailpour M. Experimental study of evaporation heat transfer of R-134a inside a corrugated tube with different tube inclinations. international communications in heat and mass transfer. 2014 Jul 1;55:8-14.

[5] Mohseni SG, Akhavan-Behabadi MA. Visual study of flow patterns during condensation inside a microfin tube with different tube inclinations. International communications in heat and mass transfer. 2011 Oct 1;38(8):1156-61.

[6] Yu J, Jiang Y, Cai W, Li X, Zhu Z. Condensation flow patterns and heat transfer correction for zeotropic hydrocarbon mixtures in a helically coiled tube. International Journal of Heat and Mass Transfer. 2019 Nov 1;143:118500.

[7] Estellé P, Cabaleiro D, Żyła G, Lugo L, Murshed SS. Current trends in surface tension and wetting behavior of nanofluids. Renewable and Sustainable Energy Reviews. 2018 Oct 1;94:931-44.

[8] Saisorn S, Wongwises S. The effects of channel diameter on flow pattern, void fraction and pressure drop of two-phase air-water flow in circular micro-channels. Experimental thermal and fluid science. 2010 May 1;34(4):454-62.

[9] Lips S, Meyer JP. Two-phase flow in inclined tubes with specific reference to condensation: a review. International Journal of Multiphase Flow. 2011 Oct 1;37(8):845-59.

[10] Barnea D. A unified model for predicting flow-pattern transitions for the whole range of pipe inclinations. International Journal of Multiphase Flow. 1987 Jan 1;13(1):1-2.

[11] Nitheanandan T, Soliman HM. Influence of tube inclination on the flow regime boundaries of condensing steam. The Canadian Journal of Chemical Engineering. 1993 Feb;71(1):35-41.

[12] Wang WC, Ma XH, Wei ZD, Yu P. Two-phase flow patterns and transition characteristics for in-tube condensation with different surface inclinations. International journal of heat and mass transfer. 1998 Oct $1 ; 41(24): 4341-9$.

[13] Ghajar AJ, Tang CC. Heat transfer measurements, flow pattern maps, and flow visualization for nonboiling two-phase flow in horizontal and slightly inclined pipe. Heat Transfer Engineering. 2007 Jun 1;28(6):525-40.

[14] Kang Y, Davies III WA, Hrnjak P, Jacobi AM. Effect of inclination on pressure drop and flow regimes in large flattened-tube steam condensers. Applied Thermal Engineering. 2017 Aug 1;123:498-513.

[15] Davies III WA, Hrnjak P. Heat transfer in a large, inclined, flattened-tube steam condenser. Heat Transfer Engineering. 2020 Sep 24;41(17):1443-56.

[16] Cao S, Ji X, Xu J. R245fa condensation heat transfer in a phase separation condenser. Experimental Thermal and Fluid Science. 2018 Nov 1;98:346-61.

[17] Lips S, Meyer JP. Effect of gravity forces on heat transfer and pressure drop during condensation of R134a. Microgravity Science and Technology. 2012 Jun;24(3):157-64.

[18] Barbosa Jr JR, Ferreira JC, Hense D. Onset of flow reversal in upflow condensation in an inclinable tube. Experimental Thermal and Fluid Science. 2016 Oct 1;77:55-70.

[19] Hanafizadeh P, Hojati A, Karimi A. Experimental investigation of oil-water two phase flow regime in an inclined pipe. Journal of Petroleum Science and Engineering. 2015 Dec 1;136:12-22.

[20] Mozafari M, Akhavan-Behabadi MA, Qobadi-Arfaee H, Hanafizadeh P, Fakoor-Pakdaman M. Experimental study on condensation flow patterns inside inclined U-bend tubes. Experimental Thermal and Fluid Science. 2015 Nov 1;68:276-87.

[21] Xiao J, Hrnjak P. A new flow regime map and void fraction model based on the flow characterization of condensation. International Journal of Heat and Mass Transfer. 2017 May 1;108:443-52.

[22] Park I, Mudawar I. Climbing film, flooding and falling film behavior in upflow condensation in tubes. International Journal of Heat and Mass Transfer. 2013 Oct 1;65:44-61. 
[23] El Hajal J, Thome JR, Cavallini A. Condensation in horizontal tubes, part 1: two-phase flow pattern map. International Journal of Heat and Mass Transfer. 2003 Aug 1;46(18):3349-63.

[24] Thome JR, El Hajal J, Cavallini A. Condensation in horizontal tubes, part 2: new heat transfer model based on flow regimes. International journal of heat and mass transfer. 2003 Aug 1;46(18):3365-87.

[25] Aroonrat K, Wongwises S. Experimental study on two-phase condensation heat transfer and pressure drop of R-134a flowing in a dimpled tube. International Journal of Heat and Mass Transfer. 2017 Mar 1;106:437-48.

[26] Cavallini A, Censi G, Del Col D, Doretti L, Longo GA, Rossetto L. Experimental investigation on condensation heat transfer and pressure drop of new HFC refrigerants (R134a, R125, R32, R410A, R236ea) in a horizontal smooth tube. International Journal of Refrigeration. 2001 Jan 1;24(1):73-87.

[27] Nualboonrueng T, Wongwises S. Two-phase flow pressure drop of HFC-134a during condensation in smooth and micro-fin tubes at high mass flux. International communications in heat and mass transfer. 2004 Oct 1;31(7):991-1004.

[28] Briggs A, Kelemenis C, Rose JW. Heat transfer and pressure drop measurements for in-tube condensation of CFC-113 using microfin tubes and wire inserts. Experimental heat transfer. 2000 Jul 1;13(3):163-81.

[29] Macdonald M, Garimella S. Hydrocarbon condensation in horizontal smooth tubes: Part I-Measurements. International Journal of Heat and Mass Transfer. 2016 Feb 1;93:75-85.

[30] Macdonald M, Garimella S. Hydrocarbon condensation in horizontal smooth tubes: Part II-Heat transfer coefficient and pressure drop modeling. International Journal of Heat and Mass Transfer. 2016 Feb 1;93:1248-61.

[31] Kim SM, Kim J, Mudawar I. Flow condensation in parallel micro-channels-Part 1: Experimental results and assessment of pressure drop correlations. International journal of heat and mass transfer. 2012 Jan 31;55(4):971-83.

[32] Son CH, Oh HK. Condensation pressure drop of R22, R134a and R410A in a single circular microtube. Heat and Mass Transfer. 2012 Aug;48(8):1437-50.

[33] Liu N, Li JM, Sun J, Wang HS. Heat transfer and pressure drop during condensation of R152a in circular and square microchannels. Experimental thermal and fluid science. 2013 May 1;47:60-7.

[34] Laohalertdecha S, Wongwises S. The effects of corrugation pitch on the condensation heat transfer coefficient and pressure drop of R-134a inside horizontal corrugated tube. International Journal of Heat and Mass Transfer. 2010 Jun 1;53(13-14):2924-31.

[35] Salimpour MR, Yarmohammadi S. Effect of twisted tape inserts on pressure drop during R-404A condensation. International journal of refrigeration. 2012 Mar 1;35(2):263-9.

[36] Salimpour MR, Gholami H. Effect of inserting coiled wires on pressure drop of R-404A condensation. International journal of refrigeration. 2014 Apr 1;40:24-30.

[37] Lips S, Meyer JP. Experimental study of convective condensation in an inclined smooth tube. Part II: Inclination effect on pressure drops and void fractions. International Journal of Heat and Mass Transfer. 2012 Jan 15;55(1-3):405-12.

[38] Lips S, Meyer JP. Stratified flow model for convective condensation in an inclined tube. International Journal of Heat and Fluid Flow. 2012 Aug 1;36:83-91.

[39] Ahn TH, Yun BJ, Jeong JJ, Kang KH, Park YS, Cheon J, Jerng DW. Development of a new condensation model for the nearly-horizontal heat exchanger tube under the steam flowing conditions. International Journal of Heat and Mass Transfer. 2014 Dec 1;79:876-84.

[40] Ahn T, Kang J, Bae B, Jeong JJ, Yun B. Steam condensation in horizontal and inclined tubes under stratified flow conditions. International Journal of Heat and Mass Transfer. 2019 Oct 1;141:71-87.

[41] Würfel R, Kreutzer T, Fratzscher W. Turbulence transfer processes in adiabatic and condensing film flow in an inclined tube. Chemical Engineering \& Technology: Industrial Chemistry-Plant Equipment-Process Engineering-Biotechnology. 2003 Apr 9;26(4):439-48.

[42] Grolman E, Fortuin JM. Gas-liquid flow in slightly inclined pipes. Chemical engineering science. 1997 Dec 1;52(24):4461-71.

[43] Grolman E. Gas-Liquid Flow with Low Liquid Loading in Slightly Inclined Pipes. (Doctoral thesis) 1994 Retrieved from https://www.worldcat.org/title/gas-liquid-flow-with-low-liquid-loading-inslightlyinclined-pipes/oclc/906984277\#borrow 
[44] Ottens M, Hoefsloot HC, Hamersma PJ. Correlations predicting liquid hold-up and pressure gradient in steady-state (nearly) horizontal co-current gas-liquid pipe flow. Chemical Engineering Research and Design. 2001 Jul 1;79(5):581-92.

[45] Zhang HQ, Wang Q, Sarica C, Brill JP. Unified model for gas-liquid pipe flow via slug dynamics - part 1: model development. J. Energy Resour. Technol.. 2003 Dec 1;125(4):266-73.

[46] Zhang HQ, Wang Q, Sarica C, Brill JP. Unified model for gas-liquid pipe flow via slug dynamics-Part 2: Model validation. J. Energy Resour. Technol.. 2003 Dec 1;125(4):274-83.

[47] Woldesemayat MA, Ghajar AJ. Comparison of void fraction correlations for different flow patterns in horizontal and upward inclined pipes. International journal of multiphase flow. 2007 Apr 1;33(4):347-70.

[48] Woldesemayat MA. Comparison of void fraction correlations for two-phase flow in horizontal and upward inclined flows (Doctoral dissertation, Oklahoma State University). 2006 Retrieved from https://sh areok.org/bitstream/handle/11244/10090/Woldesemayat_okstate_0664M_1784.pdf?sequence=1

[49] Ewim DR, Meyer JP. Pressure drop during condensation at low mass fluxes in smooth horizontal and inclined tubes. International Journal of Heat and Mass Transfer. 2019 Apr 1;133:686-701.

[50] Mozafari M, Akhavan-Behabadi MA, Qobadi-Arfaee H, Fakoor-Pakdaman M. Condensation and pressure drop characteristics of R600a in a helical tube-in-tube heat exchanger at different inclination angles. Applied Thermal Engineering. 2015 Nov 5;90:571-8.

[51] Li S, Jiang Y, Cai W, Li Q, Zhang H, Ren Y. The influence of structural parameters on heat transfer and pressure drop for hydrocarbon mixture refrigerant during condensation in enhanced spiral pipes. Applied Thermal Engineering. 2018 Jul 25;140:759-74.

[52] Jung D, Song KH, Cho Y, Kim SJ. Flow condensation heat transfer coefficients of pure refrigerants. International Journal of Refrigeration. 2003 Jan 1;26(1):4-11.

[53] Zyhowski G, Brown A. Low global warming fluids for replacement of HFC-245fa and HFC-134a in ORC applications. InHoneywell report, ORC2011 seminar, TU Delft in Netherlands 2011 Sep 23.

[54] Ghim G, Lee J. Condensation heat transfer of low GWP ORC working fluids in a horizontal smooth tube. International Journal of Heat and Mass Transfer. 2017 Jan 1;104:718-28.

[55] Kim SM, Mudawar I. Flow condensation in parallel micro-channels-Part 2: Heat transfer results and correlation technique. International Journal of Heat and Mass Transfer. 2012 Jan 31;55(4):984-94.

[56] Oh HK, Son CH. Condensation heat transfer characteristics of R-22, R-134a and R-410A in a single circular microtube. Experimental thermal and fluid science. 2011 May 1;35(4):706-16.

[57] Yang Y, Jia L. Experimental investigation on heat transfer coefficient during upward flow condensation of R410A in vertical smooth tubes. Journal of Thermal Science. 2015 Apr 1;24(2):155-63.

[58] Kondou C, Mishima F, Koyama S. Condensation and evaporation of R32/R1234ze (E) and R744/R32/R1234ze (E) flow in horizontal microfin tubes. Science and Technology for the Built Environment. 2015 Jul 4;21(5):564-77.

[59] Diani A, Cavallini A, Rossetto L. R1234yf condensation inside a $3.4 \mathrm{~mm}$ ID horizontal microfin tube. International Journal of Refrigeration. 2017 Mar 1;75:178-89.

[60] Arslan G, Eskin N. Forced Convective Condensation of R134A Vapor Inside a Vertical Microfin Tube. Experimental Heat Transfer. 2016 Nov 1;29(6):707-20.

[61] Miyara A, Nonaka K, Taniguchi M. Condensation heat transfer and flow pattern inside a herringbonetype micro-fin tube. International journal of refrigeration. 2000 Mar 1;23(2):141-52.

[62] Yarmohammadi S, Farhadi M. Optimization of thermal and flow characteristics of R-404A vapor condensation inside corrugated tubes. Experimental Thermal and Fluid Science. 2016 Dec 1;79:1-12.

[63] Li M, Guo Q, Lv J, Li D. Research on condensation heat transfer characteristics of R447A, R1234ze, R134a and R32 in multi-port micro-channel tubes. International Journal of Heat and Mass Transfer. 2018 Mar 1;118:637-50.

[64] Meyer JP, Ewim DR. Heat transfer coefficients during the condensation of low mass fluxes in smooth horizontal tubes. International Journal of Multiphase Flow. 2018 Feb 1;99:485-99.

[65] Akers WW, Deans HA, Crosser OK. Condensing heat transfer within horizontal tubes. Chem. Eng. Progr.. 1958 Oct 1;54.

[66] Lips S, Meyer JP. Experimental study of convective condensation in an inclined smooth tube. Part I: Inclination effect on flow pattern and heat transfer coefficient. International Journal of Heat and Mass Transfer. 2012 Jan 15;55(1-3):395-404. 
[67] Adelaja AO, Ewim DR, Dirker J, Meyer JP. An improved heat transfer correlation for condensation inside inclined smooth tubes. International Communications in Heat and Mass Transfer. 2020 Oct 1;117:104746.

[68] Adelaja AO, Dirker J, Meyer JP. Convective condensation heat transfer of R134a in tubes at different inclination angles. International Journal of Green Energy. 2016 Jun 20;13(8):812-21.

[69] Mohseni SG, Akhavan-Behabadi MA, Saeedinia M. Flow pattern visualization and heat transfer characteristics of R-134a during condensation inside a smooth tube with different tube inclinations. International Journal of Heat and Mass Transfer. 2013 May 1;60:598-602.

[70] Xing F, Xu J, Xie J, Liu H, Wang Z, Ma X. Froude number dominates condensation heat transfer of R245fa in tubes: effect of inclination angles. International Journal of Multiphase Flow. 2015 May 1;71:98-115.

[71] Wang JC, Ma Y. Condensation heat transfer inside vertical and inclined thermosyphons. J. Heat Transfer. 1991 Aug 1;113(3):777-80.

[72] Wang BX, Du XZ. Study on laminar film-wise condensation for vapor flow in an inclined small/minidiameter tube. International journal of heat and mass transfer. 2000 May 15;43(10):1859-68.

[73] Yang JG, Ju XL, Ye S. An empirical correlation for steam condensing and flowing downward in a 50mm diameter inclined tube. In Advanced Materials Research 2013 (Vol. 732, pp. 67-73). Trans Tech Publications Ltd.

[74] Hussein HM, Mohamad MA, El-Asfouri AS. Theoretical analysis of laminar-film condensation heat transfer inside inclined wickless heat pipes flat-plate solar collector. Renewable Energy. 2001 Jul 1;23(34):525-35.

[75] Shah MM. An improved and extended general correlation for heat transfer during condensation in plain tubes. Hvac\&R Research. 2009 Sep 1;15(5):889-913.

[76] Shah MM. Comprehensive correlations for heat transfer during condensation in conventional and $\mathrm{mini} /$ micro channels in all orientations. International journal of refrigeration. $2016 \mathrm{Jul}$ 1;67:22-41.

[77] Camaraza-Medina Y, Hernandez-Guerrero A, Luviano-Ortiz JL, Mortensen-Carlson K, Cruz-Fonticiella OM, García-Morales OF. New model for heat transfer calculation during film condensation inside pipes. International Journal of Heat and Mass Transfer. 2019 Jan 1;128:344-53.

[78] Ewim DR, Meyer JP, Abadi SN. Condensation heat transfer coefficients in an inclined smooth tube at low mass fluxes. International Journal of Heat and Mass Transfer. 2018 Aug 1;123:455-67.

[79] Akhavan-Behabadi MA, Kumar R, Mohseni SG. Condensation heat transfer of R-134a inside a microfin tube with different tube inclinations. International Journal of Heat and Mass Transfer. 2007 Nov 1;50(2324):4864-71.

[80] Adelaja AO, Ewim DR, Dirker J, Meyer JP. Heat transfer, void fraction and pressure drop during condensation inside inclined smooth and microfin tubes. Experimental Thermal and Fluid Science. 2019 Dec 1;109:109905.

[81] Khoeini, D., Akhavan-Behabadi, M. A., \& Saboonchi, A. (2012). Experimental study of condensation heat transfer of R-134a flow in corrugated tubes with different inclinations. International Communications in Heat and Mass Transfer, 39(1), 138-143.

[82] Yildiz, S., Duymaz, G., Ziegler, F., \& Auracher, H. (2017). Heat transfer during reflux condensation of $\mathrm{R} 134 \mathrm{a}$ inside a micro-fin tube with different tube inclinations. International Journal of Refrigeration, 74, 425-434.

[83] Ghiaasiaan, S. M. (2007). Two-phase flow, boiling, and condensation: in conventional and miniature systems. Cambridge University Press.

[84] Julia, J. E., \& Hibiki, T. (2011). Flow regime transition criteria for two-phase flow in a vertical annulus. International Journal of Heat and Fluid Flow, 32(5), 993-1004

[85] Jepson, D. M., Azzopardi, B. J., \& Whalley, P. B. (1989). The effect of gas properties on drops in annular flow. International Journal of Multiphase Flow, 15(3), 327-339.

[86] Saisorn S, Kaew-On J, Wongwises S. An experimental investigation of flow boiling heat transfer of R134a in horizontal and vertical mini-channels. Exp Therm Fluid Sci [Internet]. 2013;46:232-44. Available from: http://dx.doi.org/10.1016/j.expthermflusci.2012.12.015

[87] Wongwises, S., \& Pipathattakul, M. (2006). Flow pattern, pressure drop and void fraction of two-phase gas-liquid flow in an inclined narrow annular channel. Experimental Thermal and Fluid Science, 30(4), 345-354. 
[88] Hernández, L., Julia, J. E., Ozar, B., Hibiki, T., \& Ishii, M. (2011). Flow regime identification in boiling two-phase flow in a vertical annulus. Journal of Fluids Engineering, 133(9), 091304.

[89] Layssac, T., Lips, S., \& Revellin, R. (2019). Effect of inclination on heat transfer coefficient during flow boiling in a mini-channel. International Journal of Heat and Mass Transfer, 132, 508-518.

[90] Krishnamurthy S, Peles Y. Flow boiling heat transfer on micro pin fins entrenched in a microchannel. Journal of Heat Transfer. 2010 Apr 1;132(4).

[91] Zhang H, Wang S, Wang J. Experimental study on boiling flow of liquid nitrogen in inclined tubesVelocities and length distributions of Taylor bubbles. Journal of the Taiwan Institute of Chemical Engineers. 2009 Jul 1;40(4):431-8.

[92] Cornwell K, Kew PA. Boiling in small parallel channels. InEnergy Efficiency in Process Technology 1993 (pp. 624-638). Springer, Dordrecht.

[93] Kandlikar SG, Steinke ME, Tian S, Campbell LA. High speed photographic observation of flow boiling of water in parallel minichannels. In35th Proceedings of National Heat Transfer Conference 2001 Jun 10.

[94] Lakshminarasimhan MS, Hollingsworth DK, Witte LC. Boiling incipience in narrow channels. ASMEPUBLICATIONS-HTD. 2000;366:55-64.

[95] Sardeshpande MV, Ranade VV. Two-phase flow boiling in small channels: A brief review. Sadhana. 2013 Dec 1;38(6):1083-126.

[96] Brutin D, Tadrist L. Pressure drop and heat transfer analysis of flow boiling in a minichannel: influence of the inlet condition on two-phase flow stability. International journal of heat and mass transfer. 2004 May 1;47(10-11):2365-77.

[97] Zhang W, Hibiki T, Mishima K. Correlations of two-phase frictional pressure drop and void fraction in mini-channel. International Journal of Heat and Mass Transfer. 2010 Jan 15;53(1-3):453-65.

[98] Chisholm D. A theoretical basis for the Lockhart-Martinelli correlation for two-phase flow. International Journal of Heat and Mass Transfer. 1967 Dec 1;10(12):1767-78.

[99] Dukler AE, Wicks III M, Cleveland RG. Frictional pressure drop in two-phase flow: B. An approach through similarity analysis. AIChE Journal. 1964 Jan;10(1):44-51.

[100] Mishima K, Hibiki T. Some characteristics of air-water two-phase flow in small diameter vertical tubes. International journal of multiphase flow. 1996 Aug 1;22(4):703-12.

[101] Celen A, Çebi A, Dalkılıç AS. Investigation of boiling heat transfer characteristics of R134a flowing in smooth and microfin tubes. International Communications in Heat and Mass Transfer. 2018 Apr 1;93:2133.

[102] Tong W, Bergles AE, Jensen MK. Pressure drop with highly subcooled flow boiling in small-diameter tubes. Experimental Thermal and Fluid Science. 1997 Oct 1;15(3):202-12.

[103] Müller-Steinhagen H, Heck K. A simple friction pressure drop correlation for two-phase flow in pipes. Chemical Engineering and Processing: Process Intensification. 1986 Nov 1;20(6):297-308.

[104] Bandel J, Schlünder EU. Druckverlust und Wärmeübergang bei der Verdampfung siedender Kältemittel im durchströmten Rohr. Chemie Ingenieur Technik. 1973 Mar;45(6):345-50.

[105] Yan J, Guo P, Bi Q, Liu Z, Zhang Q, Yang Z. Pressure drop for highly subcooled water flow boiling under high heat and mass fluxes. Applied Thermal Engineering. 2017 Sep 1;124:1061-74.

[106] Tran TN, Chyu MC, Wambsganss MW, France DM. Two-phase pressure drop of refrigerants during flow boiling in small channels: an experimental investigation and correlation development. International Journal of Multiphase Flow. 2000 Nov 1;26(11):1739-54.

[107] Ribatski G, Wojtan L, Thome JR. An analysis of experimental data and prediction methods for two-phase frictional pressure drop and flow boiling heat transfer in micro-scale channels. Experimental Thermal and Fluid Science. 2006 Oct 1;31(1):1-9.

[108] Steinke ME, Kandlikar SG. Flow boiling and pressure drop in parallel flow microchannels. InInternational Conference on Nanochannels, Microchannels, and Minichannels 2003 Jan 1 (Vol. 36673, pp. 567-579).

[109] Yun R, Heo JH, Kim Y. Evaporative heat transfer and pressure drop of R410A in microchannels. International journal of refrigeration. 2006 Jan 1;29(1):92-100.

[110] Yan YY, Lin TF. Evaporation heat transfer and pressure drop of refrigerant R-134a in a small pipe. International Journal of Heat and Mass Transfer. 1998 Oct 1;41(24):4183-94. 
[111] Mancin S, Diani A, Rossetto L. Experimental measurements of R134a flow boiling inside a 3.4-mm ID microfin tube. Heat Transfer Engineering. 2015 Sep 22;36(14-15):1218-29.

[112] Park CY, Hrnjak PS. CO2 and R410A flow boiling heat transfer, pressure drop, and flow pattern at low temperatures in a horizontal smooth tube. International Journal of Refrigeration. 2007 Jan 1;30(1):16678.

[113] Friedel L. Improved friction pressure drop correlation for horizontal and vertical two-phase pipe flow. Proc. of European Two-Phase Flow Group Meet., Ispra, Italy, 1979. 1979.

[114] Kuo CS, Wang CC. Horizontal flow boiling of R22 and R407C in a $9.52 \mathrm{~mm}$ micro-fin tube. Applied Thermal Engineering. 1996 Aug 1;16(8-9):719-31.

[115] Rollmann P, Spindler K. New models for heat transfer and pressure drop during flow boiling of R407C and R410A in a horizontal microfin tube. International Journal of Thermal Sciences. 2016 May 1;103:5766.

[116] Didi MO, Kattan N, Thome JR. Prediction of two-phase pressure gradients of refrigerants in horizontal tubes. International Journal of refrigeration. 2002 Nov 1;25(7):935-47.

[117] Kattan N. Contribution to the heat transfer analysis of substitute refrigerants in evaporator tubes with smooth or enhanced tube surfaces.(Doctoral thesis, Verlag nicht ermittelbar).

[118] Lockhart RW. Proposed correlation of data for isothermal two-phase, two-component flow in pipes. Chem. Eng. Prog.. 1949;45:39-48.

[119] Grönnerud R. Investigation of liquid hold-up, flow-resistance and heat transfer in circulation type evaporators, part IV: two-phase flow resistance in boiling refrigerants. Bull. De l'Inst. Du Froid, Annexe. $1972 ; 1$.

[120] Chisholm D. Pressure gradients due to friction during the flow of evaporating two-phase mixtures in smooth tubes and channels. International Journal of Heat and Mass Transfer. 1973 Feb 1;16(2):347-58.

[121] Bankoff SG. A variable density single-fluid model for two-phase flow with particular reference to steamwater flow. Journal of Heat Transfer (US). 1960 Nov 1;82.

[122] Chawla JM. Wärmeübergang und Druckabfall in waagerechten Rohren bei der Strömung von verdampfenden Kältemitteln. VDI-Verlag; 1967.

[123] Maddi MK, Rao DP. Experimental studies on flow boiling in inclined tubes: in the regions encountered in solar collectors. The Canadian Journal of Chemical Engineering. 1995 Feb;73(1):73-84.

[124] Wang CC, Chang WJ, Dai CH, Lin YT, Yang KS. Effect of inclination on the convective boiling performance of a microchannel heat sink using HFE-7100. Experimental thermal and fluid science. 2012 Jan 1;36:143-8.

[125] Jang Y, Park C, Lee Y, Kim Y. Flow boiling heat transfer coefficients and pressure drops of FC-72 in small channel heat sinks. International journal of refrigeration. 2008 Sep 1;31(6):1033-41.

[126] Tshuva M, Barnea D, Taitel Y. Two-phase flow in inclined parallel pipes. International journal of multiphase flow. 1999 Sep 1;25(6-7):1491-503.

[127] Laohalertdecha S, Wongwises S. An experimental study into the evaporation heat transfer and flow characteristics of R-134a refrigerant flowing through corrugated tubes. International journal of refrigeration. 2011 Jan 1;34(1):280-91.

[128] Piasecka M. Impact of selected parameters on refrigerant flow boiling heat transfer and pressure drop in minichannels. International Journal of Refrigeration. 2015 Aug 1;56:198-212.

[129] García-Cascales JR, Vera-García F, Corberán-Salvador JM, Gonzálvez-Maciá J. Assessment of boiling and condensation heat transfer correlations in the modelling of plate heat exchangers. International Journal of Refrigeration. 2007 Sep 1;30(6):1029-41.

[130] Dalkilic AS, Teke İ, Wongwises S. Heat transfer enhancement during downward laminar flow condensation of R134a in vertical smooth and microfin tubes. Isi Bilimi ve Teknigi Dergisi/Journal of Thermal Science \& Technology. 2012 Jun 1;32(1).

[131] Akhavan-Behabadi MA, Mohseni SG, Razavinasab SM. Evaporation heat transfer of R-134a inside a microfin tube with different tube inclinations. Experimental thermal and fluid science. 2011 Sep 1;35(6):996-1001.

[132] Kandlikar SG. Fundamental issues related to flow boiling in minichannels and microchannels. Experimental Thermal and Fluid Science. 2002 Jun 1;26(2-4):389-407. 
[133] Gungor KE, Winterton RH. A general correlation for flow boiling in tubes and annuli. International Journal of Heat and Mass Transfer. 1986 Mar 1;29(3):351-8.

[134] Cooper MG. Saturation nucleate pool boiling-a simple correlation. InIChemE Symp. Ser. 1984 (Vol. 86, p. 786).

[135] Özdemir MR. Single-phase flow and flow boiling of water in rectangular metallic microchannels (Doctoral dissertation, Brunel University London).

[136] Lazarek GM, Black SH. Evaporative heat transfer, pressure drop and critical heat flux in a small vertical tube with R-113. International Journal of Heat and Mass Transfer. 1982 Jul 1;25(7):945-60.

[137] Li W, Wu Z. A general correlation for adiabatic two-phase pressure drop in micro/mini-channels. International Journal of Heat and Mass Transfer. 2010 Jun 1;53(13-14):2732-9.

[138] Candan AY, Markal BU, Aydin OR, Avci ME. Saturated flow boiling characteristics in single rectangular minichannels: effect of aspect ratio. Experimental Heat Transfer. 2018 Nov 2;31(6):531-51.

[139] Markal B, Aydin O, Avci M. Effect of aspect ratio on saturated flow boiling in microchannels. International Journal of Heat and Mass Transfer. 2016 Feb 1;93:130-43.

[140] Markal B, Aydin O, Avci M. An experimental investigation of saturated flow boiling heat transfer and pressure drop in square microchannels. International Journal of Refrigeration. 2016 May 1;65:1-1.

[141] Nedaei M. Subcooled flow boiling heat transfer enhancement in microchannels/tubes with modifications of surface characteristics with micro/nano structures and films (Master's dissertation).Retrieved from https://tez.yok.gov.tr/UlusalTezMerkezi/

[142] Kandlikar SG. A general correlation for saturated two-phase flow boiling heat transfer inside horizontal and vertical tubes.

[143] Passos JC, Kuser VF, Haberschill P, Lallemand M. Convective boiling of R-407c inside horizontal microfin and plain tubes. Experimental thermal and fluid science. 2003 Jul 1;27(6):705-13.

[144] Dalkılıç AS, Özman C, Sakamatapan K, Wongwises S. Experimental investigation on the flow boiling of R134a in a multi-microchannel heat sink. International Communications in Heat and Mass Transfer. 2018 Feb 1;91:125-37.

[145] Özdemir MR. Experimental study on single phase flow and boiling heat transfer in microchannels at high flow rates(Master's dissertation). Retrieved from https://tez.yok.gov.tr/UlusalTezMerkezi/

[146] Wambsganss MW, France DM, Jendrzejczyk JA, Tran TN. Boiling heat transfer in a horizontal smalldiameter tube.

[147] Reid RS, Pate MB, Bergles AE. Evaporation of refrigerant 113 flowing inside smooth tubes. American Society of Mechanical Engineers, New York, NY; 1987 Jan 1.

[148] Tran TN, Wambsganss MW, France DM. Small circular-and rectangular-channel boiling with two refrigerants. International Journal of Multiphase Flow. 1996 Jun 1;22(3):485-98.

[149] Kasza KE, Didascalou T, Wambsganss MW. Microscale flow visualization of nucleate boiling in small channels: mechanisms influencing heat transfer. Argonne National Lab., IL (United States); 1997 Jul 1.

[150] Shiferaw D, Karayiannis TG, Kenning DB. Flow boiling in a $1.1 \mathrm{~mm}$ tube with R134a: Experimental results and comparison with model. International Journal of Thermal Sciences. 2009 Feb 1;48(2):331-41.

[151] Ravigururajan TS, Cuta J, McDonald CE, Drost MK. Effects of heat flux on two-phase flow characteristics of refrigerant flows in a micro-channel heat exchanger. American Society of Mechanical Engineers, New York, NY (United States); 1996 Dec 31.

[152] Kundu A, Kumar R, Gupta A. Flow boiling heat transfer characteristics of R407C inside a smooth tube with different tube inclinations. International journal of refrigeration. 2014 Sep 1;45:1-2.

[153] Kundu A, Kumar R, Gupta A. Evaporative heat transfer of R134a and R407C inside a smooth tube with different inclinations. International Journal of Heat and Mass Transfer. 2014 Sep 1;76:523-33.

[154] Gang W, Bi Q, Wang H, Yang Z, Zhu X, Hu Z. Forced convection heat transfer using high temperature and pressure water in an upward-inclined tube. Journal of heat transfer. 2012 Feb 1;134(2).

[155] Morcos SM, Mobarak A, Hilal M, Mohareb MR. Boiling heat transfer in horizontal and inclined rectangular channels.

[156] Wang S, Yang D, Xie B, Wang L, Wang Y. Experimental investigation on heat transfer characteristics of water in inclined downward tube of a supercritical pressure CFB boiler. Journal of Thermal Science. 2015 Oct;24(5):478-87.

[157] Jeong U, Kim SJ. Subcooling effect on boiling heat transfer of inclined downward-facing surface under low flow and pressure. International Journal of Heat and Mass Transfer. 2018 Dec 1;127:182-95. 
Journal of Thermal Engineering, Review Article, Vol. 7, No. 3, pp. 483-549, March, 2021

Table 1. Experimental working conditions presented in the studies of pressure drop of condensation inside horizontal and vertical smooth and enhanced channels

\begin{tabular}{|c|c|c|c|c|c|c|c|c|c|c|c|}
\hline Researcher & Fluid & $\begin{array}{c}\text { Tube } \\
\text { Groove } \\
\text { Type }\end{array}$ & $\begin{array}{c}\text { Channel } \\
\text { Type }\end{array}$ & $\begin{array}{c}\text { Channel } \\
\text { Hydraulic } \\
\text { Diameter } \\
(\mathbf{m m}) \\
\end{array}$ & $\begin{array}{l}\text { Channel } \\
\text { Length } \\
(\mathrm{mm})\end{array}$ & Orientation & $\begin{array}{c}\text { Pressure } \\
\text { [MPa] }\end{array}$ & $\begin{array}{c}\text { Temperature } \\
\left({ }^{\circ} \mathrm{C}\right)\end{array}$ & $\begin{array}{c}\text { Heat } \\
\text { Flux } \\
\left(\mathbf{k W} / \mathbf{m}^{2}\right)\end{array}$ & $\begin{array}{c}\text { Mass } \\
\text { Flux } \\
\left(\mathrm{kg} / \mathbf{m}^{2} \mathbf{s}\right)\end{array}$ & $\begin{array}{l}\text { Vapour } \\
\text { Quality }\end{array}$ \\
\hline Cavallini et al. [26] & $\begin{array}{l}\text { R134a, R125, } \\
\text { R32, R410A, } \\
\text { R236ea }\end{array}$ & Smooth & Circular & 8 & 1600 & $0^{\circ}$ & 4 & $30-50$ & N/A & $100-750$ & $\begin{array}{c}0.15- \\
0.85\end{array}$ \\
\hline $\begin{array}{l}\text { Nualboonrueng and } \\
\text { Wongwises [27] }\end{array}$ & $\mathrm{R} 134 \mathrm{a}$ & $\begin{array}{l}\text { Smooth } \\
\text { Microfin }\end{array}$ & Circular & $8.12-8.92$ & 2500 & $0^{\circ}$ & N/A & $30-40$ & 20 & $400-800$ & $0.1-0.8$ \\
\hline $\begin{array}{c}\text { Briggs et al. } \\
{[28]}\end{array}$ & $\begin{array}{l}\text { CFC-113, CFC- } \\
\text { 113/Air Mixture }\end{array}$ & $\begin{array}{l}\text { Smooth } \\
\text { Microfin }\end{array}$ & Circular & 20.8 & 750 & $+90^{\circ}$ & $\begin{array}{c}0.0001- \\
0.6\end{array}$ & N/A & $5-60$ & $26-88$ & N/A \\
\hline Kim et al. [31] & FC-72 & Smooth & Rectangular & 1 & 299 & $0^{\circ}$ & $0.1-0.14$ & $57.2-62.3$ & $4.3-32.1$ & $68-367$ & N/A \\
\hline Son and Oh [32] & $\begin{array}{l}\text { R22, R134a, } \\
\text { R410A }\end{array}$ & Smooth & Circular & 1.77 & 1220 & $0^{\circ}$ & N/A & 40 & $5-30$ & $450-1050$ & $0.2-0.9$ \\
\hline Liu et al. [33] & $\mathrm{R} 152 \mathrm{a}$ & Smooth & $\begin{array}{c}\text { Circular } \\
\text { Rectangular }\end{array}$ & $1.152,0.952$ & 336,352 & $0^{\circ}$ & $0-6$ & 40,50 & N/A & $200-800$ & $0.1-0.9$ \\
\hline $\begin{array}{l}\text { Laohalertdecha and } \\
\text { Wongwises [34] }\end{array}$ & $\mathrm{R} 134 \mathrm{a}$ & $\begin{array}{c}\text { Smooth } \\
\text { Corrugated }\end{array}$ & Circular & 8.7 & 2000 & $0^{\circ}$ & N/A & $40-50$ & 5,10 & $200-700$ & $0-0.9$ \\
\hline $\begin{array}{c}\text { Salimpour and } \\
\text { Yarmohammadi } \\
\text { [35] }\end{array}$ & $\mathrm{R} 404 \mathrm{~A}$ & $\begin{array}{l}\text { Twisted- } \\
\text { Tape } \\
\text { Inserted }\end{array}$ & Circular & 14.1 & 1000 & $0^{\circ}$ & N/A & $27.88-34.61$ & $\begin{array}{c}4.33- \\
14.3\end{array}$ & $71.2-142.4$ & $\begin{array}{c}0.24- \\
0.87\end{array}$ \\
\hline $\begin{array}{c}\text { Salimpour and } \\
\text { Gholami [36] }\end{array}$ & R404A & $\begin{array}{l}\text { Coiled-Wire } \\
\text { Inserted }\end{array}$ & Circular & 14.1 & 1000 & $0^{\circ}$ & N/A & $27.88-33.2$ & $4.33-15$ & $71.2-142.4$ & $0.2-0.82$ \\
\hline
\end{tabular}


Journal of Thermal Engineering, Review Article, Vol. 7, No. 3, pp. 483-549, March, 2021

Table 2. Experimental working conditions presented in the studies of pressure drop of condensation inside inclined smooth and enhanced channels

\begin{tabular}{|c|c|c|c|c|c|c|c|c|c|c|c|}
\hline Researcher & Fluid & $\begin{array}{c}\text { Tube } \\
\text { Groove } \\
\text { Type }\end{array}$ & $\begin{array}{c}\text { Channel } \\
\text { Type }\end{array}$ & $\begin{array}{c}\text { Channel } \\
\text { Hydraulic } \\
\text { Diameter } \\
(\mathrm{mm})\end{array}$ & $\begin{array}{c}\text { Channel } \\
\text { Length } \\
(\mathbf{m m})\end{array}$ & Orientation & $\begin{array}{c}\text { Pressure } \\
\text { [MPa] }\end{array}$ & $\begin{array}{c}\text { Temperature } \\
\left({ }^{\circ} \mathrm{C}\right)\end{array}$ & $\begin{array}{c}\text { Heat } \\
\text { Flux } \\
\left(\mathbf{k W} / \mathbf{m}^{2}\right)\end{array}$ & $\begin{array}{c}\text { Mass } \\
\text { Flux } \\
\left(\mathbf{k g} / \mathbf{m}^{2} \mathbf{s}\right)\end{array}$ & $\begin{array}{l}\text { Vapour } \\
\text { Quality }\end{array}$ \\
\hline Lips and Meyer [38] & $\mathrm{R} 134 \mathrm{a}$ & Smooth & Circular & 8.38 & 1488 & $-90^{\circ}<\alpha<+90^{\circ}$ & N/A & 40 & 5.1 & 200 & $0.1-0.9$ \\
\hline Ahn et al. [40] & Water & Smooth & Circular & 40 & 3000 & $-10^{\circ}<\alpha<0^{\circ}$ & $0.1-0.5$ & $115-135$ & $150 \mathrm{~kW}$ & $10-50$ & $0.1-1$ \\
\hline $\begin{array}{c}\text { Würfel et al. } \\
\text { [41] }\end{array}$ & $\begin{array}{c}\text { Air-water } \\
\text { Air-nheptane } \\
\text { Nheptane }\end{array}$ & Smooth & Circular & 30 & 2000 & $0^{\circ}<\alpha<+90^{\circ}$ & N/A & N/A & N/A & N/A & N/A \\
\hline $\begin{array}{l}\text { Grolman and Fortuin } \\
\qquad[42]\end{array}$ & $\begin{array}{c}\text { Water } \\
\text { Saturated Air- } \\
\text { Water } \\
\text { Air-Tetracedane }\end{array}$ & Smooth & Circular & $15-51$ & $\begin{array}{l}1100 \\
15000\end{array}$ & $-3^{\circ}<\alpha<+6^{\circ}$ & 0.1 & $\begin{array}{c}\text { Room } \\
\text { Temperature }\end{array}$ & N/A & N/A & N/A \\
\hline $\begin{array}{c}\text { Ottens et al. } \\
{[44]}\end{array}$ & $\begin{array}{c}\text { Air-Water } \\
\text { (Air-Water } \\
\text { +Glycol) } \\
\text { (Air-Water } \\
\text { +Glycerol) } \\
\text { Tween80 }\end{array}$ & Smooth & Circular & $9.53-12.7$ & $\begin{array}{c}11000- \\
22000\end{array}$ & $-5^{\circ}<\alpha<+6^{\circ}$ & N/A & N/A & N/A & N/A & N/A \\
\hline Zhang et al. [45-46] & $\begin{array}{c}\text { Air- } \\
\text { AquiGlycerine } \\
\text { Air-Kerosene } \\
\text { Air-Lube Oil } \\
\text { Air-Water } \\
\text { Air-Light } \\
\text { Machine Oil } \\
\text { Natural Gas- } \\
\text { Crude Oil }\end{array}$ & Smooth & Circular & $23-76.3$ & $\begin{array}{c}10000- \\
25000\end{array}$ & $-90^{\circ}<\alpha<+90^{\circ}$ & $0.1-3$ & N/A & N/A & N/A & N/A \\
\hline
\end{tabular}


Journal of Thermal Engineering, Review Article, Vol. 7, No. 3, pp. 483-549, March, 2021

Table 3. Experimental working conditions presented in the studies of the heat transfer coefficient of condensation inside horizontal and vertical smooth and enhanced channels

\begin{tabular}{|c|c|c|c|c|c|c|c|c|c|c|c|}
\hline Researcher & Fluid & $\begin{array}{c}\text { Tube } \\
\text { Groove } \\
\text { Type }\end{array}$ & $\begin{array}{c}\text { Channel } \\
\text { Type }\end{array}$ & $\begin{array}{c}\text { Channel } \\
\text { Hydraulic } \\
\text { Diameter } \\
(\mathbf{m m})\end{array}$ & $\begin{array}{c}\text { Channel } \\
\text { Length } \\
(\mathrm{mm})\end{array}$ & Orientation & $\begin{array}{c}\text { Pressure } \\
\text { [MPa] }\end{array}$ & $\begin{array}{c}\text { Temperature } \\
\left({ }^{\circ} \mathrm{C}\right)\end{array}$ & $\begin{array}{c}\text { Heat } \\
\text { Flux } \\
\left(\mathbf{k W} / \mathbf{m}^{2}\right)\end{array}$ & $\begin{array}{c}\text { Mass } \\
\text { Flux } \\
\left(\mathrm{kg} / \mathrm{m}^{2} \mathrm{~s}\right)\end{array}$ & $\begin{array}{l}\text { Vapour } \\
\text { Quality }\end{array}$ \\
\hline Jung et al. [52] & $\begin{array}{l}\text { R12, R22, R32, } \\
\text { R123, R125, } \\
\text { R134a, R142b }\end{array}$ & Smooth & Circular & N/A & 1000 & $0^{\circ}$ & N/A & 40 & $7.3-7.7$ & $100-300$ & $\begin{array}{c}0.077- \\
0.23\end{array}$ \\
\hline $\begin{array}{c}\text { Zyhowski and } \\
\text { Brown [53] }\end{array}$ & $\begin{array}{l}\text { R245fa, R134a, } \\
\text { R1234yf, } \\
\text { R1234ze(E), }\end{array}$ & Smooth & Circular & N/A & N/A & N/A & $\begin{array}{c}0.341- \\
0.474\end{array}$ & 20,25 & N/A & N/A & N/A \\
\hline Ghim and Lee [54] & $\begin{array}{c}\text { R245fa, } \\
\text { Novec®649, } \\
\text { HFE-7000 }\end{array}$ & Smooth & Circular & 7.75 & 330.2 & $0^{\circ}$ & $\begin{array}{c}175.3- \\
343.2\end{array}$ & $49.9-66.2$ & N/A & $150-700$ & $\begin{array}{c}0.05- \\
0.95\end{array}$ \\
\hline Oh and Son [56] & $\begin{array}{l}\text { R22, R134a, } \\
\text { R410a }\end{array}$ & Smooth & Circular & 1.77 & 1220 & $0^{\circ}$ & 1.534 & 40 & N/A & $450-1050$ & $\begin{array}{c}0.07- \\
0.95\end{array}$ \\
\hline Yang and Jia [57] & $\mathrm{R} 410 \mathrm{a}$ & Smooth & Circular & 8.02 & $300-600$ & $+90^{\circ}$ & $\begin{array}{l}1.94- \\
2.93\end{array}$ & $31-48$ & $\mathrm{~N} / \mathrm{A}$ & $103-490$ & $\begin{array}{c}0.91- \\
0.98\end{array}$ \\
\hline Diani et al. [59] & R1234yf & Microfin & Circular & 3.4 & N/A & $0^{\circ}$ & $1-3$ & 30,40 & N/A & $100-1000$ & $0.2-0.95$ \\
\hline $\begin{array}{c}\text { Arslan and Eskin } \\
{[60]}\end{array}$ & $\mathrm{R} 134 \mathrm{a}$ & $\begin{array}{c}\text { Helical } \\
\text { Microfin }\end{array}$ & Circular & 9.49 & N/A & $+90^{\circ}$ & $\begin{array}{c}0.57- \\
0.59\end{array}$ & N/A & $1.5-5.5$ & $20-100$ & N/A \\
\hline $\begin{array}{l}\text { Yarmohammadi } \\
\text { and Farhadi [62] }\end{array}$ & $\mathrm{R} 404 \mathrm{a}$ & Corrugated & Circular & 8.7 & 1000 & $0^{\circ}$ & N/A & $29.2-35.8$ & N/A & $187-561$ & $\begin{array}{c}0.18- \\
0.85\end{array}$ \\
\hline $\begin{array}{l}\text { Li et al. } \\
\text { [63] }\end{array}$ & $\begin{array}{c}\text { R447a } \\
\text { (R32/R1234ze/R1 } \\
\text { 25), } \\
\text { R32/R134a, R32/ } \\
\text { R1234ze, R410a, } \\
\text { R32, R134a, } \\
\text { R1234ze }\end{array}$ & $\begin{array}{l}\text { Multi-port } \\
\text { extruded }\end{array}$ & Circular & 0.86 & 480 & $0^{\circ}$ & N/A & $35-45$ & N/A & $100-300$ & $\begin{array}{c}0.05- \\
0.96\end{array}$ \\
\hline $\begin{array}{c}\text { Aroonrat and } \\
\text { Wongwises [24] }\end{array}$ & $\mathrm{R} 134 \mathrm{a}$ & Dimpled & Circular & 8.1 & 1500 & $0^{\circ}$ & N/A & $40-50$ & $10-20$ & $300-500$ & $0.1-0.8$ \\
\hline
\end{tabular}


Journal of Thermal Engineering, Review Article, Vol. 7, No. 3, pp. 483-549, March, 2021

Table 4. Experimental working conditions presented in the studies of the heat transfer coefficient of condensation inside inclined smooth and enhanced channels

\begin{tabular}{|c|c|c|c|c|c|c|c|c|c|c|c|}
\hline Researcher & Fluid & $\begin{array}{c}\text { Tube } \\
\text { Groove } \\
\text { Type }\end{array}$ & $\begin{array}{c}\text { Channel } \\
\text { Type }\end{array}$ & $\begin{array}{c}\text { Channel } \\
\text { Hydraulic } \\
\text { Diameter } \\
\text { (mm) }\end{array}$ & $\begin{array}{c}\text { Channel } \\
\text { Length } \\
(\mathbf{m m})\end{array}$ & Orientation & $\begin{array}{c}\text { Pressure } \\
\text { [MPa] }\end{array}$ & $\begin{array}{c}\text { Temperature } \\
\left({ }^{\circ} \mathrm{C}\right)\end{array}$ & $\begin{array}{c}\text { Heat } \\
\text { Flux } \\
\left(\mathbf{k W} / \mathbf{m}^{2}\right)\end{array}$ & $\begin{array}{c}\text { Mass } \\
\text { Flux } \\
\left(\mathrm{kg} / \mathrm{m}^{2} \mathrm{~s}\right)\end{array}$ & $\begin{array}{l}\text { Vapour } \\
\text { Quality }\end{array}$ \\
\hline $\begin{array}{c}\text { Lips and Meyer } \\
{[66,37]} \\
\end{array}$ & $\mathrm{R} 134 \mathrm{a}$ & Smooth & Circular & 8.38 & 1488 & $-90^{\circ}<\alpha<+90^{\circ}$ & N/A & 40 & $0.2 \mathrm{~kW}$ & $200-600$ & $0.1-0.9$ \\
\hline Adelaja et al. [68] & $\mathrm{R} 134 \mathrm{a}$ & Smooth & Circular & 9.55 & 1488 & $-90^{\circ}<\alpha<+90^{\circ}$ & N/A & 50 & $\begin{array}{c}0.23- \\
0.27 \mathrm{~kW}\end{array}$ & $200-400$ & $0.1-0.9$ \\
\hline $\begin{array}{c}\text { Mohseni et al. } \\
\text { [69] }\end{array}$ & $\mathrm{R} 134 \mathrm{a}$ & Smooth & Circular & 8.38 & 1040 & $-90^{\circ}<\alpha<+90^{\circ}$ & N/A & 35 & N/A & $53-212$ & $0.2-0.8$ \\
\hline Xing et al. [70] & $\mathrm{R} 245 \mathrm{fa}$ & Smooth & Circular & 14.81 & 1200 & $-90^{\circ}<\alpha<+90^{\circ}$ & $\begin{array}{c}40.5 \\
\text { (Vapour } \\
\text { Pressure) }\end{array}$ & 55.4 & $\begin{array}{c}1.16- \\
4.34 \mathrm{~kW}\end{array}$ & $\begin{array}{c}191.3- \\
705.4\end{array}$ & $\begin{array}{c}0.191- \\
0.947\end{array}$ \\
\hline $\begin{array}{c}\text { Wang and Ma } \\
{[71]}\end{array}$ & Water & Smooth & Circular & 20 & 1800 & $+15^{\circ}<\alpha<+90^{\circ}$ & $\begin{array}{c}0.008- \\
0.15\end{array}$ & N/A & $10-40$ & $\begin{array}{c}18-108 \\
\mathrm{~kg} / \mathrm{h}\end{array}$ & N/A \\
\hline $\begin{array}{c}\text { Wang \& Du } \\
{[72]}\end{array}$ & Water & Smooth & Circular & N/A & N/A & $0^{\circ}<\alpha<+45^{\circ}$ & $\begin{array}{c}1.077- \\
1.571 \\
\text { (Vapour } \\
\text { Pressure) }\end{array}$ & $40-100$ & $0-3 \mathrm{~kW}$ & $\begin{array}{l}11.3- \\
94.5\end{array}$ & $0-1$ \\
\hline $\begin{array}{c}\text { Yang et al. } \\
\text { [73] }\end{array}$ & Steam (Water) & Smooth & Circular & 50 & 4050 & $+30^{\circ}$ & N/A & $85-103$ & N/A & $\begin{array}{c}73-103 \\
\mathrm{~kg} / \mathrm{h}\end{array}$ & N/A \\
\hline $\begin{array}{c}\text { Akhavan-Behabadi et } \\
\text { al. [79] }\end{array}$ & $\mathrm{R} 134 \mathrm{a}$ & Microfin & Circular & 8.92 & 1040 & $-90^{\circ}<\alpha<+90^{\circ}$ & N/A & $26-32$ & $8.7-20.3$ & $54-107$ & $0.2-0.8$ \\
\hline $\begin{array}{c}\text { Khoeini et al. } \\
{[81]}\end{array}$ & $\mathrm{R} 134 \mathrm{a}$ & Corrugated & Circular & 8.32 & 700 & $-90^{\circ}<\alpha<+90^{\circ}$ & N/A & $24-38$ & $8.8-42.2$ & $87-253$ & $0.2-0.8$ \\
\hline Yildiz et al. [82] & $\mathrm{R} 134 \mathrm{a}$ & Microfin & Circular & 7 & 500 & $+30^{\circ}<\alpha<+90^{\circ}$ & 0.74 & N/A & N/A & $\begin{array}{c}1.44- \\
2.59 \mathrm{~kg} / \mathrm{s}\end{array}$ & N/A \\
\hline
\end{tabular}


Journal of Thermal Engineering, Review Article, Vol. 7, No. 3, pp. 483-549, March, 2021

Table 5. Experimental working conditions presented in the studies of condensation and flow regimes inside channels

\begin{tabular}{|c|c|c|c|c|c|c|c|c|c|c|c|c|}
\hline Researcher & Fluid & $\begin{array}{c}\text { Tube } \\
\text { Groove } \\
\text { Type }\end{array}$ & $\begin{array}{c}\text { Channel } \\
\text { Type }\end{array}$ & $\begin{array}{c}\text { Channel } \\
\text { Hydraulic } \\
\text { Diameter } \\
(\mathbf{m m}) \\
\end{array}$ & $\begin{array}{l}\text { Channel } \\
\text { Length } \\
(\mathrm{mm})\end{array}$ & Orientation & $\begin{array}{c}\text { Pressure } \\
\text { [MPa] }\end{array}$ & $\begin{array}{c}\text { Temperature } \\
\left({ }^{\circ} \mathrm{C}\right)\end{array}$ & $\begin{array}{c}\text { Heat } \\
\text { Flux } \\
\left(\mathbf{k W} / \mathbf{m}^{2}\right)\end{array}$ & $\begin{array}{c}\text { Mass } \\
\text { Flux } \\
\left(\mathrm{kg} / \mathbf{m}^{2} \mathbf{s}\right)\end{array}$ & Flow Regimes & Identicator \\
\hline $\begin{array}{c}\text { Nitheanandan } \\
\text { and Soliman } \\
{[11]}\end{array}$ & Water & Smooth & Circular & 13.4 & 1040 & $-10^{\circ}<\alpha<+10^{\circ}$ & $0.1-0.18$ & $99.6-117$ & N/A & $21.9-277$ & $\begin{array}{l}\text { Annular/annular } \\
\text { wavy/wavy/slug }\end{array}$ & $\begin{array}{c}\text { Visual } \\
\text { Observation }\end{array}$ \\
\hline $\begin{array}{c}\text { Ghajar and } \\
\text { Tang [13] }\end{array}$ & Air-Water & Smooth & Circular & 27.9 & 2790 & $0^{\circ}<\alpha<+7^{\circ}$ & N/A & N/A & $1.8-10.9$ & $\begin{array}{l}0.0131-1.13 \\
\mathrm{~kg} / \mathrm{min} \\
\text { (for air) } \\
0.761-42.5 \\
\mathrm{~kg} / \mathrm{min} \\
\text { (for water) }\end{array}$ & $\begin{array}{c}\text { Annular/wavy/ } \\
\text { stratified/slug/ } \\
\text { bubbly }\end{array}$ & $\begin{array}{c}\text { Visual } \\
\text { Observation }\end{array}$ \\
\hline $\begin{array}{c}\text { Cao et al. } \\
\text { [16] }\end{array}$ & R245fa & Smooth & Circular & 14.7 & 1600 & $-30^{\circ}<\alpha<+30^{\circ}$ & 0.50 & $63.1 \pm 0.3$ & $\begin{array}{c}33.78- \\
67.2\end{array}$ & $\begin{array}{c}198.8- \\
504.7\end{array}$ & $\begin{array}{c}\text { Annular/ } \\
\text { Intermittent/ } \\
\text { Stratified-wavy/ } \\
\text { Stratified- } \\
\text { smooth }\end{array}$ & $\begin{array}{l}\text { High-Speed } \\
\text { Flow } \\
\text { Visualisation }\end{array}$ \\
\hline $\begin{array}{l}\text { Lips and } \\
\text { Meyer } \\
{[17]}\end{array}$ & $\mathrm{R} 134 \mathrm{a}$ & Smooth & Circular & 8.38 & 1488 & $-90^{\circ}<\alpha<+90^{\circ}$ & N/A & 40 & N/A & $200-400$ & $\begin{array}{l}\text { İntermittent/ } \\
\text { Annular/ } \\
\text { stratified }\end{array}$ & $\begin{array}{c}\text { Visual } \\
\text { Observation }\end{array}$ \\
\hline $\begin{array}{c}\text { Mozafari et al. } \\
{[20]}\end{array}$ & $\mathrm{R} 134 \mathrm{a}$ & U-Bend & Circular & 7.747 & N/A & $-90^{\circ}<\alpha<+90^{\circ}$ & N/A & $11.6-29.5$ & N/A & $52-225$ & $\begin{array}{l}\text { Slug (stratified- } \\
\text { wavy)/ } \\
\text { intermittent/ } \\
\text { semi- } \\
\text { annular/annular }\end{array}$ & $\begin{array}{c}\text { High-Speed } \\
\text { Digital } \\
\text { Camera }\end{array}$ \\
\hline $\begin{array}{c}\text { Park and } \\
\text { Mudawar [22] }\end{array}$ & FC-72 & Smooth & Circular & 11.89 & 1260 & $+90^{\circ}$ & $0.1-0.11$ & $57.41-72.93$ & N/A & $\begin{array}{c}1.08-12.93 \\
\mathrm{~g} / \mathrm{s} \text { (for FC- } \\
72 \text { ) } \\
6.09-977.79 \\
\text { (for cooling } \\
\text { water) }\end{array}$ & $\begin{array}{c}\text { Falling } \\
\text { film/oscillating } \\
\text { film/flooding/ } \\
\text { climbing film }\end{array}$ & $\begin{array}{c}\text { High-Speed } \\
\text { Video } \\
\text { Camera }\end{array}$ \\
\hline $\begin{array}{c}\text { Thome et al. } \\
\text { [24] }\end{array}$ & $\begin{array}{c}15 \\
\text { Different } \\
\text { Fluids }\end{array}$ & Smooth & Circular & $3.1-21.4$ & N/A & $0^{\circ}$ & $\begin{array}{c}0.08- \\
3.18\end{array}$ & $23.1-65.2$ & $10-40$ & $24-1022$ & $\begin{array}{c}\text { Annular/ } \\
\text { intermittent/ } \\
\text { stratified- } \\
\text { wavy/fully } \\
\text { stratified/mist }\end{array}$ & $\begin{array}{l}\text { Different } \\
\text { Types }\end{array}$ \\
\hline
\end{tabular}


Journal of Thermal Engineering, Review Article, Vol. 7, No. 3, pp. 483-549, March, 2021

Table 6. Correlations used for the determination of Nusselt number and two-phase heat transfer condensation in channels during condensation

\begin{tabular}{|c|c|c|c|}
\hline Researcher & Study Type & Model/Correlation & Validity Range \\
\hline $\begin{array}{l}\text { Wang and } \\
\text { Ma [71] }\end{array}$ & Experimental & $\frac{h_{m, o}}{h_{N u}}=\left(\frac{2 L}{D}\right)^{\frac{\cos \alpha}{4}}\left(0.54+5.86 \times 10^{-3} \alpha\right) ; h_{N u}=0.943\left[\frac{\rho_{f} g h_{f v} k_{f}^{3} \sin \alpha}{L \mu_{f}^{2} \Delta T}\right]^{1 / 4}$ & $\begin{array}{l}+15^{\circ}<\alpha<+90^{\circ} \\
\text { For liquid filling is } \\
\text { larger than } 10 \%\end{array}$ \\
\hline $\begin{array}{l}\text { Wang and } \\
\text { Du [72] }\end{array}$ & $\begin{array}{c}\text { Experimental \& } \\
\text { Analytical }\end{array}$ & $h\left(z_{i}, \varphi_{i}\right)=\frac{1}{\left[\ln \frac{R+\delta_{w}}{R k_{w}}+\ln \frac{R}{R-\delta_{f}\left(z_{i}, \varphi_{i}\right) k_{f}}\right] R} ; N u\left(z_{i}\right)=\frac{1}{2 \pi} \int_{0}^{2 \pi} \frac{2 h\left(z_{i}, \varphi_{i}\right) R}{k_{f}} \mathrm{~d} \varphi$ & $0^{\circ}<\alpha<+45^{\circ}$ \\
\hline $\begin{array}{l}\text { Hussein et } \\
\text { al. [74] }\end{array}$ & Theoretical & $h_{\text {cond }}=\left(\frac{L}{D}\right)^{(0.254)(\cos \alpha)^{0.385}}\left[\frac{\rho_{f}^{2} h_{f v} g k_{f}^{3}}{\mu_{f}^{2} L \Delta T}\right]^{0.25}\left[0.997-0.334(\cos \alpha)^{0.108}\right]$ & $\begin{array}{l}0^{\circ}<\alpha<+90^{\circ} \\
\text { For flat-plate solar } \\
\text { collectors with } \\
\text { inclined wickless } \\
\quad \text { heat pipes }\end{array}$ \\
\hline $\begin{array}{l}\text { Würfel et al. } \\
\qquad[41]\end{array}$ & Experimental & $\begin{array}{l}N u=a G(\alpha) \operatorname{Re}_{\text {cond }}^{c}\left(1+\tau^{+}\right)^{d} P r_{\text {cond }}^{e} ; G(\alpha)=(1+\sin \alpha)^{b} ; \tau^{+}=\frac{f_{F, 2 \mathrm{P}} \psi \rho_{g} V_{g}^{2}}{\left(8 \rho_{\text {cond }} v^{2}\right) / L} ; L=\left(\frac{v^{2}}{g}\right)^{1 / 3} \\
\psi=\frac{f_{F, \text { cond }}}{f_{F, 2 \mathrm{P}}} ; \operatorname{Re} e_{\text {cond }}=\frac{\stackrel{\mathrm{g}}{m_{\text {cond }}}}{\pi D \mu_{\text {cond }}} ; f \text { for } a=2.536 \times 10^{-2}, b=0.214, c=0.077, d=0.501 e=0.4\end{array}$ & $\begin{array}{l}0^{\circ}<\alpha<+90^{\circ} \\
\text { For film } \\
\text { condensation in } \\
\text { turbulent two-phase } \\
\quad \text { flow }\end{array}$ \\
\hline $\begin{array}{l}\text { Shah } \\
\text { [75] }\end{array}$ & Theoretical & $\begin{array}{l}h_{\mathrm{I}}=h_{1 \mathrm{P}}\left(\frac{\mu_{f}}{14 \mu_{v}}\right)^{n}\left[(1-x)^{0.8}+\frac{3.8 x^{0.76}(1-x)^{0.04}}{p_{\mathrm{r}}^{0.38}}\right] ; h_{N u}=1.32 R e_{1 P, f}^{-1 / 3}\left[\frac{\rho_{f}\left(\rho_{f}-\rho_{v}\right) g k_{f}^{3}}{\mu_{f}^{2}}\right]^{1 / 3} ; \operatorname{Re}_{1 \mathrm{P}, f}=\frac{G(1-x) D}{\mu_{f}} \\
n=0.0058+0.0557 p_{\mathrm{r}} ; h_{2 \mathrm{P}}=h_{\mathrm{I}} \text { for Regime I } ; h_{2 \mathrm{P}}=h_{\mathrm{I}}+h_{N u} \text { for Regime II } ; h_{2 \mathrm{P}}=h_{N u} \text { for Regime III }\end{array}$ & $\begin{array}{l}\text { For horizontal, } \\
\text { vertical downward, } \\
15^{\circ} \text { downward ( } 22 \\
\text { various fluids) }\end{array}$ \\
\hline $\begin{array}{l}\text { Lips and } \\
\text { Meyer [38] }\end{array}$ & Experimental & $\begin{array}{l}\bar{h}=\frac{\bar{h}_{f} \theta_{\text {strat }}+\bar{h}_{p}\left(\pi-\theta_{\text {strat }}\right)}{\pi} ; \bar{h}_{f}=\frac{1}{\theta_{\text {strat }}} \int_{0}^{\theta_{s t r a t}} \frac{k_{f}}{\delta(\theta)} d \theta ; \bar{h}_{p}=\frac{1}{\sum d s_{w, i}} \sum h_{p, i} d s_{w, i} ; h_{p, i}=\frac{\left(d s_{w, i}-d s\right) k_{f}}{d s_{w, i} \delta_{i} \ln \left(d s_{w, i} / d s\right)} \\
\delta(\theta)=\left(\frac{3}{2} \frac{\mu_{f} \Delta T k_{f} D}{\rho_{f}\left(\rho_{f}-\rho_{v}\right) g h_{f v} \cos \alpha} Z\right)^{1 / 4} ; Z=\frac{4}{3} \frac{1}{\sin ^{4 / 3}(\theta)} \int_{0}^{\theta} \sin ^{4 / 3} t d t\end{array}$ & $\begin{array}{l}-90^{\circ}<\alpha<+90^{\circ} \\
\text { For R134a } \\
\text { refrigeration in a } \\
\text { smooth tube }\end{array}$ \\
\hline
\end{tabular}


Journal of Thermal Engineering, Review Article, Vol. 7, No. 3, pp. 483-549, March, 2021

Table 6. Correlations used for the determination of Nusselt number and two-phase heat transfer condensation in channels during condensation (Cont.)

\begin{tabular}{|c|c|c|c|}
\hline Researcher & Study Type & Model/Correlation & Validity Range \\
\hline Yang et al. [73] & Experimental & $\begin{array}{l}N u=A \operatorname{Re}_{f}{ }_{f}^{0.193}\left(\frac{P r_{f}}{X_{t t}}\right)^{0.34} F_{\alpha}^{0.3} ; A=\frac{300 D^{0.8}}{\mu_{f}^{0.145} c_{p f}^{0.34} k_{f}^{0.66}} ; R e_{f}=\frac{G D(1-x)}{\mu_{f}} \\
X_{t t}=\left(\frac{1-x}{x}\right)^{0.9}\left(\frac{\rho_{v}}{\rho_{f}}\right)^{0.5}\left(\frac{\mu_{f}}{\mu_{v}}\right)^{0.1} ; F_{\alpha}=\left(1+(1-x)^{0.2} \cos \left(\alpha-10^{\circ}\right)\right) / x^{0.4}\end{array}$ & $\begin{array}{l}\text { For inclination angle } \\
\text { of }+30^{\circ} \text { and better } \\
\text { prediction of steam } \\
\text { condensation in } \\
\text { larger-diameter } \\
\text { inclined tubes }\end{array}$ \\
\hline Ahn et al. [39] & Theoretical & $h_{f}=0.729\left(1+8.7 \times 10^{-4} R e_{v}^{0.57}\right)\left[\frac{g \rho_{f}\left(\rho_{f}-\rho_{v}\right) h_{f v} k_{f}{ }^{3}}{\mu_{f} D\left(T_{s a t}-T_{w}\right)}\right]^{0.25} ; R e_{v}=\frac{G D_{h v} x}{\mu_{v} \varepsilon} ; D_{h v}=\frac{4 A_{v}}{S_{v}+S_{i n t}}$ & $-3^{\circ}<\alpha<0^{\circ}$ \\
\hline $\begin{array}{l}\text { Xing et al. } \\
\text { [70] }\end{array}$ & Experimental & $\begin{array}{l}\frac{h}{h_{\alpha=0}}=\left(1+\frac{3.024}{F r_{v}^{0.935}} \alpha\right)\left\{1+\left[\frac{0.172}{F r^{0.17} x_{\text {ave }}^{0.239}}-0.197\right] \sin (3 \alpha)\right\} \text { for } \mathrm{O}^{\circ}<\alpha<90^{\circ} ; \quad F r=\frac{G^{2}}{\rho_{f}^{2} g d_{\mathrm{i}}} \\
\frac{h}{h_{\alpha=0}}=\left(1+\frac{3.024}{F r_{v}^{0.935}} \alpha\right)\left\{1+\left[\frac{0.24}{F r^{0.584} x_{\text {ave }}^{0.654}}-0.03\right]|\sin (6 \alpha)|\right\} \text { for }-90^{\circ}<\alpha<0^{\circ} ; \quad F r_{v}=\frac{G^{2} x_{\text {ave }}^{2}}{\rho_{v}^{2} g d_{\mathrm{i}}}\end{array}$ & $\begin{array}{l}-90^{\circ}<\alpha<+90^{\circ} \\
\text { For R245fa } \\
\text { refrigeration }\end{array}$ \\
\hline $\begin{array}{l}\text { Shah } \\
\text { [76] }\end{array}$ & Theoretical & $\begin{array}{l}h_{\mathrm{I}}=h_{1 \mathrm{P}}\left(\frac{\mu_{f}}{14 \mu_{g}}\right)^{n}\left[1+\frac{3.8}{Z^{0.95}}\right] ; h_{N u}=1.32 R e_{1 P, f}^{-1 / 3}\left[\frac{\rho_{f}\left(\rho_{f}-\rho_{v}\right) g k_{f}^{3}}{\mu_{f}^{2}}\right]^{1 / 3} \Leftrightarrow h_{2 \mathrm{P}}=h_{\mathrm{I}} \text { for Regime I } \\
h_{2 \mathrm{P}}=h_{\mathrm{I}}+h_{N u} \text { for Regime II } ; h_{2 \mathrm{P}}=h_{N u} \text { for Regime III } ; Z=(1 / x-1)^{0.8} p_{\mathrm{r}}^{0.4}\end{array}$ & $\begin{array}{l}-90^{\circ}<\alpha<+90^{\circ} \\
\text { For conventional } \\
\text { smooth and mini- } \\
\quad \text { channel }\end{array}$ \\
\hline $\begin{array}{c}\text { Adelaja et al. } \\
{[68]}\end{array}$ & Experimental & $\begin{array}{l}\frac{N u_{2 \mathrm{P}}}{N u}=1.03 X_{t t}^{-0.56} \operatorname{HMFR}^{0.2} ; N u=0.23 \operatorname{Re}_{f}^{0.8} \operatorname{Pr}_{f}^{0.4} ; H M F R=\left(\frac{Q / \mathrm{A}}{G h_{f v}}\right) \\
X_{t t}=\left(\frac{1-x}{x}\right)^{0.9}\left(\frac{\rho_{v}}{\rho_{f}}\right)^{0.5}\left(\frac{\mu_{f}}{\mu_{v}}\right)^{0.1} ; \operatorname{Re}_{f}=\frac{G D(1-x)}{\mu_{f}} ; \operatorname{Pr}=\frac{\mu_{f} \mathrm{c}_{p f}}{k_{f}}\end{array}$ & $\begin{array}{l}-90^{\circ}<\alpha<+90^{\circ} \\
\text { For R134a } \\
\text { refrigeration } \\
\text { in a smooth tube }\end{array}$ \\
\hline $\begin{array}{c}\text { Mohseni et al. } \\
\text { [69] }\end{array}$ & Experimental & $\begin{array}{l}N u=1.371 \operatorname{Pr}^{1 / 3}\left(G D / \mu_{f}\right)^{0.69}\left[\frac{\left(\rho_{f} / \rho_{\text {mix }}\right)_{\text {in }}^{0.5}+\left(\rho_{f} / \rho_{\text {mix }}\right)_{\text {out }}^{0.5}}{2}\right]^{0.91} .(\Delta x . D / L)^{0.29}\left(1+(1-1)^{0.1} \cos \left(\alpha-10^{o}\right)\right)^{0.1} \\
\rho_{f} / \rho_{\text {mix }}=1+x\left(\rho_{f}-\rho_{v}\right) / \rho_{v} ; N u=\frac{h D}{k_{f}} ; \operatorname{Pr}=\frac{\mu_{f} c_{p f}}{k_{f}}\end{array}$ & $\begin{array}{c}-90^{\circ}<\alpha<+90^{\circ} \\
\text { For R134a } \\
\text { refrigeration in a } \\
\text { smooth tube }\end{array}$ \\
\hline Akers et al. [65] & Experimental & \begin{tabular}{|l|l|l} 
For $R e_{e q} \leq 5 \times 10^{4}$ & $N u_{l}=5.03 R e_{e q}{ }^{1 / 3} \operatorname{Pr}_{l}{ }^{1 / 3}$ \\
For $R e_{e q}>5 \times 10^{4}$ & $N u_{l}=0.0265 R e_{e q}{ }^{0.8} P_{l}{ }^{1 / 3}$ \\
& where, $N u_{l}=\frac{h D_{h}}{k_{l}} ; R e_{e q}=\frac{G_{e q} D_{h}}{\mu_{l}} ; G_{e q}=G\left[(1-x)+x\left(\frac{\rho_{l}}{\rho_{v}}\right)^{0.5}\right]$
\end{tabular} & $\begin{array}{c}\text { For } \\
\text { horizontal tubes }\end{array}$ \\
\hline
\end{tabular}


Journal of Thermal Engineering, Review Article, Vol. 7, No. 3, pp. 483-549, March, 2021

Table 7. Correlations used for the determination of frictional multiplier/frictional pressure drop in tubes during condensation

\begin{tabular}{|c|c|c|c|}
\hline Researcher & Study Type & Model/Correlation & Validity Range \\
\hline $\begin{array}{l}\text { Grolman and } \\
\text { Fortuin [42] }\end{array}$ & Experimental & $\begin{array}{l}f=\frac{f_{\text {int }}}{\left(0.05+f_{\text {int }}\right)+\left(1-H_{f}\right)^{1.5}}\left(\frac{v_{g s}}{\sqrt{g D}}\right)\left(\frac{\sigma_{\text {int }}}{\mu_{f} \sqrt{g D}}\right)^{0.04}\left(\frac{\rho_{f} g D^{2}}{\sigma_{i n t}}\right)^{0.22} ; f_{\text {int }}=\frac{0.0625}{\left[\log _{10}\left(\frac{15}{R e_{g}}+\frac{k_{e}}{3.715 D}\right)\right.} \\
H_{f}=\frac{v_{f s}}{v_{g s}}\left[1+\left(\frac{\rho_{f}}{\rho_{g}} 108 \operatorname{Re}_{f s}^{-0.726}\right)^{0.5}\right]\end{array}$ & $\begin{array}{l}-3^{\circ}<\alpha<+6^{\circ} \\
\text { For air-water } \\
\text { and air-tetracedane } \\
\text { condensation }\end{array}$ \\
\hline $\begin{array}{l}\text { Ottens et al. } \\
\qquad 44]\end{array}$ & Theoretical & $\begin{array}{l}\frac{f_{\text {int }}}{f_{g}}=\frac{\mathrm{C}}{v_{i n t}}+7.21 \sqrt{\frac{h_{f}}{D}\left(\frac{v_{g s}}{4.5}-1\right)} \text { for } v_{g s}<4.5 \mathrm{~m} / \mathrm{s} \quad ; \frac{f_{\text {int }}}{f_{g}}=6.80 \frac{\mathrm{C}}{\sqrt{g D}}-1.82 \quad \text { for } f_{\text {int }}<f_{g} \\
h_{f}=0.5 D\left(1-\left(1-H_{f} / \theta\right)^{0.5}\right) ; H_{f}=A_{f} /\left(A_{f}+A_{g}\right)\end{array}$ & $-5^{\circ}<\alpha<+6^{\circ}$ \\
\hline $\begin{array}{c}\text { Zhang et al. } \\
\text { [45] }\end{array}$ & Theoretical & $\begin{array}{l}f=C \operatorname{Re}^{-n} ; C=16, n=1 \text { for } \operatorname{Re}<2000 ; C=0.046, n=0.2 \text { for } \operatorname{Re}>3000 \\
f_{\text {int }}=f_{g}\left[1+14.3 H_{f}\left(\frac{v_{g s}}{v_{g s, t}}-1\right)\right]\end{array}$ & $\begin{array}{l}-90^{\circ}<\alpha<+90^{\circ} \\
\text { The model is based } \\
\text { on the slug flow } \\
\text { dynamics }\end{array}$ \\
\hline $\begin{array}{l}\text { Würfel et al. } \\
\text { [41] }\end{array}$ & Experimental & $\begin{array}{l}f_{F, 2 \mathrm{P}}=f_{F, 1 \mathrm{P}}\left(1+a \cdot R e_{F, W}^{b} \operatorname{Re}_{\tau, 2 \mathrm{P}}^{c}\right) ; f_{F, 1 \mathrm{P}}=0.3414 R e_{g}^{-0.25} ; \operatorname{Re}_{F, W}=(1-E) R e_{f} ; R e_{\tau, 2 \mathrm{P}}=\frac{\delta_{f} v_{\tau, 2 \mathrm{P}}}{v_{f}} \\
\delta_{f}=\frac{v_{\text {sonic }} \Delta \tau_{f}}{2} ; v_{\tau, 2 \mathrm{P}}=\sqrt{\frac{\tau_{i n t}}{\rho_{g}}} ; a=2.98 \cdot 10^{-6} b=1.66 \quad c=0.529\end{array}$ & $\begin{array}{l}0^{\circ}<\alpha<+90^{\circ} \\
\text { For film } \\
\text { condensation in } \\
\text { turbulent two-phase } \\
\quad \text { flow }\end{array}$ \\
\hline $\begin{array}{c}\text { Woldesemayat } \\
\text { and Ghajar } \\
\text { [47] }\end{array}$ & Theoretical & $\begin{array}{l}\varepsilon=\frac{v_{s v}}{v_{s v}\left(1+\left(\frac{v_{s f}}{v_{s v}}\right)^{\left(\rho_{v} / \rho_{f}\right)^{0.1}}\right)+2.9\left[\frac{g D \sigma(1+\cos \alpha)\left(\rho_{f}-\rho_{v}\right)}{\rho_{f}^{2}}\right]^{0.25}+(1.22+1.22 \sin \alpha)^{\mathrm{P}_{\text {atm }} / \mathrm{P}_{\text {system }}}} \\
v_{\text {drift }}=2.9\left[\frac{g D \sigma(1+\cos \alpha)\left(\rho_{f}-\rho_{v}\right)}{\rho_{f}{ }^{2}}\right]^{0.25}+(1.22+1.22 \sin \alpha)^{\mathrm{P}_{\text {atm }} / \mathrm{P}_{\text {system }}}\end{array}$ & $\begin{array}{l}-90^{\circ}<\alpha<+90^{\circ} \\
\text { For air/kerosene, } \\
\quad \text { air/lubeoil, } \\
\text { air/water, air/light- } \\
\quad \text { machine oil, } \\
\text { and natural- } \\
\text { gas/crude-oil fluids }\end{array}$ \\
\hline
\end{tabular}


Journal of Thermal Engineering, Review Article, Vol. 7, No. 3, pp. 483-549, March, 2021

Table 8. Major findings presented in the studies of condensation in tubes

\begin{tabular}{|c|c|c|}
\hline Researcher & Graph Axes & Trends \\
\hline \multirow{2}{*}{$\begin{array}{l}\text { Wongwises and } \\
\text { Pipathattakul } \\
\text { [87] }\end{array}$} & $\Delta \mathrm{P}-\mathrm{V}$ & Pressure drop increases with increasing superficial gas velocity \\
\hline & $\varepsilon-\mathrm{V}$ & Void fraction increases with increasing superficial gas velocity \\
\hline \multirow{3}{*}{$\begin{array}{l}\text { Lips and Meyer } \\
{[66,37-38]}\end{array}$} & $\alpha-h$ & $\begin{array}{l}\text { Inclination angle affects the heat transfer coefficient differently } \\
\text { for various mass flows }\end{array}$ \\
\hline & $\Delta \mathrm{P}-\alpha$ & Pressure drop increases with increasing inclination angle \\
\hline & $\varepsilon-\alpha$ & Void fraction decreases with increasing inclination angle \\
\hline $\begin{array}{l}\text { Adelaja et al. } \\
\text { [68] }\end{array}$ & $\alpha-h$ & $\begin{array}{l}\text { Heat transfer coefficient increases with increasing inclination angle } \\
\left(\text { for } \alpha<0^{\circ}\right) \\
\text { Inclination angle affects the heat transfer coefficient differently for } \\
\text { various mass flows }\left(\text { for } \alpha<0^{\circ}\right)\end{array}$ \\
\hline $\begin{array}{l}\text { Mohseni et al. } \\
\text { [69] }\end{array}$ & $h-x$ & Heat transfer coefficient increases with increasing vapour quality \\
\hline Xing et al. [70] & $\Delta \mathrm{P}-\alpha$ & $\begin{array}{l}\text { General trend is that the pressure drop increases with increasing } \\
\text { inclination angle, except for partial decreases }\end{array}$ \\
\hline $\begin{array}{c}\text { Wang and Ma } \\
\text { [71] }\end{array}$ & $\frac{h_{m, o}}{h_{N u}}-\alpha$ & $\begin{array}{l}\text { Mean condensation heat transfer ratio changes with the inclination } \\
\text { angle to peak at around } 40^{\circ}\end{array}$ \\
\hline $\begin{array}{l}\text { Wang and } \mathrm{Du} \\
\quad[72]\end{array}$ & $\mathrm{Nu}-(1-\mathrm{x})$ & Nusselt number increases with increasing vapour quality \\
\hline Ahn et al. [39] & $\mathrm{Nu}_{\mathrm{lam}} / \mathrm{Nu}_{\mathrm{turb}}-\mathrm{Re}$ & $\begin{array}{l}\text { Ratio of Nusselt number increases with vapour Reynolds number (for } \\
\text { film condensation heat transfer) }\end{array}$ \\
\hline \multirow{3}{*}{ Ahn et al. [40] } & $h-x$ & Heat transfer coefficient increases with increasing vapour quality \\
\hline & $h-G$ & Heat transfer coefficient increases with increasing mass flux \\
\hline & h-P & Heat transfer coefficient decreases with increasing pressure drop \\
\hline \multirow{3}{*}{ Yang et al. [73] } & h-Re & Heat transfer coefficient increases with increasing Reynolds number \\
\hline & h-L & Heat transfer coefficient decreases with increasing tube axial distance \\
\hline & $\mathrm{T}_{\text {steam }}-\mathrm{L}$ & Steam temperature decreases with increasing tube axial distance \\
\hline
\end{tabular}


Journal of Thermal Engineering, Review Article, Vol. 7, No. 3, pp. 483-549, March, 2021

Table 9. Experimental working conditions presented in the studies of the pressure drop of boiling inside horizontal and vertical smooth and enhanced channels

\begin{tabular}{|c|c|c|c|c|c|c|c|c|c|c|c|}
\hline Researcher & Fluid & $\begin{array}{c}\text { Tube } \\
\text { Groove } \\
\text { Type }\end{array}$ & $\begin{array}{c}\text { Channel } \\
\text { Type }\end{array}$ & $\begin{array}{c}\text { Channel } \\
\text { Hydraulic } \\
\text { Diameter } \\
(\mathbf{m m}) \\
\end{array}$ & $\begin{array}{c}\text { Channel } \\
\text { Length } \\
(\mathbf{m m})\end{array}$ & Orientation & $\begin{array}{c}\text { Pressure } \\
\text { [MPa] }\end{array}$ & $\begin{array}{c}\text { Temperature } \\
\left({ }^{\circ} \mathrm{C}\right)\end{array}$ & $\begin{array}{c}\text { Heat } \\
\text { Flux } \\
\left(\mathbf{k W} / \mathbf{m}^{2}\right)\end{array}$ & $\begin{array}{c}\text { Mass } \\
\text { Flux } \\
\left(\mathrm{kg} / \mathrm{m}^{2} \mathbf{s}\right)\end{array}$ & $\begin{array}{l}\text { Vapour } \\
\text { Quality }\end{array}$ \\
\hline $\begin{array}{c}\text { Tong et al. } \\
\text { [102] }\end{array}$ & Water & Smooth & Circular & $\begin{array}{l}\text { From } 1.05 \\
\text { mm i.d. to } \\
2.44 \mathrm{~mm} \text { i.d. }\end{array}$ & N/A & Vertical & $\begin{array}{c}\text { Exit } \\
\text { pressure } \\
4-16 \text { bar }\end{array}$ & $22-66$ & $\begin{array}{c}50000- \\
80000\end{array}$ & $\begin{array}{c}25000- \\
45000\end{array}$ & N/A \\
\hline $\begin{array}{c}\text { Yan et al. } \\
\text { [105] }\end{array}$ & Water & Smooth & Circular & $9 \mathrm{~mm}$ i.d. & 400 & Vertical & $3-5$ & $\begin{array}{l}6 \text { - } 224 \text { (liquid } \\
\text { subcooling) }\end{array}$ & $0-12500$ & $\begin{array}{l}6000- \\
10000\end{array}$ & N/A \\
\hline $\begin{array}{c}\text { Tran et al. } \\
\text { [106] }\end{array}$ & $\begin{array}{c}\text { R-134a } \\
\text { R-12 } \\
\text { R-113 }\end{array}$ & Smooth & $\begin{array}{c}\text { Circular } \\
\text { Rectangular }\end{array}$ & $\begin{array}{c}2.46 \text { i.d. (R- } \\
134 \mathrm{a}, \mathrm{R}-12) \\
2.92 \text { i.d.(R- } \\
113) \\
4.06 \times 1.7(\mathrm{R}- \\
12)\end{array}$ & $\begin{array}{c}412(\mathrm{R}-113) \\
914 \text { for circular } \\
(\mathrm{R}-12) \\
881 \text { for } \\
\text { rectangular } \\
(\mathrm{R}-12) \\
914(\mathrm{R} 134-\mathrm{a})\end{array}$ & Horizontal & $\begin{array}{c}\text { Six } \\
\text { different } \\
\text { pressures } \\
\text { from } \\
0.138 \text { to } \\
0.856\end{array}$ & $5-15$ & $2.2-129$ & $33-832$ & N/A \\
\hline $\begin{array}{l}\text { Yun et al. } \\
\text { [109] }\end{array}$ & $\mathrm{R} 410 \mathrm{~A}$ & Smooth & Rectangular & $\begin{array}{l}1.36 \mathrm{~mm} \text { h.d. } \\
1.44 \mathrm{~mm} \text { h.d. }\end{array}$ & N/A & Horizontal & $\begin{array}{l}0.799 \\
0.933 \\
1.085\end{array}$ & $0,5,10$ & $10-20$ & $200-400$ & $0.1-0.85$ \\
\hline $\begin{array}{c}\text { Mancin et al. } \\
{[111]}\end{array}$ & $\mathrm{R} 134 \mathrm{a}$ & Microfin & Circular & $3.4 \mathrm{~mm}$ i.d. & 300 & Horizontal & 3 & 30 & $10,25,50$ & $190-940$ & $0.2-0.99$ \\
\hline $\begin{array}{c}\text { Park and } \\
\text { Hrnjak [112] }\end{array}$ & $\begin{array}{c}\mathrm{CO} 2 \\
\mathrm{R} 410 \mathrm{~A} \\
\mathrm{R} 22\end{array}$ & Smooth & Circular & $6.1 \mathrm{~mm}$ i.d. & 150 & Horizontal & $\mathrm{N} / \mathrm{A}$ & $-15,-30$ & $5-15$ & $100-400$ & $0.1-0.8$ \\
\hline $\begin{array}{c}\text { Jang et al. } \\
{[125]}\end{array}$ & FC-72 & Smooth & Circular & $\begin{array}{l}2 \mathrm{~mm} \text { i.d. } \\
4 \mathrm{~mm} \text { i.d. }\end{array}$ & 100 & Horizontal & $\begin{array}{c}0.067- \\
0.182\end{array}$ & $45-75$ & $5-300$ & $\begin{array}{c}265.3 \text { to } \\
663.1 \text { for } \\
2 \mathrm{~mm} \\
132.7 \text { to } \\
439.6 \text { for } \\
4 \mathrm{~mm}\end{array}$ & N/A \\
\hline
\end{tabular}


Journal of Thermal Engineering, Review Article, Vol. 7, No. 3, pp. 483-549, March, 2021

Table 10. Experimental working conditions presented in the studies of the pressure drop of boiling inside inclined smooth and enhanced channels

\begin{tabular}{|c|c|c|c|c|c|c|c|c|c|c|c|}
\hline Researcher & Fluid & $\begin{array}{c}\text { Tube } \\
\text { Groove } \\
\text { Type }\end{array}$ & $\begin{array}{c}\text { Channel } \\
\text { Type }\end{array}$ & $\begin{array}{c}\text { Channel } \\
\text { Hydraulic } \\
\text { Diameter } \\
(\mathbf{m m}) \\
\end{array}$ & $\begin{array}{c}\text { Channel } \\
\text { Length } \\
(\mathrm{mm})\end{array}$ & Orientation & $\begin{array}{c}\text { Pressure } \\
\text { [MPa] }\end{array}$ & $\begin{array}{c}\text { Temperature } \\
\left({ }^{\circ} \mathrm{C}\right)\end{array}$ & $\begin{array}{c}\text { Heat } \\
\text { Flux } \\
\left(\mathbf{k W} / \mathbf{m}^{2}\right)\end{array}$ & $\begin{array}{c}\text { Mass } \\
\text { Flux } \\
\left(\mathbf{k g} / \mathbf{m}^{2} \mathbf{s}\right)\end{array}$ & $\begin{array}{l}\text { Vapour } \\
\text { Quality }\end{array}$ \\
\hline $\begin{array}{c}\text { Wang et al. } \\
\text { [124] }\end{array}$ & $\begin{array}{l}\text { HFE - } \\
7100\end{array}$ & Smooth & Rectangular & $\begin{array}{c}0.825 \mathrm{~mm} \\
\text { h.d. }\end{array}$ & 25.40 & $-90^{\circ}$ to $+90^{\circ}$ & 0.110 & N/A & $25-37.5$ & $100,200,300$ & $0.2-0.45$ \\
\hline $\begin{array}{c}\text { Wongwises } \\
\text { and } \\
\text { Pipathattakul } \\
\text { [87] }\end{array}$ & Water & Smooth & Circular & $\begin{array}{c}8 \mathrm{~mm} \text { i.d. } \\
12.5 \mathrm{~mm} \text { o.d. }\end{array}$ & 880 & $0^{\circ}, 30^{\circ}, 60^{\circ}$ & $\begin{array}{l}\text { Up to } 10 \\
\text { bar }\end{array}$ & N/A & N/A & $\begin{array}{c}0.063-0.315 \\
0.3-1.5 \\
1-4 \\
4 \text { - } 36 \text { LPM for all }\end{array}$ & N/A \\
\hline $\begin{array}{c}\text { Tshuva et al. } \\
{[126]}\end{array}$ & Water & Smooth & Circular & $24 \mathrm{~mm}$ i.d. & 3000 & $\begin{array}{c}10 \text { different } \\
\text { angles from } \\
0^{\circ} \text { to } 90^{\circ}\end{array}$ & 0.101 & N/A & N/A & $\begin{array}{l}0.15-5.60 \mathrm{~m} / \mathrm{s} \\
\quad \text { for gas } \\
0.02-3.03 \mathrm{~m} / \mathrm{s} \\
\text { for liquid }\end{array}$ & N/A \\
\hline $\begin{array}{c}\text { Piasecka } \\
{[128]}\end{array}$ & $\begin{array}{c}\text { Fluorinert } \\
\text { FC-72 }\end{array}$ & Microfin & Rectangular & $\begin{array}{l}1 \mathrm{~mm} \text { deep } \mathrm{x} \\
40 \text { wide } \mathrm{mm}\end{array}$ & 360 & $\begin{array}{l}0^{\circ} \text { to } 180^{\circ} \text { with } \\
45^{\circ} \text { increment }\end{array}$ & $\begin{array}{c}0.120- \\
0.130\end{array}$ & $\begin{array}{c}\Delta T_{\text {sub }}=28 \mathrm{~K} \\
32 \mathrm{~K}, 43 \mathrm{~K}\end{array}$ & 21.5 & 286 & N/A \\
\hline
\end{tabular}

Table 11. Experimental working conditions presented in the studies of the heat transfer coefficient of boiling inside horizontal and vertical smooth and enhanced channels

\begin{tabular}{|c|c|c|c|c|c|c|c|c|c|c|}
\hline Researcher & Fluid & $\begin{array}{c}\text { Tube } \\
\text { Groove } \\
\text { Type } \\
\end{array}$ & $\begin{array}{l}\text { Channel } \\
\text { Type }\end{array}$ & $\begin{array}{c}\text { Channel Hydraulic } \\
\text { Diameter } \\
(\mathrm{mm}) \\
\end{array}$ & $\begin{array}{c}\text { Channel } \\
\text { Length } \\
(\mathrm{mm}) \\
\end{array}$ & Orientation & $\begin{array}{l}\text { Pressure } \\
\text { [MPa] }\end{array}$ & $\begin{array}{c}\text { Temperature } \\
\left({ }^{\circ} \mathrm{C}\right)\end{array}$ & $\begin{array}{c}\text { Heat } \\
\text { Flux } \\
\left(\mathbf{k W} / \mathbf{m}^{2}\right) \\
\end{array}$ & $\begin{array}{c}\text { Mass } \\
\text { Flux } \\
\left(\mathrm{kg} / \mathrm{m}^{2} \mathrm{~s}\right) \\
\end{array}$ \\
\hline $\begin{array}{l}\text { Ong and } \\
\text { Thome [2] }\end{array}$ & $\begin{array}{l}\text { R134a } \\
\text { R236fa } \\
\text { R245fa }\end{array}$ & Smooth & Circular & $1.030 \mathrm{~mm}$ i.d. & 180 & Horizontal & $\begin{array}{l}7.9 \text { bar for R134a } \\
3.3 \text { bar for R236fa } \\
1.8 \text { bar for R245fa }\end{array}$ & $\begin{aligned} \mathrm{T}_{\text {sat }} & =31^{\circ} \mathrm{C} \\
\Delta \mathrm{T}_{\text {sub }} & =2 \text { to } 9 \mathrm{~K}\end{aligned}$ & $2.3-250$ & $200-1600$ \\
\hline $\begin{array}{c}\text { Passos et al. } \\
{[143]}\end{array}$ & R- 407c & $\begin{array}{l}\text { Smooth } \\
\text { Microfin }\end{array}$ & Circular & $\begin{array}{l}7 \mathrm{~mm} \text { o.d. (smooth) } \\
12.7 \mathrm{~mm} \text { o.d. (microfin) }\end{array}$ & 1500 & Horizontal & 0.770 & 9.76 & 10,20 & $200-300$ \\
\hline $\begin{array}{c}\text { Dalkılıç et al. } \\
{[144]}\end{array}$ & $\mathrm{R} 134 \mathrm{a}$ & Microfin & Rectangular & $\begin{array}{l}0.470 \mathrm{~mm} \text { deep } \times 0.382 \\
\mathrm{~mm} \text { width } \\
0.416 \text { fin thickness }\end{array}$ & 40 & Horizontal & $5.37-7.27$ bar & $18,23,28$ & $25-500$ & $800-1200$ \\
\hline $\begin{array}{l}\text { Wambsganss } \\
\text { et al. [146] }\end{array}$ & $\mathrm{R}-113$ & Smooth & Circular & $2.92 \mathrm{~mm}$ i.d. & 368 & Horizontal & $0.124-0.160$ & $\begin{array}{l}20 \text { to } 50 \\
\text { Inlet temp. }\end{array}$ & $8.8-90.75$ & $50-300$ \\
\hline $\begin{array}{c}\text { Shiferaw et al. } \\
{[150]}\end{array}$ & R134a & Smooth & Circular & $1.1 \mathrm{~mm}$ i.d. & 150 & Horizontal & $6-12$ bar & N/A & $16-150$ & $100-600$ \\
\hline
\end{tabular}


Journal of Thermal Engineering, Review Article, Vol. 7, No. 3, pp. 483-549, March, 2021

Table 12. Experimental working conditions presented in the studies of the heat transfer coefficient of boiling inside inclined smooth and enhanced channels

\begin{tabular}{|c|c|c|c|c|c|c|c|c|c|c|c|}
\hline Researcher & Fluid & $\begin{array}{c}\text { Tube } \\
\text { Groove } \\
\text { Type }\end{array}$ & $\begin{array}{l}\text { Channel } \\
\text { Type }\end{array}$ & $\begin{array}{c}\text { Channel } \\
\text { Hydraulic } \\
\text { Diameter } \\
(\mathbf{m m})\end{array}$ & $\begin{array}{c}\text { Channel } \\
\text { Length } \\
(\mathrm{mm})\end{array}$ & Orientation & $\begin{array}{l}\text { Pressure } \\
\text { [MPa] }\end{array}$ & $\begin{array}{c}\text { Temperature } \\
\left({ }^{\circ} \mathrm{C}\right)\end{array}$ & $\begin{array}{c}\text { Heat } \\
\text { Flux } \\
\left(\mathbf{k W} / \mathbf{m}^{2}\right)\end{array}$ & $\begin{array}{c}\text { Mass } \\
\text { Flux } \\
\left(\mathbf{k g} / \mathbf{m}^{2} \mathbf{s}\right)\end{array}$ & $\begin{array}{l}\text { Vapour } \\
\text { Quality }\end{array}$ \\
\hline $\begin{array}{l}\text { Kundu et al. } \\
\text { [152] }\end{array}$ & $\mathrm{R} 407 \mathrm{C}$ & Smooth & Circular & $7 \mathrm{~mm}$ i.d. & 1200 & $\begin{array}{l}5 \text { different } \\
\text { angles from } \\
0^{\circ} \text { to } 90^{\circ}\end{array}$ & $0.618-0.686$ & $\begin{array}{c}6-9 \\
\text { Inlet temp. }\end{array}$ & $3-6$ & $100-300$ & $0.1-0.9$ \\
\hline $\begin{array}{l}\text { Kundu et al. } \\
\text { [153] }\end{array}$ & $\begin{array}{l}\mathrm{R} 134 \mathrm{a} \\
\mathrm{R} 407 \mathrm{C}\end{array}$ & Smooth & Circular & $\begin{array}{l}7.0 \mathrm{~mm} \text { i.d. } \\
9.52 \mathrm{~mm} \\
\text { o.d. } \\
\text { with } 1.2 \mathrm{~m} \\
\text { length }\end{array}$ & 1200 & $\begin{array}{l}5 \text { different } \\
\text { angles from } \\
0^{\circ} \text { to } 90^{\circ}\end{array}$ & $\begin{array}{c}\text { R134a (bar); } \\
3.61,3.79 \\
4.01 \\
\text { R407C(bar); } \\
6.22,6.47 \\
6.86\end{array}$ & $\begin{array}{c}5-9 \\
\text { Inlet temp. }\end{array}$ & $3-10$ & $100-300$ & $0.1-0.9$ \\
\hline $\begin{array}{c}\text { Gang et al. } \\
{[154]}\end{array}$ & Water & Smooth & Circular & $26 \mathrm{~mm}$ i.d. & 2000 & $20^{\circ}$ & $9-28$ & $\begin{array}{l}\text { Wall temp. up to } \\
6650\end{array}$ & $200-600$ & $\begin{array}{l}600- \\
1500\end{array}$ & N/A \\
\hline $\begin{array}{l}\text { Morcos et al. } \\
{[155]}\end{array}$ & Water & Smooth & Rectangular & $\begin{array}{c}2.67 \text { and } \\
0.37 \mathrm{AR} \\
(\text { when } \\
\text { rotating } \\
\left.90^{\circ}\right)\end{array}$ & 2200 & $\begin{array}{l}0^{\circ}, 15^{\circ} \\
30^{\circ}, 45^{\circ}\end{array}$ & 0.118 & N/A & $\begin{array}{c}8,10,12 \\
14\end{array}$ & $\begin{array}{c}3,6,9 \\
12 \\
\mathrm{~kg} / \mathrm{h}\end{array}$ & N/A \\
\hline $\begin{array}{l}\text { Wang et al. } \\
\text { [156] }\end{array}$ & Water & Smooth & Circular & $\begin{array}{l}20 \mathrm{~mm} \text { i.d. } \\
\text { with } 2 \mathrm{~m}\end{array}$ & 2000 & $45^{\circ}$ & 11.5 to 28 & $\begin{array}{l}\text { Wall temp. } \\
325-500\end{array}$ & $50-585$ & $\begin{array}{l}450- \\
1550\end{array}$ & $\begin{array}{c}0.04- \\
0.12\end{array}$ \\
\hline $\begin{array}{l}\text { Jeong and } \\
\text { Kim [157] }\end{array}$ & Water & Smooth & Rectangular & $19 \mathrm{~mm}$ i.d. & 216 & $10^{\circ}$ & $1.07 \mathrm{bar}$ & $\Delta T_{\text {sub }}=5-25 \mathrm{~K}$ & $50-400$ & $40-300$ & N/A \\
\hline $\begin{array}{l}\text { Akhavan- } \\
\text { Behabadi et } \\
\text { al. [131] }\end{array}$ & R-134a & Microfin & Circular & $\begin{array}{l}8.92 \mathrm{~mm} \\
\text { i.d. }\end{array}$ & 1100 & $\begin{array}{c}\text { Seven } \\
\text { different } \\
\text { angles from - } \\
90^{\circ} \text { to }+90^{\circ}\end{array}$ & N/A & $-17-12^{\circ} \mathrm{C}$ & $2.1-5.3$ & $\begin{array}{c}53,80 \\
107,136\end{array}$ & $\begin{array}{c}\text { Inlet } \\
0.1-0.9 \\
\text { Outlet } \\
0.3-1.0\end{array}$ \\
\hline
\end{tabular}


Journal of Thermal Engineering, Review Article, Vol. 7, No. 3, pp. 483-549, March, 2021

Table 13. Experimental working conditions presented in the studies of boiling and flow regimes inside channels

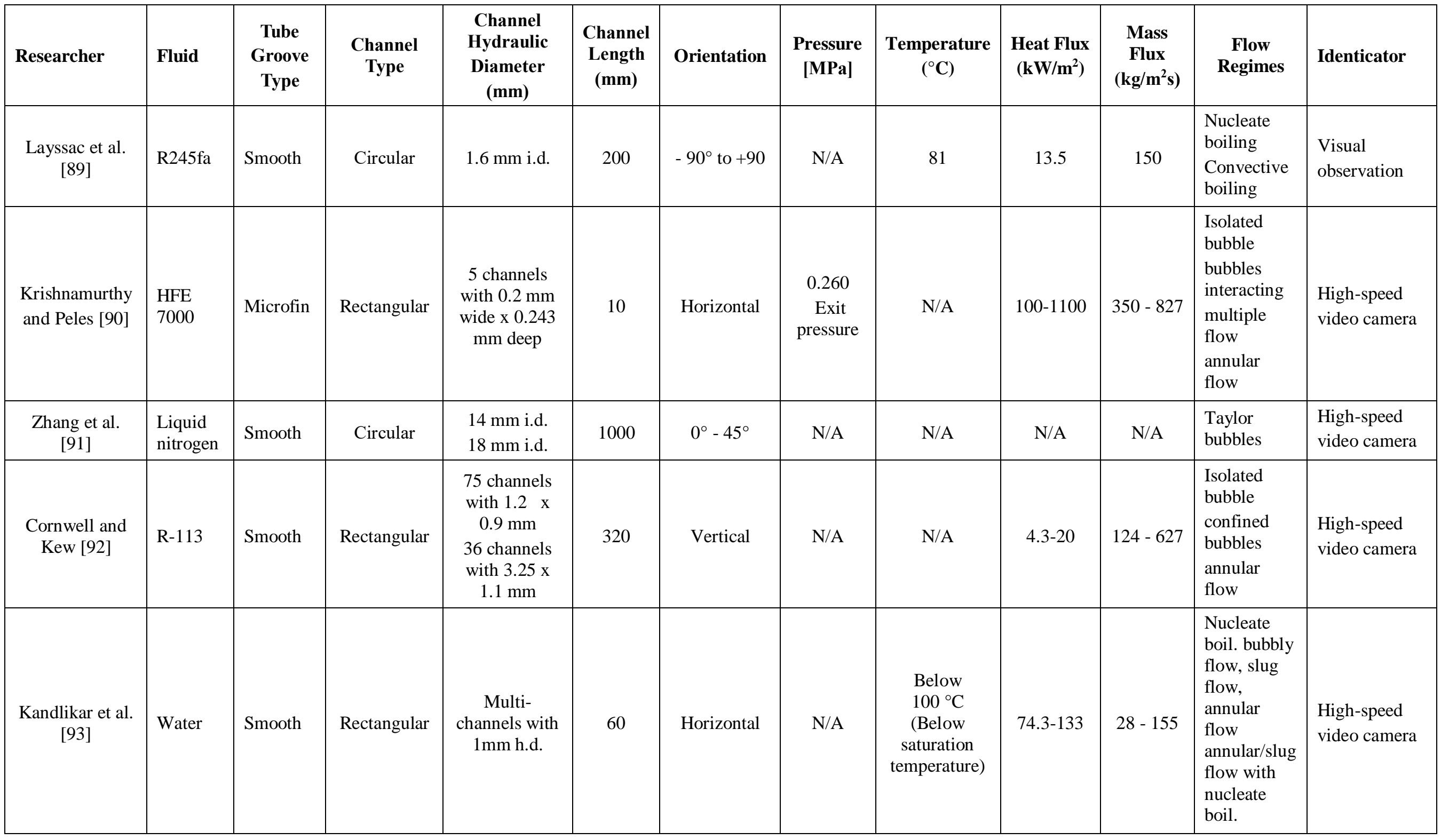


Journal of Thermal Engineering, Review Article, Vol. 7, No. 3, pp. 483-549, March, 2021

Table 14. Correlations used for the determination of Nusselt number and two-phase heat transfer boiling in channels during boiling

\begin{tabular}{|c|c|c|c|}
\hline Researcher & Study Type & Model/Correlation & Validity Range \\
\hline $\begin{array}{l}\text { Kundu et } \\
\text { al. [152] }\end{array}$ & Experimental & 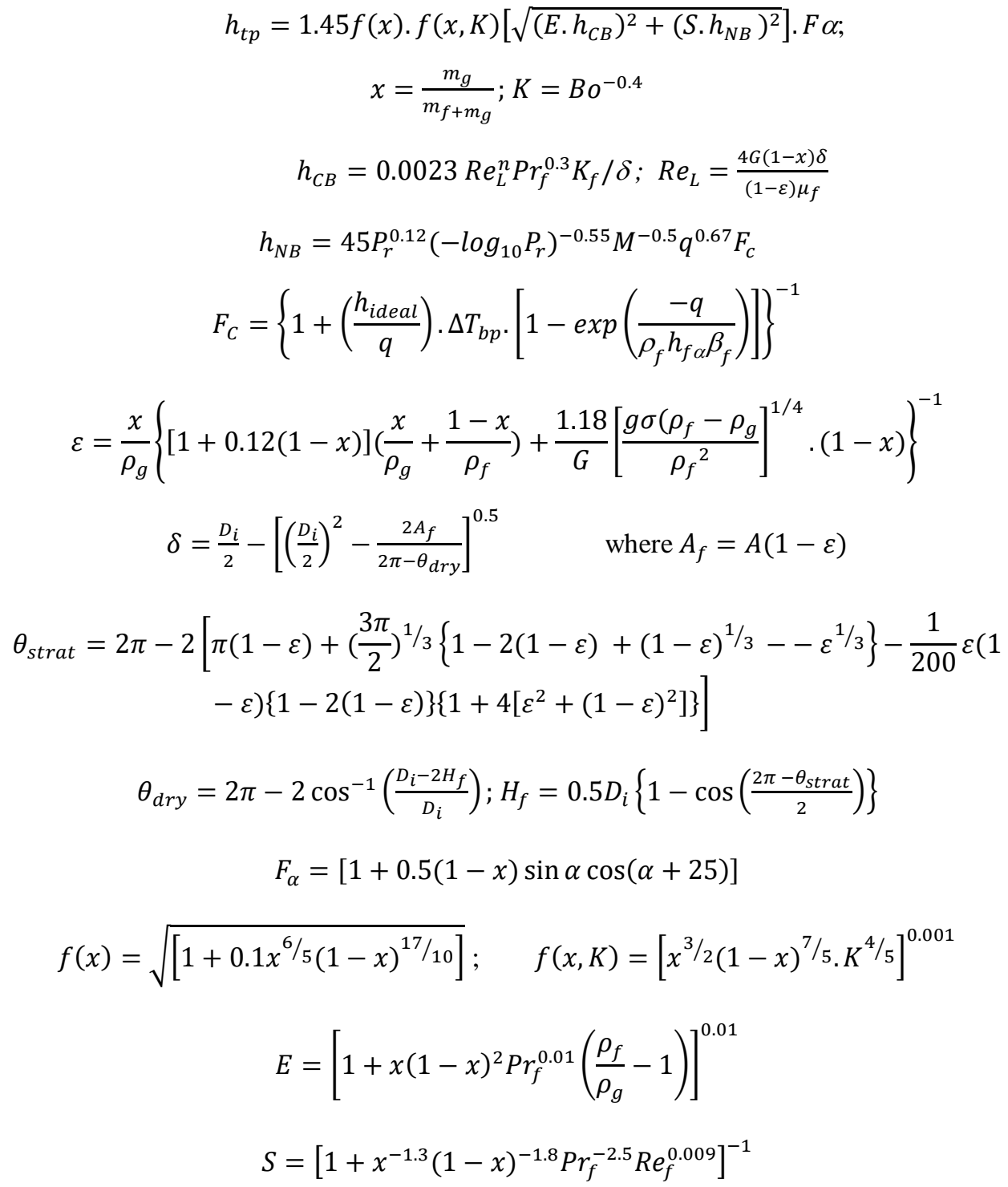 & $\begin{array}{c}\text { For } G \leq 200 \\
\qquad n=0.65 \\
\text { For inclined tubes }\end{array}$ \\
\hline
\end{tabular}


Table 14. Correlations used for the determination of Nusselt number and two-phase heat transfer boiling in channels during boiling (Cont.)

\begin{tabular}{|c|c|c|c|}
\hline Researcher & Study Type & Model/Correlation & Validity Range \\
\hline $\begin{array}{l}\text { Kundu et } \\
\text { al. [152] }\end{array}$ & Experimental & $\begin{array}{c}\theta_{d r y}=0 \\
F_{\alpha}=[1+0.5(1-x) \sin \alpha \cos (\alpha+50)] \\
f .(x)=\sqrt{\left[1+0.1 x^{\left.3 / 2(1-x)^{2}\right]}\right.} \\
f(x, K)=\left[x(1-x)^{\left.3 / 2 . K^{3 / 5}\right]}\right]^{0.001} \\
E=\left[1+x(1-x)^{2} \operatorname{Pr}_{f}^{0.01}\left(\frac{\rho_{f}}{\rho_{g}}-1\right)\right]^{0.01} \\
S=\left[1+x^{-1.2}(1-x)^{-2} P_{f}^{-2.5} R e_{f}^{0.009}\right]^{-1}\end{array}$ & $\begin{array}{l}\text { For } G>200 \\
\qquad n=0.6\end{array}$ \\
\hline $\begin{array}{c}\text { Morcos et } \\
\text { al. [155] }\end{array}$ & Experimental & $\begin{array}{c}\mathrm{Nu}_{\mathrm{TP}}=\mathrm{C}_{1} \cdot \mathrm{f}(\theta)\left(\mathrm{Re}_{\mathrm{TP}}\right)^{1.25}\left(R e_{l}\right)^{-0.78} \\
\mathrm{f}(\theta)=1+\sin \theta \cos (\theta+30)\end{array}$ & $\begin{array}{c}\quad 0 \leq \theta \leq 45 \\
\text { Slug-annular flow } \\
\text { patterns two-phase } \\
\text { forced convection } \\
\text { region } \\
\text { For inclined tubes }\end{array}$ \\
\hline $\begin{array}{l}\text { Akhavan- } \\
\text { Behabadi et } \\
\text { al. [131] }\end{array}$ & Experimental & $\begin{array}{c}h=\left[\frac{\pi D L\left(T_{w o}-T_{s}\right)}{Q}-\frac{D}{2 k} \ln \left(\frac{D_{o}}{D}\right)\right]^{-1} \\
Q=\eta V I\end{array}$ & $\begin{array}{c}\mathrm{R}-134 \mathrm{a} \\
\text { For inclined tubes }\end{array}$ \\
\hline $\begin{array}{c}\text { Wang et al. } \\
\text { [156] }\end{array}$ & Experimental & $\begin{array}{l}\text { For top surface: } \\
N u_{b}=0.003259 \operatorname{Re}_{b}^{0.824} \operatorname{Pr}_{b}^{0.242}\left(\frac{\rho_{w}}{\rho_{b}}\right)^{0.156}\left(\frac{\lambda_{w}}{\lambda_{b}}\right)^{0.341} \\
\text { For bottom surface: } \\
N u_{b}=0.07623 R e_{b}^{0.6256} \operatorname{Pr}_{b}^{0.596}\left(\frac{\rho_{w}}{\rho_{b}}\right)^{0.634}\left(\frac{\lambda_{w}}{\lambda_{b}}\right)^{0.260}\end{array}$ & $\begin{array}{l}\text { Supercritical } \\
\text { pressure region } \\
\text { For inclined tubes }\end{array}$ \\
\hline
\end{tabular}


Table 14. Correlations used for the determination of Nusselt number and two-phase heat transfer boiling in channels during boiling (Cont.)

\begin{tabular}{|c|c|c|c|}
\hline Researcher & Study Type & Model/Correlation & $\begin{array}{l}\text { Validity } \\
\text { Range }\end{array}$ \\
\hline $\begin{array}{c}\text { Kandlikar } \\
\text { [142] }\end{array}$ & Experimental & $\begin{array}{l}\text { For vertical flow with water: } \\
\qquad h_{T P}=C_{1} \mathrm{Co}^{C_{2}} h_{l}+C_{3} B o^{C_{4}} h_{l} \\
\text { where Co }<0.65 \text { - convective boiling region. } \\
\text { Co }>0.65 \text {-nucleate boiling region } \\
\text { Fluid-dependent parameter for other fluids: } \\
\qquad \frac{h_{T P}}{h_{l}}=C_{1} \mathrm{Co}^{C_{2}}+C_{3} B o^{C_{4}} F_{f l}\end{array}$ & $\begin{array}{c}\text { For horizontal } \\
\text { and vertical } \\
\text { tubes }\end{array}$ \\
\hline $\begin{array}{c}\text { Lazarek and } \\
\text { Black } \\
{[136]}\end{array}$ & Experimental & $\begin{array}{c}h_{t p}=\frac{k_{L}}{D} 30 R e_{L}^{0.857} B o^{0.714} \\
R e_{L}=\frac{G(1-x) D}{\mu_{L}}\end{array}$ & $\begin{array}{c}\text { Based on } 728 \\
\text { data points. } \\
\mathrm{D}=3.1 \mathrm{~mm} \text {, } \\
\mathrm{R}-113 \\
\text { For vertical } \\
\text { tubes }\end{array}$ \\
\hline $\begin{array}{c}\text { Gungor et al. } \\
\text { [133] }\end{array}$ & Experimental & 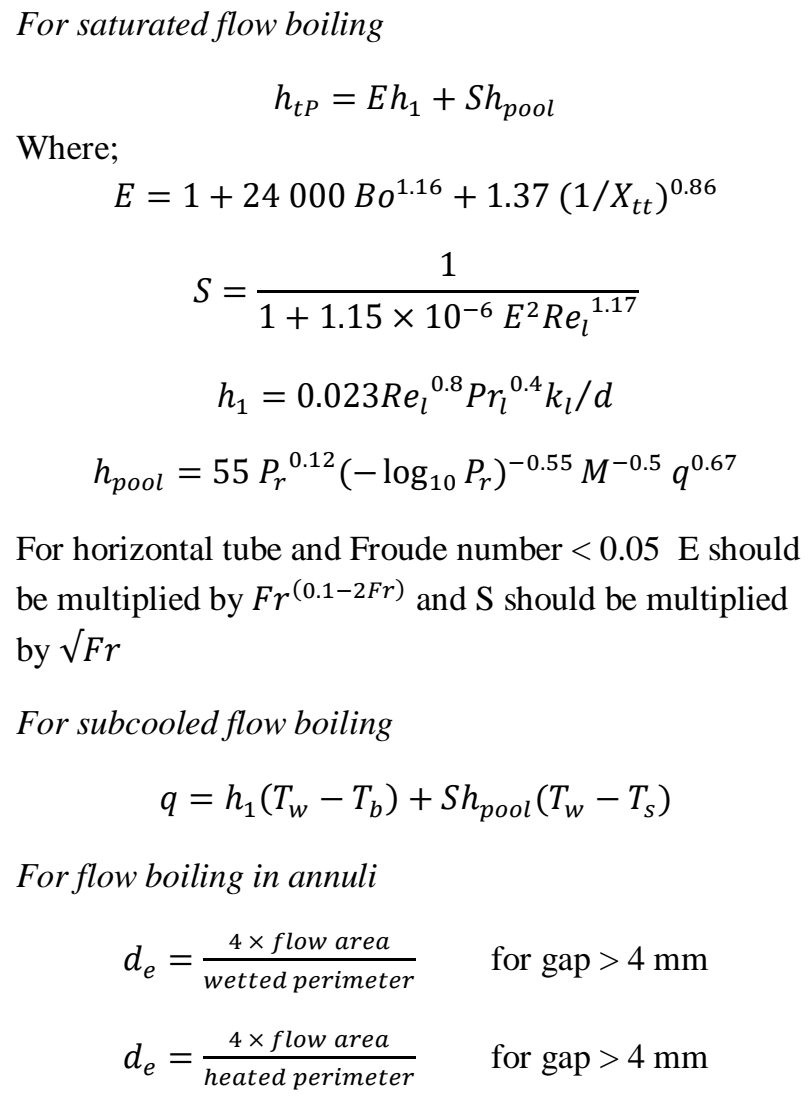 & $\begin{array}{l}\text { For horizontal } \\
\text { and vertical } \\
\text { tubes }\end{array}$ \\
\hline
\end{tabular}


Table 15. Correlations used for the determination of frictional multiplier/frictional pressure drop in tubes during boiling

\begin{tabular}{|c|c|c|c|c|c|c|}
\hline Researcher & Study Type & Geometry & $\begin{array}{l}\text { Tube } \\
\text { Groove } \\
\text { Type }\end{array}$ & Fluid & Model/Correlation & $\begin{array}{c}\text { Validity } \\
\text { Range }\end{array}$ \\
\hline $\begin{array}{c}\text { Rollmann } \\
\text { and } \\
\text { Spindler } \\
{[115]}\end{array}$ & Experimental & $\begin{array}{l}55 \text { fin } \\
\text { with helix } \\
\text { angle of } \\
15^{\circ} \\
\text { Tube of } \\
8.95 \mathrm{~mm} \\
\text { i.d. at fin } \\
\text { root }\end{array}$ & Microfin & $\begin{array}{l}\text { R407C } \\
\text { R410A }\end{array}$ & $\begin{aligned}\left(\frac{d P}{d z}\right)_{f}=\frac{f G^{2}}{2 D_{i}}( & \left(\frac{2 B o}{D_{i}}+x_{l}\right)\left(v_{v}\right. \\
& \left.\left.-v_{l}\right)+v_{l}\right) \\
B o= & \frac{\dot{q}}{G h_{f g}} \\
\mathrm{f}= & 0.05\end{aligned}$ & - \\
\hline $\begin{array}{c}\text { Kuo and } \\
\text { Wang } \\
{[114]}\end{array}$ & Experimental & $\begin{array}{l}\text { Tube of } \\
9.52 \mathrm{~mm} \\
\text { nominal } \\
\text { diameter }\end{array}$ & Microfin & $\begin{array}{l}\text { R22 } \\
\text { R407C }\end{array}$ & $\begin{array}{c}\left(\frac{d P}{d z}\right)_{f}=\frac{2 f G^{2} \bar{v}}{D_{i}} \\
f=0.0127 \\
\bar{v}=x v_{v}+(1-x) v_{l} \\
\bar{\mu}=\bar{\rho}\left(x v_{v} \mu_{v}+(1-x) v_{l} \mu_{l}\right) \\
R e_{e q}=\frac{G D_{i}}{\bar{\mu}}\end{array}$ & - \\
\hline
\end{tabular}

Table 16. Major findings presented in the studies of boiling in tubes

\begin{tabular}{|c|c|c|}
\hline Researcher & Graph Axes & Trends \\
\hline \multirow{3}{*}{$\begin{array}{l}\text { Akhavan-Behabadi et al. } \\
\text { [131] }\end{array}$} & $x-h$ & $\begin{array}{l}\text { Heat transfer coefficient increases with } \\
\text { increasing vapour quality until a vapour quality } \\
\text { nears } 70-85 \% \text {. }\end{array}$ \\
\hline & $\alpha-\mathrm{h}$ & $\begin{array}{l}\text { Tube inclination angle has huge effect on the } \\
\text { heat transfer coefficient. }\end{array}$ \\
\hline & $G-h$ & $\begin{array}{l}\text { The heat transfer coefficient increases with } \\
\text { increasing mass flux at a given vapour quality. }\end{array}$ \\
\hline \multirow{3}{*}{$\begin{array}{c}\text { Brutin and Tadrist } \\
\text { [96] }\end{array}$} & $R e_{I N}-\Delta P$ & $\begin{array}{l}\text { Pressure loss increases with increase in } \\
\text { Reynolds number until the Reynolds number } \\
\text { nears } 25000 \text {, then decreases until the Reynolds } \\
\text { number nears } 5500 \text {, then again increases with } \\
\text { the Reynolds number more than } 5500 \text {. }\end{array}$ \\
\hline & $\operatorname{Re}_{\mathrm{IN}}-\lambda$ & $\begin{array}{l}\text { Friction factor decreases as Reynolds number } \\
\text { increases. The decrease rate of friction factor is } \\
\text { higher at Reynolds number } 10-2000 \text { than the } \\
\text { decrease rate at Reynolds number } 2000-10000 \text {. }\end{array}$ \\
\hline & $\operatorname{Re}_{\text {IN }}-x_{\text {out }}$ & $\begin{array}{l}\text { Exit vapour quality decreases with increase in } \\
\text { inlet Reynolds number for five different heat } \\
\text { fluxes. }\end{array}$ \\
\hline
\end{tabular}


Table 16. Major findings presented in the studies of boiling in tubes (Cont.)

\begin{tabular}{|c|c|c|}
\hline Researcher & Graph Axes & Trends \\
\hline \multirow{5}{*}{$\begin{array}{l}\text { Celen et al. } \\
\text { [101] }\end{array}$} & $x-h$ & $\begin{array}{l}\text { Average heat transfer coefficient increases } \\
\text { with increase in vapour quality for a given mass } \\
\text { flux, but the increment decreases with } \\
\text { decreasing mass flux. }\end{array}$ \\
\hline & $\mathrm{T}-\mathrm{h}$ & $\begin{array}{l}\text { Average heat transfer coefficient increases as } \\
\text { saturation temperature increases. }\end{array}$ \\
\hline & $\mathrm{x}-\Delta \mathrm{P}$ & $\begin{array}{l}\text { Total pressure drop increases with increase in } \\
\text { average vapour quality for three different mass } \\
\text { fluxes with saturation temperatures of } 15^{\circ} \mathrm{C} \\
\text { and } 22^{\circ} \mathrm{C} \text {. }\end{array}$ \\
\hline & $\mathrm{G}-\Delta \mathrm{P}$ & $\begin{array}{l}\text { Increasing mass flux results in increasing total } \\
\text { pressure drop. }\end{array}$ \\
\hline & $\mathrm{T}-\Delta \mathrm{P}$ & $\begin{array}{l}\text { Total pressure drop increases with increasing } \\
\text { saturation temperature. }\end{array}$ \\
\hline \multirow{6}{*}{$\begin{array}{l}\text { Özdemir } \\
{[145]}\end{array}$} & $f-R e$ & $\begin{array}{l}\text { For fully developed flow, friction factor } \\
\text { decreases with increasing Reynolds number } \\
\text { between } 250 \text { and } 900 \text {. It is nearly constant with } \\
\text { increasing Reynolds number between } 900 \text { and } \\
1300 \text { and decreases a little with increasing } \\
\text { Reynolds number between } 1300 \text { and } 1900 \text {. }\end{array}$ \\
\hline & $f-R e$ & $\begin{array}{l}\text { Friction factor obtained is in good agreement } \\
\text { with theoretical model at } 254 \text { micron tube. }\end{array}$ \\
\hline & $f-\operatorname{Re}$ & $\begin{array}{l}\text { Friction factor obtained differs substantially } \\
\text { from theoretical model at } 685 \text { micron tube. }\end{array}$ \\
\hline & $T_{w}-\mathrm{q}$ & $\begin{array}{l}\text { Inner-wall temperatures increase with heat } \\
\text { flux. }\end{array}$ \\
\hline & $\mathrm{T}_{\mathrm{w}}-\mathrm{G}$ & $\begin{array}{l}\text { Increasing mass rates result in lower channel } \\
\text { surface temperature at constant heat fluxes. }\end{array}$ \\
\hline & $h-G$ & $\begin{array}{l}\text { Local heat transfer coefficient increases with } \\
\text { increasing mass flux. }\end{array}$ \\
\hline \multirow{5}{*}{$\begin{array}{l}\text { Jang et al. } \\
\text { [125] }\end{array}$} & $G-\Delta \mathrm{P}$ & $\begin{array}{l}\text { Pressure drop increases with increasing mass } \\
\text { flux. }\end{array}$ \\
\hline & $x-\Delta P$ & $\begin{array}{l}\text { Pressure drop increases with increasing vapour } \\
\text { quality. }\end{array}$ \\
\hline & $\mathrm{T}-\Delta \mathrm{P}$ & $\begin{array}{l}\text { Pressure drop decreases with increasing } \\
\text { saturation temperature. }\end{array}$ \\
\hline & $\mathrm{T}-\mathrm{h}$ & $\begin{array}{l}\text { Heat transfer coefficient slightly increases with } \\
\text { increasing saturation temperature up to } 65^{\circ} \mathrm{C} \text {, } \\
\text { but it decreases with increasing saturation } \\
\text { temperature beyond } 65^{\circ} \mathrm{C} \text {. }\end{array}$ \\
\hline & $\mathrm{T}-\mathrm{h}$ & $\begin{array}{l}\text { Saturation temperature has almost no effect on } \\
\text { the heat transfer coefficient. }\end{array}$ \\
\hline
\end{tabular}


Table 16. Major findings presented in the studies of boiling in tubes (Cont.)

\begin{tabular}{|c|c|c|}
\hline Researcher & Graph Axes & Trends \\
\hline & $x-h$ & $\begin{array}{l}\text { Heat transfer coefficient of FC- } 72 \\
\text { progressively increases with vapour quality up } \\
\text { to } 0.25 \text { at all mass fluxes and saturation } \\
\text { temperatures. }\end{array}$ \\
\hline \multirow{4}{*}{$\begin{array}{c}\text { Krishnamurthy and Peles } \\
{[90]}\end{array}$} & $h-G$ & $\begin{array}{l}\text { Heat transfer coefficients are higher for pin fin } \\
\text { channel than for plain ones at different mass } \\
\text { fluxes. }\end{array}$ \\
\hline & $x-h$ & $\begin{array}{l}\text { Heat transfer coefficient increases with } \\
\text { increasing vapour quality at different mas } \\
\text { fluxes. }\end{array}$ \\
\hline & $\mathrm{h}$ & $\begin{array}{l}\text { Heat transfer coefficient of subcooled boiling } \\
\text { is a little higher than for single-phase flow, } \\
\text { particularly in the isolated bubble. }\end{array}$ \\
\hline & $h-q$ & $\begin{array}{l}\text { Heat transfer coefficient of boiling increase } \\
\text { with increasing heat flux, while it is constant in } \\
\text { single-phase region. }\end{array}$ \\
\hline \multirow{4}{*}{$\begin{array}{l}\text { Kundu et al. } \\
\text { [153] }\end{array}$} & $h-q$ & $\begin{array}{l}\text { Heat transfer coefficient increases with } \\
\text { increasing heat flux at mass velocity of } 100 \\
\mathrm{~kg} / \mathrm{m}^{2} \mathrm{~s} \text {. }\end{array}$ \\
\hline & $x-h$ & $\begin{array}{l}\text { Heat transfer coefficient increases with } \\
\text { increasing vapour quality at mass velocity of } \\
100 \mathrm{~kg} / \mathrm{m}^{2} \mathrm{~s} \text {. }\end{array}$ \\
\hline & $h-G$ & $\begin{array}{l}\text { At the initial period of boiling, the heat transfer } \\
\text { coefficient increases with increasing mass } \\
\text { velocity for both R407C and R134a. }\end{array}$ \\
\hline & $\alpha-h$ & $\begin{array}{l}\text { Heat transfer coefficient increases with } \\
\text { increasing inclination angle from the horizonta } \\
\text { condition at the same average vapour quality } \\
\text { until value of } 0.8 \text { for R407C and R134a for } \\
\text { fixed mass fluxes. }\end{array}$ \\
\hline
\end{tabular}

